Document downloaded from:

http://hdl.handle.net/10251/68693

This paper must be cited as:

Molina Puerto, J. (2016). Graphene-based fabrics and their applications: a review. RSC Advances. 6:68261-68291. doi:10.1039/c6ra12365a.

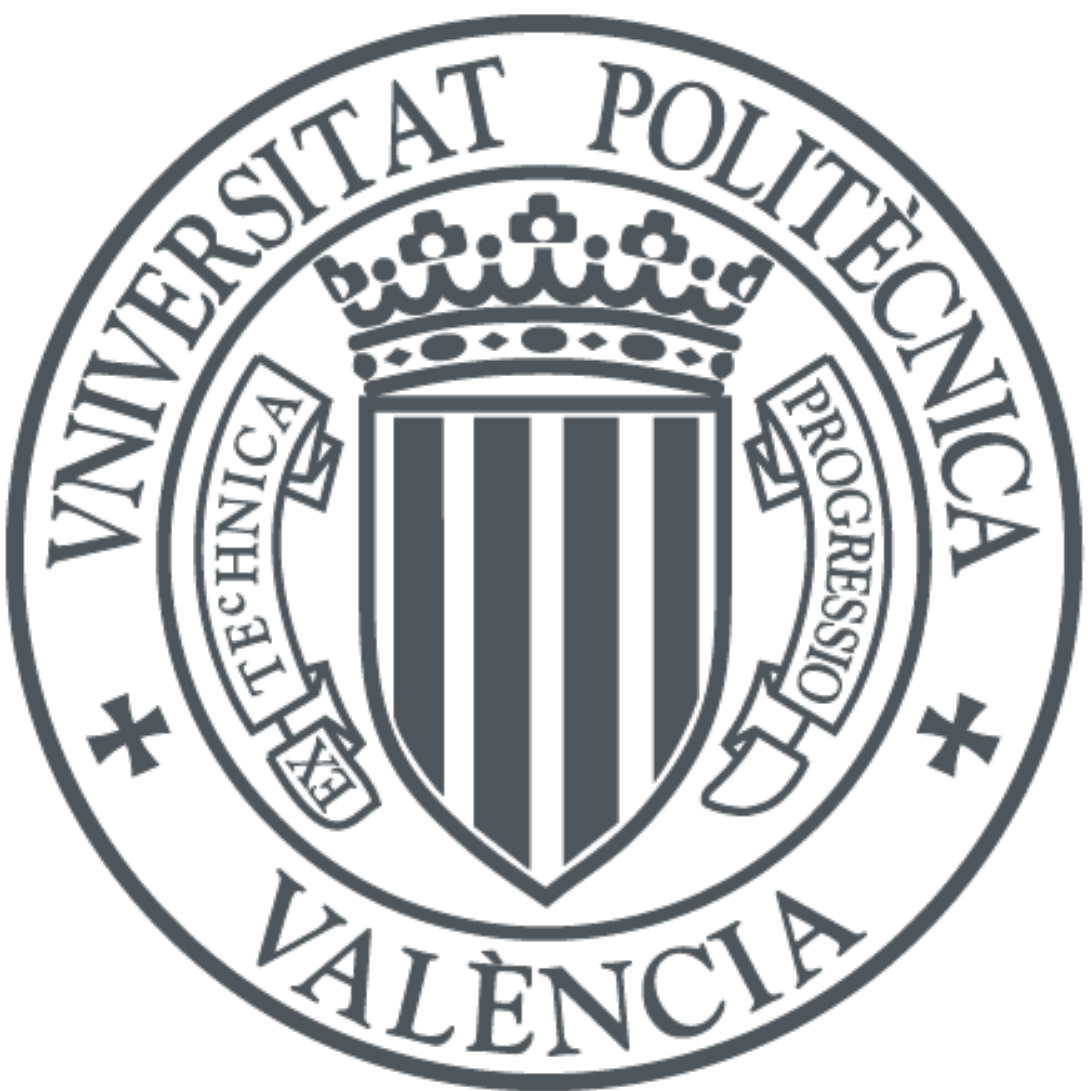

The final publication is available at

http://dx.doi.org/10.1039/C6RA12365A

Copyright Royal Society of Chemistry

Additional Information 


\title{
Graphene-based fabrics and their applications: A review
}

\author{
J. Molina ${ }^{1}$ \\ ${ }^{1}$ Departamento de Ingeniería Textil y Papelera, EPS de Alcoy, Universitat Politècnica \\ de València, Plaza Ferrándiz y Carbonell s/n, 03801 Alcoy, Spain
}

\begin{abstract}
Graphene has emerged as a revolutionary material in different fields of science and engineering due to its extraordinary properties such as: high electron mobility, high thermal conductivity, mechanical properties, easy functionalization, etc. The field of textiles is continuously integrating new materials to provide fabrics with new functionalities, hence its incorporation on fabrics was a logical step. Its application to the field of textiles has been recently reported, which has allowed the development of textiles with different functionalities such as: antistatic, UV-protecting, electroconductive, photocatalytic, antibacterial, energy storage in supercapacitors, electrodes for batteries, thermal conductivity, sensors, etc. Up to date no review has been written regarding graphene-based fabrics and their applications. The present review aims to fill the existing gap and provide perspectives into the preparation and applications of graphene-based fabrics and yarns.
\end{abstract}

Keywords: graphene, fabrics, antistatic, energy storage, photocatalysis, supercapacitor

\footnotetext{
* Corresponding author. Fax: +34 96652 8438; telephone: +34 966528583

E-mail address: jamopue@doctor.upv.es (J. Molina)
} 


\section{Abbreviations:}

AQSA: anthraquinone-2-sulfonic acid sodium salt monohydrate, APS: ammonium persulphate, BN: boron nitride, BSA: bovine serum albumin, CNT: carbon nanotube, CV: cyclic voltammetry, CVD: chemical vapor deposition, DMF: dimethylformamide, ERGO: electrochemically reduced graphene oxide, FLG: few layer graphene, G: graphene, GFV: graphene woven fabrics, GNP: graphene nanoplate, GNR: graphene nanoribbon, GNS: graphene nanosheet, GO: graphene oxide, GWF: graphene woven fabric, MB: methylene blue, MWCNT: multiwalled carbon nanotube, $\mathrm{Na}_{2} \mathrm{NDS}$ : naphthalene-2,6-disulfonic acid disodium salt, NCPCl: N-cetylpyridinium chloride, NP: nanoparticle, Pani: polyaniline, PBS: phosphate buffer solution, PDMS: polydimethylsiloxane, PEDOT: poly(3,4-ethylenedioxythiophene), PES: polyester, PET: poly(ethyleneterephthalate), PLA: polylactic acid, PMS: polymethylsiloxane, PP: polypropylene, PSS: poly(styrenesulfonate), PU: polyurethane, PVA: polyvinyl alcohol, PVP: poly(vinylpyrrolidone), QD: quantum dot, RGO: reduced graphene oxide, SDS: sodium dodecyl sulfonate, SWCNT: single walled carbon nanotubes, UPF: ultraviolet protection factor, WPU: waterborne anionic aliphatic polyurethane.

\section{Introduction}

The field of textiles has experimented a great development and high degree of innovation during the last years. Modern textiles cannot longer be considered as mere garments since nowadays they incorporate new functionalities. These functionalites are normally provided by the development and application of new materials. The different applications developed include: flame resistance [1], thermal regulation [2], electrochromic [3], antimicrobial [4], UV protection [5], self-cleaning [6], solar energy harvesting [7], photonic [8], electrical conduction [9], or even catalysis [10] have been reported on textiles. Electrical conduction is of particular interest since its development allows the integration of computing, digital components and electronics in the fabrics. Different 
methods have been developed for conferring conductivity on fabrics, such as: the employment of metallic fibres [11], chemical metallization of fibers [12], extrusion of fibers with conducting particles [13] or the synthesis of conducting polymer film on the fabrics [14-16].

Recently, graphene has emerged as a revolutionary material due to its amazing properties such as: high electron mobility at room temperature $\left(2.5 \cdot 10^{5} \mathrm{~cm}^{2} \cdot \mathrm{V}^{-1} \cdot \mathrm{s}^{-1}\right)$, high thermal conductivity (above $\left.3000 \mathrm{~W} \cdot \mathrm{m} \cdot \mathrm{K}^{-1}\right)$, Young's Modulus (1 TPa), intrinsic strength (130 GPa), impermeability to any gases, ability to sustain high electric currents densities, easy chemical functionalization, etc. [17]. Its isolation in 2004 by A.K. Geim and K.S. Novoselov [18] and the groundbreaking experiments they performed allowed them to be awarded the Nobel Prize in Physics in 2010 [19]. Possible applications of graphene materials pointed out in bibliography include: flexible electronics, photonics and optoelectronics, spintronics, composite materials, energy generation and storage, biomedical applications, sensors, etc. [17,20]. The number of papers published every year related to graphene has suffered an exponential evolution, as does the number of patents. European Union has devoted a great economic effort (1000 million €) to graphene research under the Graphene Flagship Horizon 2020 programme. The aim of this programme is "to take graphene and related layered materials from the realm of fundamental science to industrial and societal applications in the space of ten years”. Having mentioned all the properties and applications of graphene materials family, the integration of graphene into textiles was a logical step to achieve not only conductive textiles but also multifunctional fabrics. Several reviews have been written about the production and application of graphene fibers that is another area of development in the field [21-24]. The methods for the production of G fibers are normally based on the coagulation of a precursor solution. However, up to date, no review has been written about 
graphene-based fabrics and their applications. The aim of this review is to fill the existing gap with an evaluation of all the work performed in this area and their applications. The review is focused on the most widely employed approaches to obtain G-based fabrics: The chemical deposition of G, GO or RGO on fabrics and the production of GWFs by means of CVD.

\section{Graphene-based fabrics}

Mainly, three methods have been developed in bibliography for the production of graphene-based fabrics/yarns. The first one is the coating of fabrics/yarns with $G$ materials such as G, GO, RGO, etc. The second one consists in the CVD process of $\mathrm{G}$ on a metallic mesh ( $\mathrm{Cu}$ normally) that is later removed by an acid treatment, remaining the G-fabric structure, these type of fabrics are named graphene woven fabrics (GFV). And the third one, includes the production of G fibers and its application on fabrics that is not considered in the review.

The most widely employed method is the first one due to its easy of application, as well as scalability. As well, usually, the material employed to coat the fabrics is GO that is cheaper (según datos suministrado por Grafenea (multinacional española fabricante de óxido de grafeno (GO)) en el periodo 2016-17 el precio del GO bajará hasta 150 euros/kg y a partir de 2018 este precio se reducirá aún más, 50 euros/kg. Por lo que la progresión indica un importante abaratamiento de la materia prima. En lo que se refiere al proceso de recubrimiento de RGO a partir de la reducción de GO con ditionito (apartado C.1.4A.1.-a), lo que estamos aplicando es una adaptación del proceso que a nivel industrial se utiliza para las tinturas con colorantes tina (como el índigo de la ropa vaquera). Esto reduce los costes de una aplicación mayor escala. Además, hemos conseguido evitar el 
uso de reductores muy tóxicos y peligrosos, como la hidrazina, que son los que aparecen habitualmente en la bibliografía. En esto también estamos siendo pioneros.)

than $\mathrm{G}$ and can be obtained in larger quantities due to the process of production that consists in chemical oxidation methods $[25,26]$. GO is an insulating material due to the disrupted $\mathrm{sp}^{2}$ structure produced by the oxidation of graphite during its synthesis. However, its conductivity can be partially restored after reduction to produce RGO $[25,26]$.

\subsection{Graphene-coated fabrics}

This section provides a compilation of the work performed in bibliography employing simple coating of G, GO, RGO, etc. on fabrics or textile fibers mainly by aqueous solution impregnation (dip coating). As mentioned previously, GO is the most employed material due to its lower prize. In addition, GO has a negatively charged structure which makes it ideal for its dispersion in aqueous solutions [27]. What is more, the negative charges of GO allow its interaction with the functional groups of the fabrics, thus increasing the fixation of GO. The posterior conversion to RGO by chemical, electrochemical, thermal or UV methods allows the partial restoration of conductivity as explained previously. However, the reduction is not complete and recalcitrant oxidized groups cannot be reduced, thus conferring a negative zeta potential to the surface of RGO [27]. On the other hand, G has no charged surface and tends to precipitate in aqueous solutions. When employing $G$ in solution to coat fabrics, the deposition has to be aided by dispersants to help in the dispersion and stability of the G solutions. A lot of work has been performed employing the coating of fabrics [28-85].

Fig. 1 shows the adsorption process of GO sheets on the surface of different fibers to form a GO layer. Therafter, the reduction converts insulating GO to conducting RGO due to 
the partial restoration of the $\mathrm{sp}^{2}$ structure. GO on fabrics has a characteristic brown color, which is converted into black color after reduction. The process for fixing $\mathrm{G}$ is similar to this one but it does not include the reduction process.

The interaction of GO, G or RGO with the fibers is essential to allow their fixation on the fibers surface and obtain a proper coating with good conductivity. Functional groups present on the fibers help in their fixation. Their interaction with the fibers can be through electrostatic interaction, van der Waals forces, hydrogen bonding, $\pi-\pi$ interactions, hydrophobic interactions, etc. In order to boost their fixation, different chemicals and processes have been also employed for such purpose.

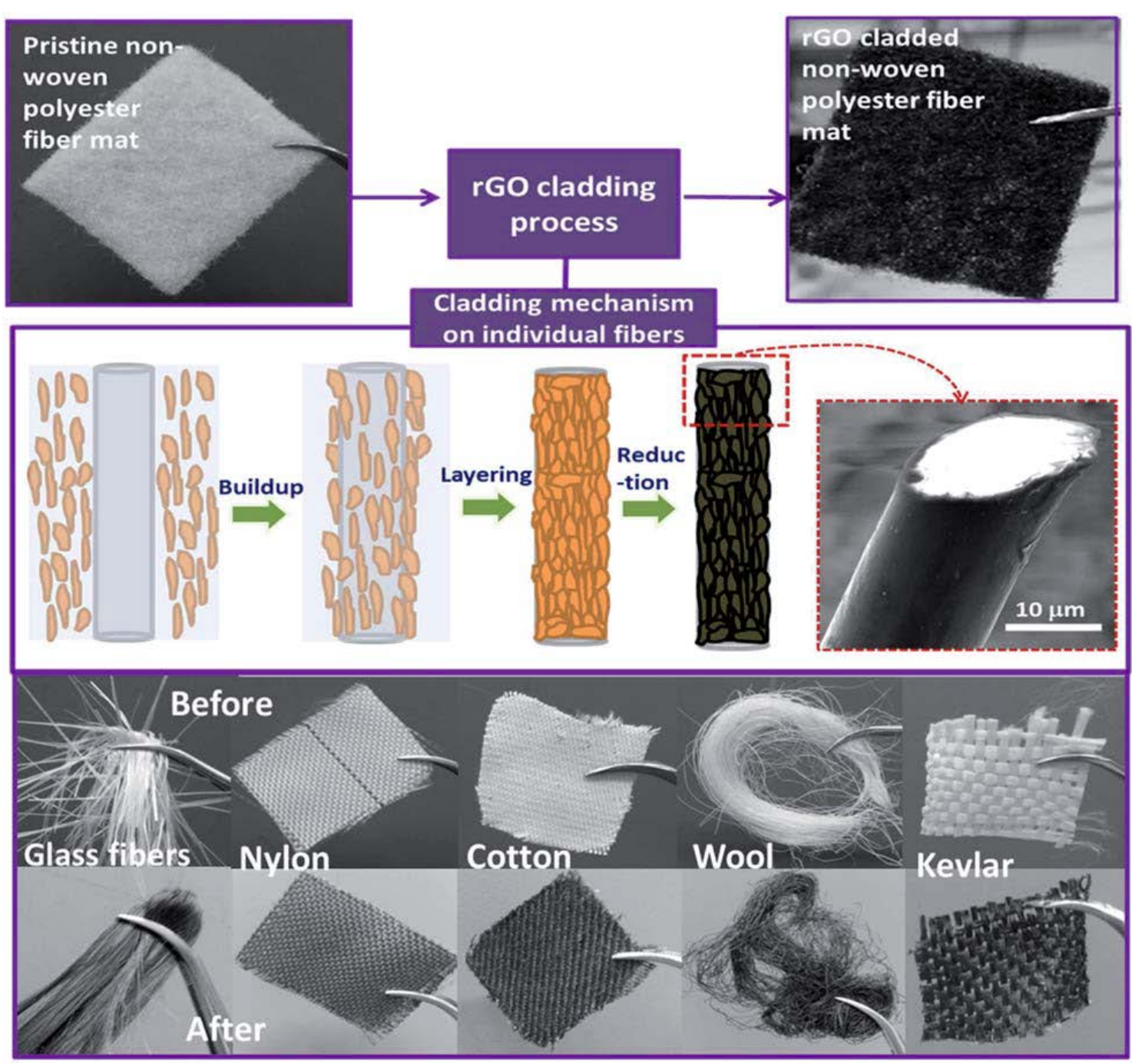

Fig. 1. Schematic of the cladding process, mechanism and photographs of cladded materials. Reproduced from [46] with permission from The Royal Society of Chemistry. 
BSA, which is a pH sensitive protein, has been widely employed for this objective $[37,40,45,49,57,58,62]$. Below $\mathrm{pH} 4.9$ it has positive charge and above $\mathrm{pH} 4.9$ negative charge. The positive charges created on the fabric helped in the adsorption process of GO (which has negative charges) and created electrostatic forces that allowed the selfassembly of GO on the fabrics. Molina et al. [45] applied plasma treatment to generate negative charges on the surface of PES, these negative charges increased the BSA fixation that charged positively the surface of the fabrics, and allowed the self assembly of GO sheets. In addition, the high roughness produced by the plasma treatment also helped in the fixation process of GO sheets. Zhao et al. [80] also applied plasma treatment in order to increase the wettability of nylon/lycra fabrics and facilitate GO adhesion.

NCPCl has been employed to treat PES fibers and increase GO adsorption [34]. The interaction between PES and NCPCl was due to hydrogen bond between carboxyl groups of PES and pyridinium group of the surfactant. A complete study taking into account the different interactions (and their energy) that can take place between the fiber surface and GO was performed. The most effective adsorption took place at $\mathrm{pH} 3(0.38 \mathrm{mg} \mathrm{GO} / \mathrm{g}$ fiber)

Chitosan has been employed as dispersant and binding additive of GNSs [28]. WPU has been also employed as dipersant and binding additive of GNPs. Hydrogen bonds were formed between -NH gropus of WPU and -OH groups of GNPs [29,31]. The employment of PU has been also reported [50], it was fixed on PET due to the interaction between the carbonyl group of PET and the $-\mathrm{NH}$ group of PU. Dipolar interactions or hydrogen bonding helped in the fixation of RGO on the fabrics. Resins have also been employed in the process of fixation of $\mathrm{G}$ derivatives [52]. 
PEI, which reacted with hydroxyl groups of cellulose, was employed to form a cationic layer on cotton fabrics. Therafter layer-by-layer self-assembly approach was employed to coat samples with multiple alternate layers (up to 6) of PEDOT-PSS-GNS (polyanion) and chitosan (polycation) based on electrostatic interaction [30].

SDS surfactant helped in the dispersion of GNRs (obtained from unzipping of CNTs) in solution but also increased their affinitiy to cotton fibers and produced a more evenly distribution of GNRs on the surface of the fibers [60] (Fig. 2). Sodium cholate surfactant has also been employed for the dispersion of GNSs [72,73].

Acid treatment has been also reported on carbon fibers to increase their hydrophilicity and increase ERGO adhesion [82].

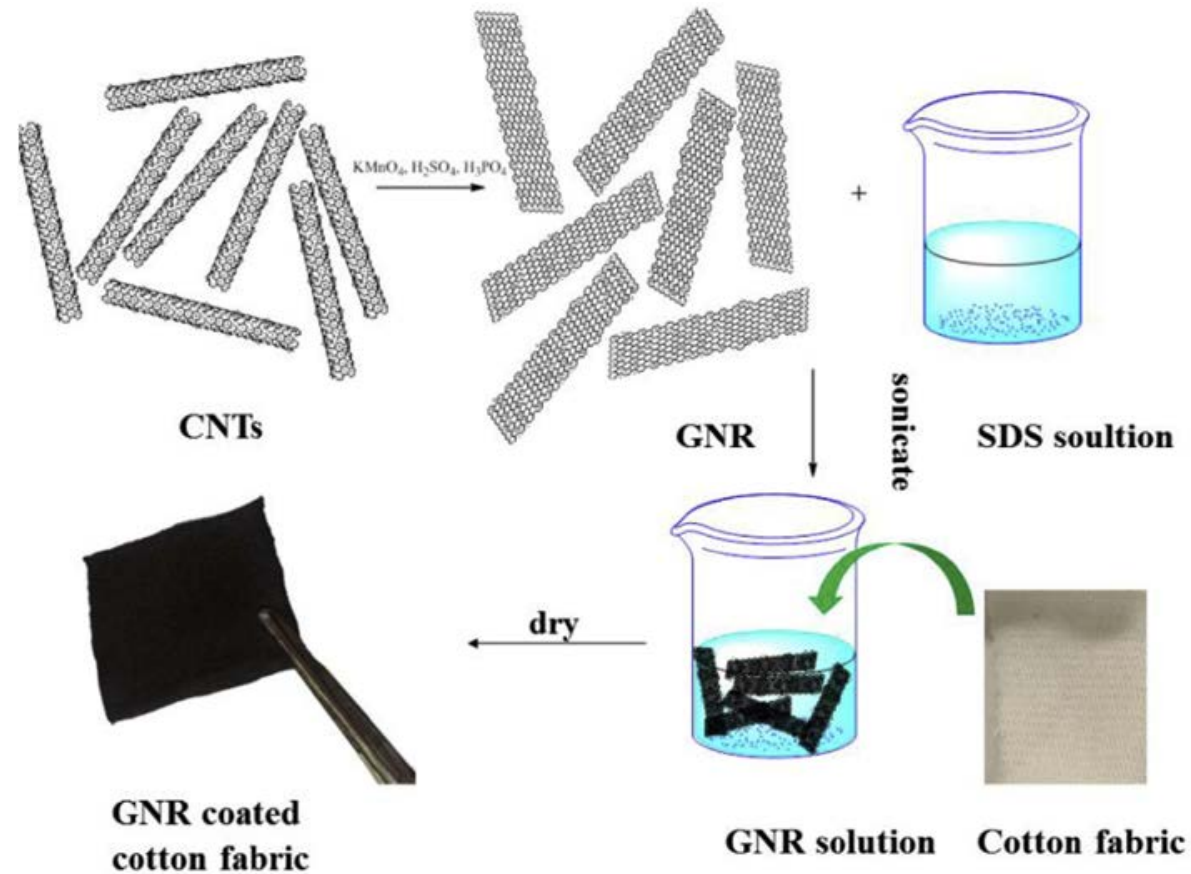

Fig. 2. Schematic illustration of the fabrication process of GNR coated cotton fabric. Reprinted from [60] with permission from Elsevier.

The dip coating method has been widely employed, and the majority of papers have employed this approach. The fabric is placed in contact with the solution containing the G material to be coated for a certain time and after this the fabric is dried. If necessary, 
reduction is performed afterwards. However, others methods for G and GO deposition have been employed, such as: Vacuum filtration [32,61], brush coating [33,78], direct electrochemical deposition [82,84], electrophoresis [64,67,68], kinetic trapping method [47], wet transfer of monolayer films [42,75] or screen printing [63]. The use of ultrasonication during the synthesis has also been reported and allowed a proper distribution of the coating on the fabrics $[48,50,61,71,76]$.

When employing GO, a reduction method is necessary to restore the conductivity of the G structure. The majority of works employing GO as precursor, employ chemical reductants such as ascorbic acid [36,38,61,80], $\mathrm{Na}_{2} \mathrm{~S}_{2} \mathrm{O}_{4}[38,39,43-45,57]$, hydroiodic acid $\quad[37,46,49,51,59,62,65,85]$, hydrazine $\quad[38,40,46,48,50,58,59,67,68,74,76,84]$, $\mathrm{NaBH}_{4}[38,69], \mathrm{NaOH}[38,83], \mathrm{TiCl}_{3}$ [54,56], ammonium hydroxide [67], hydroxylamine hydrochloride [81]. However, other methods such as thermal reduction [71,77-79], electrochemical reduction $[64,82,84]$ or UV reduction [33] have been applied due to the advantage that no chemicals are employed and no by-products are generated by the process. In the case of thermal reduction, the process has to be carried out in inert atmosphere and damage to the fibers can occur due to the elevated temperature. The electrochemical reduction needs a conductive substrate to carry the current and for this reason is mainly applied on carbon cloth substrates. In a study, the effect of the reductant $\left(\mathrm{NaBH}_{4}, \mathrm{~N}_{2} \mathrm{H}_{4}, \mathrm{C}_{6} \mathrm{H}_{8} \mathrm{O}_{6}, \mathrm{Na}_{2} \mathrm{~S}_{2} \mathrm{O}_{4}\right.$ and $\left.\mathrm{NaOH}\right)$ on the electrical properties of RGO/cotton fabrics was performed by Shateri-Khalilabad et al. [38]. To achieve proper levels of conductivity, different number of G/RGO layers are normally applied to the fabrics.

Different textile substrates have been employed in bibliography, Table 1 shows a summary of the work performed [28-85]. As well, composition, different parameters employed during the synthesis of the coating, method of reduction, application of the fabric and properties of interest have been included in Table 1. 


\subsection{Applications of graphene coated fabrics}

\subsubsection{UV-blocking}

Graphene derivatives have been widely employed as UV-blocking materials for coating the fabrics and obtain functional fabrics [28-33]. G has a UV absorption peak around 281 $\mathrm{nm}$, hence it can absorb UV radiation with a wavelength comprised in the 100-281 nm range. For wavelengths $>281$, reflection could play a role due to the planar structure of G [29]. With a value a UPF $>50$, excellent protection is achieved, in all the works performed in bibliography, high UPF factors can be easily achieved with low G concentrations. The durability of the coatings was confirmed after washing tests, where little variation of the UPF factor was observed [28-32].

Tian et al. [28] coated cotton fabrics with GNSs with the aid of chitosan as dispersant and binding additive. With a low $\mathrm{G}$ content in the coating solution $(<1 \% \mathrm{wt})$ the UV-blocking properties of the substrate increased a 60-fold when compared with bare cotton. Qu et al. [29] coated cotton fabrics with GNPs. WPU was employed to aid the dispersion of GNPs at different content (0.05-0.4 \% wt). Hydrogen bonds were formed between -NH gropus of WPU and -OH groups of GNPs. With a small GNPs content a high UPF was achieved (356.74, 10-fold increase when compared to bare cotton fabric). Tian et al. [30] deposited by electrostatic layer-by-layer self-assembly PEDOT-PSS (polyanion) and chitosan (polycation). GNS were also employed to dope PEDOT to enhance its electronic and UVshielding properties. First of all, a cationic layer was formed on cotton fabrics with PEI coating, which reacted with hydroxyl groups of cellulose fibers. Thereafter the anionic layer (GNS/PEDOT/PSS) was deposited by electrostatic self-assembly. After washing and drying, the cationic layer (chitosan) was applied. This process was repeated from 1 to 6 times. The presence of GNS produced a decrease of the electrical resistivity of 2 
orders of magnitude. The UPF also increased notably due to the presence of GNS (92.4 vs. 312, without and with GNSs, reepectively).

Hu et al. [31] coat cotton fabrics with GNPs. Fig. 3-a shows the cotton fabric prior the GNPs deposition and Fig. 3-b shows the fabric after the coating was applied. The UPF value achieved in this case was 500 (0.8 \% wt GNPs), a 60-fold increase when compared to bare cotton fabrics. In addition, the fabrics also showed increasing far-infrared emissivity as the GNPs content increased. The higher content of GNPs allows the heat to be converted into infrared light that could be detected by a thermograph (this can be observed from Fig. 3-c to Fig. 3-f). Far-infrared radiation boostes blood circulation and metabolism as well as it helps in recovering muscles form fatigue. For this reason this materials have been employed for therapeutic and health purposes. Conductivity and thermal conductivity increased as well with the increasing $\mathrm{G}$ content.
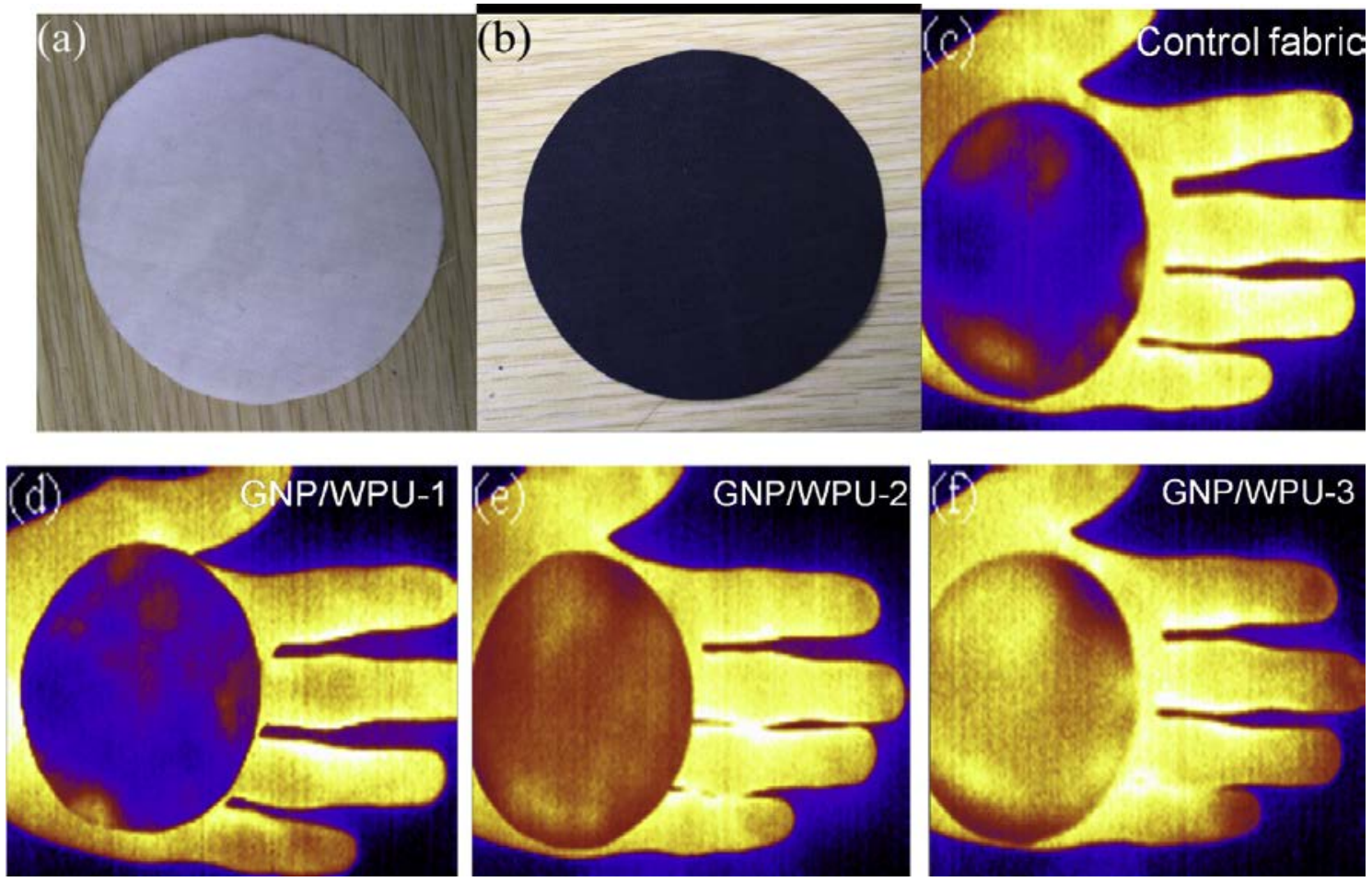

Fig. 3. Images of (a) uncoated cotton fabric, (b) graphene-coated fabric, (c-f) thermographs of graphene-coated fabrics with different coated weights (control cotton 
fabric, 240, 320, and $480 \mathrm{mg} / \mathrm{m}^{2}$ graphene-coated fabrics, respectively). Reprinted from [31] with permission from Elsevier.

Tang et al. [32] coated cotton with GO by vacuum filtration deposition, therafter Pani was chemically deposited on the surface of the GO/cotton fabric. Fabrics acted as UVblocking and conductive materials. Since GO is an insulating material, Pani provided the conductivity. When GO was deposited on the surface of cotton, it provided a substrate where Pani could be homogeneously coated and avoided aglomerations, which boosted the conductivity of the fabrics. Javed et al. [33] coated cotton and wool fabrics by brush coating with GO. Later GO was reduced to RGO by UV light irradiation, avoiding the employment of additional chemical to achieve the GO reduction. Strong GO adsorption was obtained on both fabrics due to strong van der Waals forces, hydrogen bonds and covalent bonds. Excellent UV blocking properties were also observed by the authors.

\subsubsection{Hydrophobic fabrics}

Graphene oxide is amphiphilic since it has hydrophobic areas where functional groups are not present and hydrophilic ones where they are present. The edge regions are more hydrophilic due to the presence of these functional groups and facilitate the adhesion with the functional groups of cotton fibers. However, the central part of the GO sheets is mainly composed of $\mathrm{C}=\mathrm{C}$ bonds which confere them a hydrophobic behavior in this part. Tissera et al. [35] coated cotton fabrics with GO by dipping method in solutions containing different GO concentrations. With the more concentrated solutions, thicker GO coatings were deposited on the fabrics, mid regions of GO were dominant (hydrophobic regions) and consequently more hydrophobicity was obtained. 
Shateri-Khalilabad et al. [36] produced conductive superhydrophobic textiles by coating cotton with RGO and later with nanostructured PMS (a hydrophobic material in the form of filaments 30-90 nm). GO was fixed on cotton through Van der Waals and hydrogen bonds and was reduced by ascorbic acid. The reduction of GO to RGO produced the removal of functional groups and RGO gained hydrophobicity as measured by contact angle measurements. The additional PMS coating provided nanoscale roughness and further increased the contact angle on the conductive fabrics. Thus, self-cleaning fabrics could be obtained. Fig. 4 shows images of water contact angle measurements performed on original cotton fabric (Fig. 4-a), RGO-cotton (Fig. 4-b) and PMS-RGO-cotton (Fig. 4c).
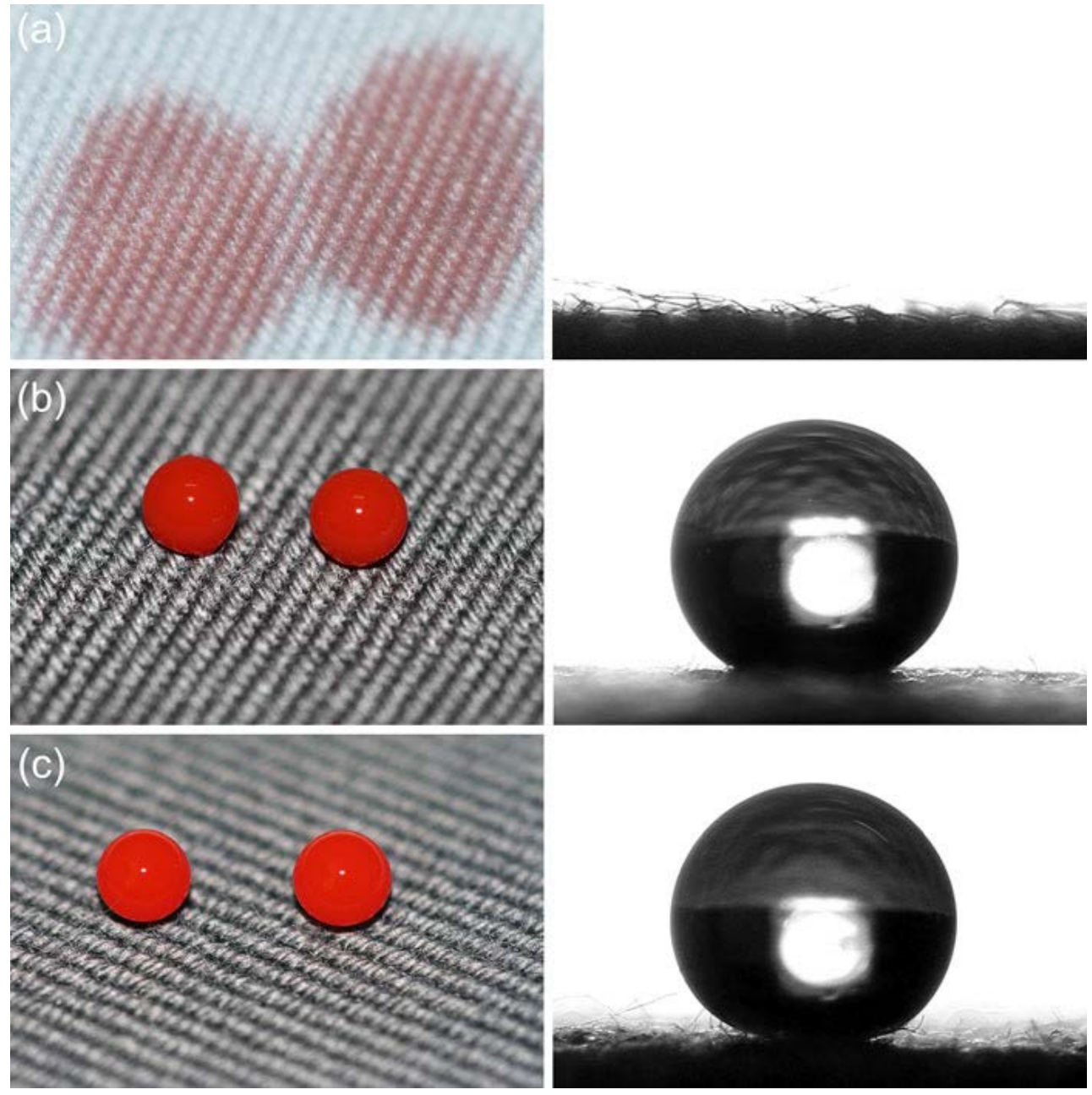
Fig. 4. Red-dyed water droplets sitting on a) the original cotton; b) the graphene-cotton; c) the PMS-graphene-cotton. The images on the right show corresponding goniometer images for $5 \mu \mathrm{L}$ droplets. Reprinted from [36] with permission from Springer.

\subsubsection{Electrically conductive fabrics}

The majority of works compiled in this review take advantage of G, or RGO coatings to produce conductive fabrics. The conductivity gained allow these fabrics to be employed for functional textiles, antistatic materials, etc. The conductivity obtained on the fabrics depends on the concentration of G or GO in the solution employed to coat the fabrics. Fig. 5 shows an evolution of the surface conductivity of PET fabrics with the RGO content employed in the dying solution. In this study, PU was employed as an intermediate adhesive layer and dipolar interactions or hydrogen bonding helped in the fixation of RGO on the fabrics. With a concentration higher than $0.001 \%$ RGO wt. in solution an abrupt change in the surface conductivity was obtained due to the formation of a continuous conducting RGO layer on PET fabrics. Being such an important parameter, the concentration of the GO/RGO/G solutions for the different studies has been also included in Table 1 when available.

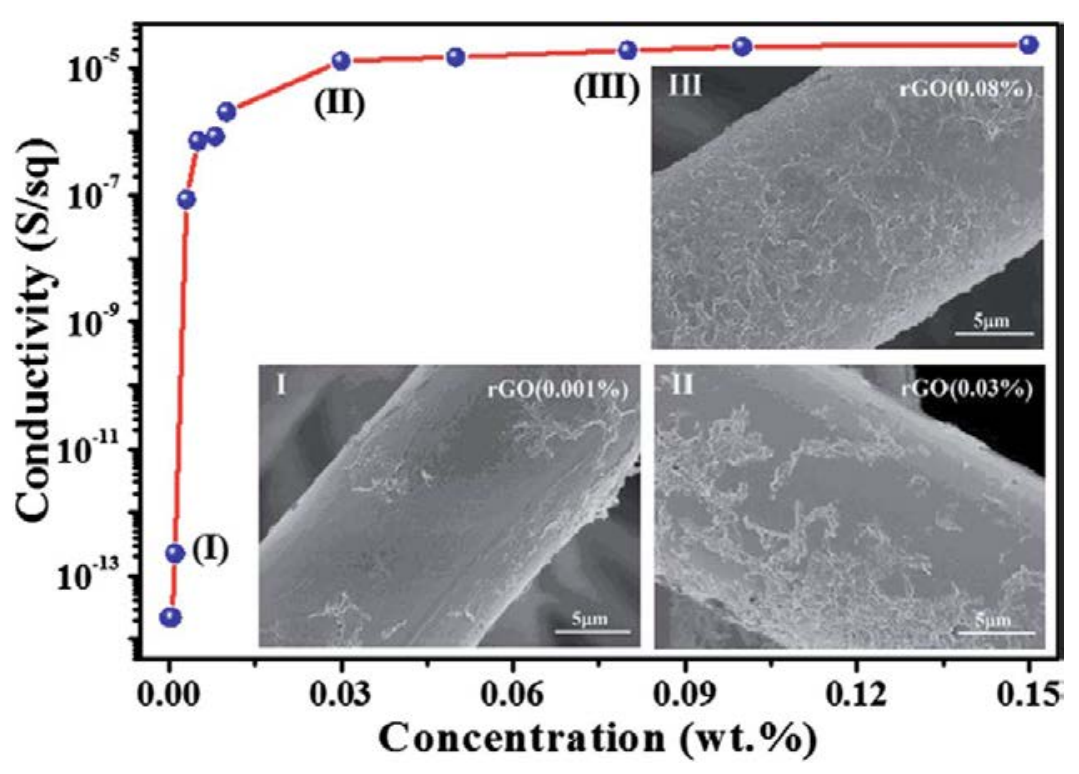


Fig. 5. Change in the surface conductivity of the composite fabrics with the increase in the weight fraction of RGO in the initial aqueous dispersion. The insets display SEM images of the composite fabrics prepared at RGO fractions of 0.001 (I), 0.030 (II) and $0.080 \mathrm{wt} \%$ (III). Reprinted from [50] with permission from The Royal Society of Chemistry.

The conductivity obtained also depends on the number of G/RGO layers applied and it is normal to obtain fabrics with high number of G/RGO coatings to achieve appropriate levels of conductivity. Fig. 6 shows an evolution of the resistance of the cotton fabrics coated with RGO-BSA (CCF-RGO) and RGO (SCF-RGO) and it can be seen that BSA coating improves the fixation and conductivity of the fabric whatever the number of coating is. The number of G/RGO layers applied on the fabrics has been also indicated in Table 1 when available.

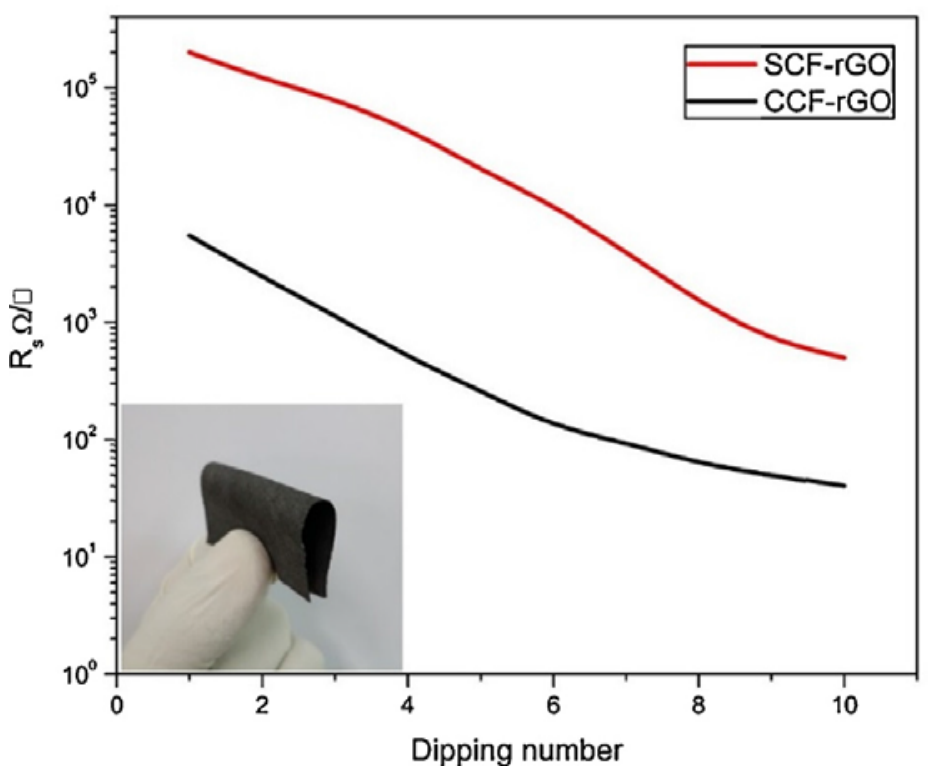

Fig. 6. Comparison of the decrease in resistance with dipping number of SCF-RGO (RGO/cotton) and CCF-RGO (RGO-BSA/cotton). Reprinted from [58] with permission from Elsevier. 
As explained previously, the reductant has also a marked influence on the conductivity obtained. Shateri-Khalilabad et al. [38] coated cotton with GO and studied the effect of the reductant employed on the conductivity of RGO/cotton fabrics obtained after chemical reduction. The reduction time is also important and it is a parameter that should be optimized when obtaining RGO coatings since it depends on the type of reductant employed as well as the synthesis conditions. In this sense, Ha et al. [49] studied the reduction process of RGO deposited on PES and cotton aided by BSA coating. Authors performed a Raman spectroscopy to study the reduction by $\mathrm{HI}$ and showed that the conducting patways on the fibers are formed within the first minute of reduction. Thereafter, conductivity remains stable till 20 min of reduction, and beyond this time, a decrease of conductivity was observed, maybe due to the deposition of $\mathrm{I}^{-}$that could act as scattering centers for the current flow.

The most important parameters of conducting fabrics have been summarized in Table 1 (conductivity, sheet resistance, electrical resitance, etc). However, some aspects of the papers dealing principally on conductivity will be summarized following (special synthesis methods, special properties or applications, etc).

Yun et al. [37] obtained conductive and colored nylon-6 yarns through dying RGO with rhodamine 6G. The conductivity of the fabrics only varied a $9 \%$ in the $220-325 \mathrm{~K}$, which demonstrated its applicability for real-life applications.

Woltornist et al. [47] coated PET simulated leather fabrics with a mixture of FLG and graphite obtained by ultrasonication. The approach employed was a kinetic trapping method, which consisted in a mixture of n-heptane and water. Both are poor solvents for FLG and graphite and both accumulate in the interface between the two solvents, the exfoliation of graphite was also facilitated in this way by means of ultrasonication. When a hydrophilic surface was present, FLG/graphite deposited on its surface. Fabrics were 
placed in contact with the mixture and were ultrasonicated to allow the deposit of the coating, weight uptakes as high as $15 \%$ of graphitic material on the fabrics were achieved. Graphite tended to accumulate in the interstices between the fibers and FLG were deposited on the surface of the fibers.

Other methods employed for obtaining conductive yarns include wet transfer of monolayer G. Neves et al. [42] synthesized monolayer G by CVD on $\mathrm{Cu}$ foil and transferred it to PP and PLA fibers by wet method to produce conductive and transparent coatings on the fibers (fibers were immobilized on a rigid PET support). The surface of the fibers was previously treated with ultraviolet-ozone treatment to remove impurities from the surface of the fibers and produced a more uniform surface that promoted $G$ adhesion.

Due to the resistive response of $G$ conducting fabrics, they have been tested as electrothermal material. Their temperature can be tuned by varying the potential and shows applicability for heating garments (for instance for maintaining the body temperature of patients, etc.) [50]. Fig. 7 shows the evolution of the temperature of RGOPU/PET fabrics depending on the applied potential.

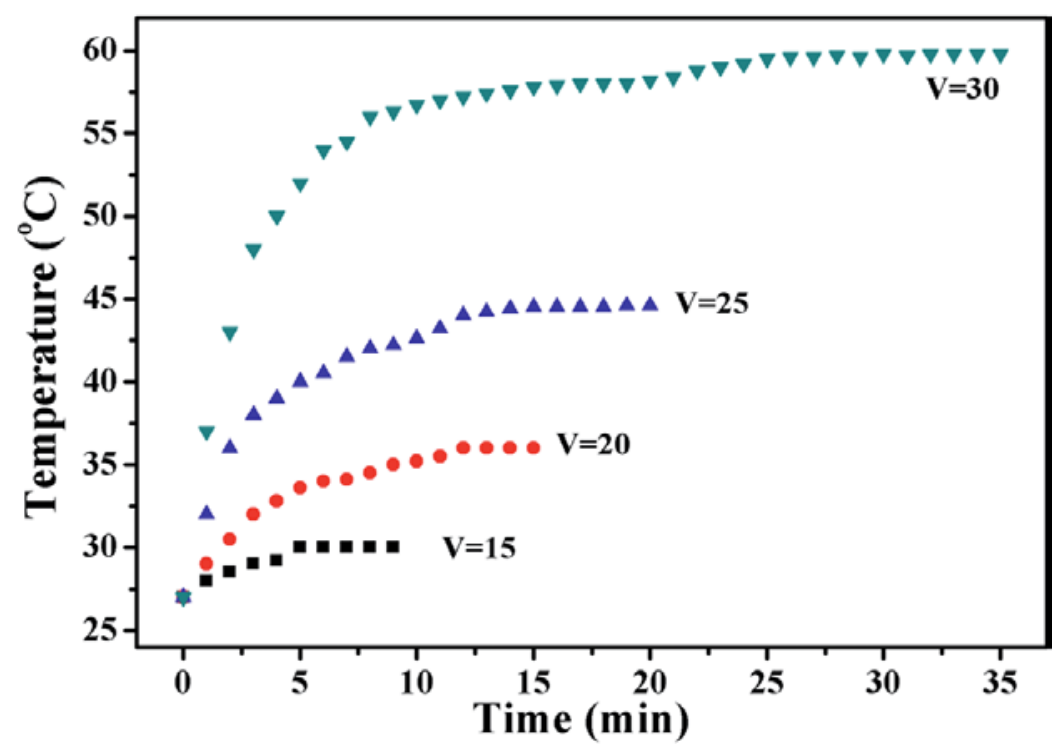


Fig. 7. Time dependence of temperature for the composite fabrics prepared in an aqueous dispersion with an RGO content of 0.080 wt \%. Reprinted from [50] with permission from The Royal Society of Chemistry.

Molina et al. published different works [43-45] in which PES fabrics were coated with RGO and they performed a complete electrochemical characterization of these materials with not traditionally employed techniques for the characterization of these materials such as: cyclic voltammetry, electrochemical impedance spectroscopy or scanning electrochemical microscopy. The RGO coatings demonstrated to be electroactive and were homogeneously distributed on the surface of the fabrics. In their electrochemical characterization using scanning electrochemical microscopy, its amphoteric behavior was observed. The RGO coatings could act either as a reductant or as an oxidant [44]. In cyclic voltammetry characterization, only low scan rates allowed the observation of RGO redox processes due to the resistive nature of the coatings, composed of lots of RGO sheets that allowed the electrical flow through the fabric.

Hsiao et al. [51] coated PU fiber mats, obtained by electrospinning, with GO, later GO was converted to RGO with hydriodic acid as the reducing agent. Electrical conduction of the fiber mats was further improved with the deposition of thiofenol-modified AgNPs. Fig. 8 shows a schematic representation of the production process, in which the functional groups of GO bonded with the functional groups of PU nanofibers by means of hydrogen bonding. AgNPs were fixed due to $\pi-\pi$ interaction between RGO and thiophenol-modified AgNPs. Fig. 9-a shows the PU nanofibers, and after GO deposition it can be seen that all the voids between the nanofibers were coated with GO (Fig. 9-b). 


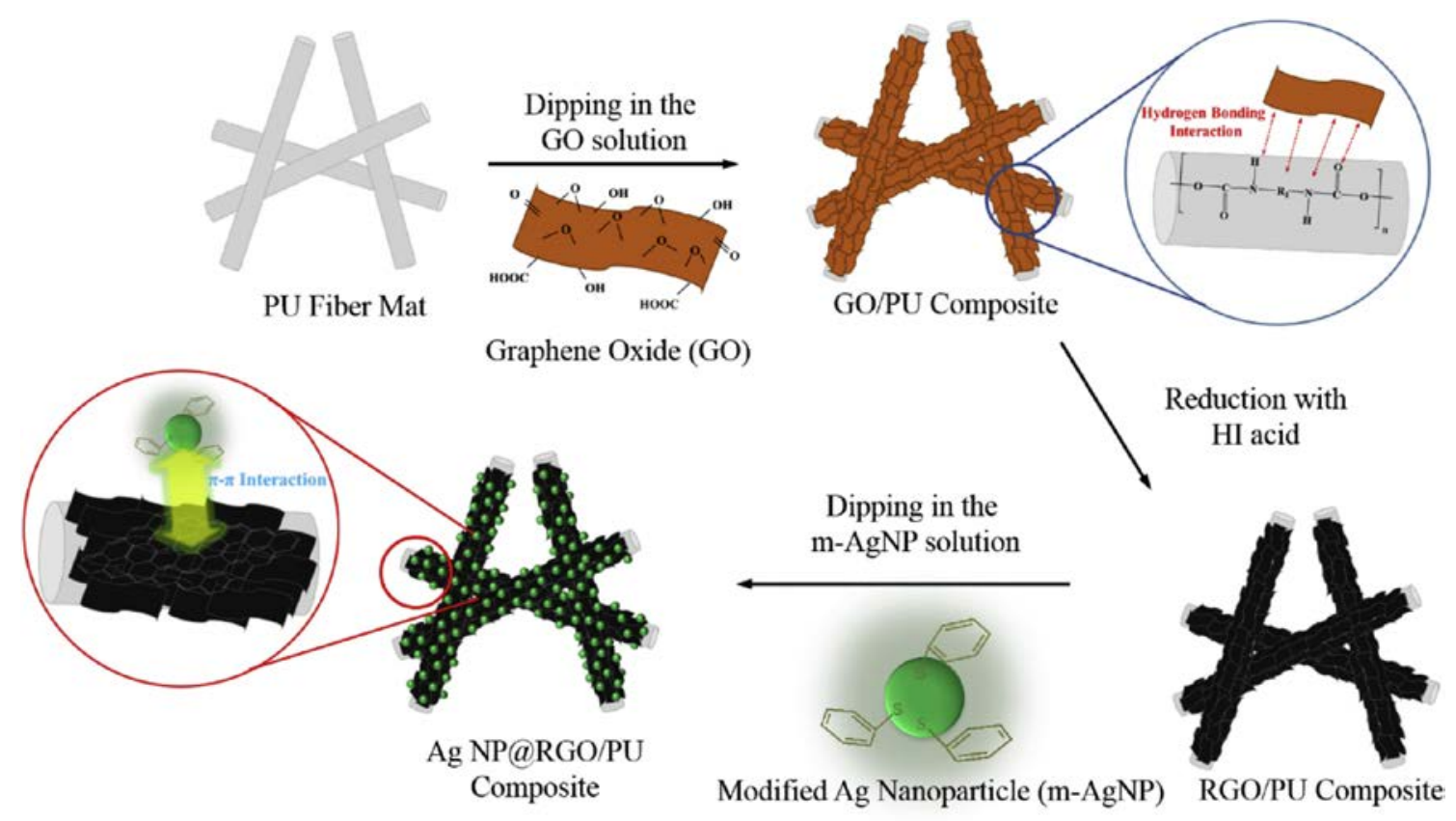

Fig. 8. Schematic representation of the procedure for preparing the AgNP@RGO/WPU composites. Reprinted from [51] with permission from Elsevier.
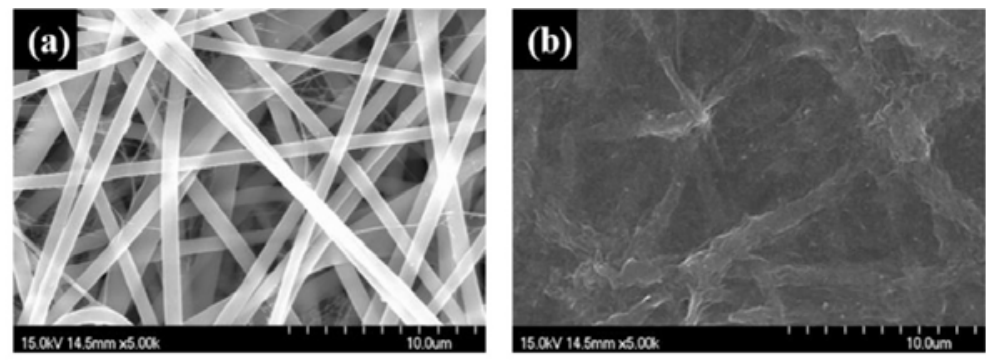

Fig. 9. SEM images of the surface of (a) PU, (b) GO/PU. Reprinted from [51] with permission from Elsevier.

Hybrid conducting materials consisting of GO and a conducting polymer were reported by Molina et al. [41] who deposited PPy/GO hybrid material on PES fabrics by means of chemical oxidation of pyrrole/GO solution by $\mathrm{FeCl}_{3}$. Different $\mathrm{GO}$ contents were employed (10, 20 and $30 \%$ wt. respect to pyrrole mass) to study the effect on the conductivity. During the polymerization, GO acted as a counter ion (negative charge) to neutralize the positive charges created in the structure of PPy (polarons and bipolarons). 
When PPy/GO was deposited the fabric became conductive (177 $\Omega /$ square, for $10 \% \mathrm{wt}$. GO content). When the GO content increased, the surface resistivity also increased slightly. An excessive amount of GO, increases electrical resistance due to its insulating nature. In addition, X-ray photoelectron spectroscopy measurements showed a decrease of the doping level of the polymer $\left(\mathrm{N}^{+} / \mathrm{N}\right)$ as the GO content increased, in accordance with the surface resistivity results. GO as counter ion has the advantage of its high size when compared with traditional organic counter ions, and cannot be expulsed from the PPy structure due to dedoping.

\subsubsection{Thermally conductive fabrics and flame retardant fabrics}

Abbas et al. [52] coated cotton fabrics with $G$ to increase its thermal conductivity. This could be useful for the production of summer clothing that allows the rapid dissipation of heat. It is also important to increase the hydrophilicity of the fabrics, which allows sweat to not be accumulated, thus allowing heat dissipation. The increase of the thermal conductivity was due to the presence of $G$ which is a good thermal conductor and it was also related to the concentration of the filler. In addition, the reduction of the air permeability of the fabrics (lower porosity) also enhanced the thermal conductivity of the fabrics. When comparing with other fillers (MWCNTs and boron nitride), better results

were obtained with G. Authors also performed dyeing of the conductive fabrics with different colors and different filler contents to see the effect of the fillers on the fabric color. The thermal conductivity provided by RGO also minimized resistive heating and allowed stable field emission [68]. Hu et al. [31] also observed the increase in the thermal conductivity of cotton fabrics when coated with GNPs.

Graphene derivatives have been also employed as flame-retardant fillers to produce fabrics with more thermal stability and flame retardant properties. Huang et al. coated 
cotton fabrics with intumescent flame retardant-polyacrylamide/GO by layer-by-layer assembly [53]. An increase in the temperature of decomposition and the time of iginition was observed. Conversely, the heat release rate was diminished.

\subsubsection{Photocatalytic fabrics, antibacterial and antifungal fabrics}

GO and RGO coatings have shown photocatalytic activity on fabrics $[55,58]$. Krishnamoorthy et al. [55] coated cotton fabrics with GO to obtain photocatalytic and antibacterial fabrics. Photocatalytic activity was measured by measuring the photoreduction of resazurin (blue) to resorufin (pink) under UV irradiation. UV- light of energy $3.54 \mathrm{eV}$ was irradiated on the fabric, which produced the creation of electron/hole pairs since the energy irradiated is higher than the GO bandgap (3.26 eV in this study). The electron reacted with the resazurin dye, which was reduced. Antibacterial activity was tested with gram-positive (Streptococcus iniae) and gram-negative (Escherichia coli DH5 $\alpha$ ) bacteria, being more toxic to the former ones. The antibacterial mechanism could involve direct contact (due to damaging produced by functional groups) and/or oxidative stress (reactive oxygen species created by GO).

Sahito et al. [58] cationised a cotton fabric with BSA. With the BSA coating an increase of $67.74 \%$ of GO deposited was obtained when compared to bare cotton. Finally, GO was converted to RGO by hydrazine hydrate vapors. Electrical conductivity and photocatalytic activity in the degradation of a MB solution were improved with the BSA coating, due to the higher amount of RGO deposited. In addition the authors pointed out the possibility of employing the fabric in the future for textile-structured solar cells.

RGO-coated fabrics have been also employed as substrate materials onto which $\mathrm{TiO}_{2} \mathrm{NPs}$ have been deposited to obtain photocatalytic fabrics [54,56,57]. Under irradiation, $\mathrm{TiO}_{2} \mathrm{NPs}$ produce electrons and holes. Electrons combine with oxygen and produce $\mathrm{O}_{2}{ }^{-}$, 
and holes and water generate hydroxyl radicals. This highly active oxygen generated species can oxidize organic pollutants. The efficiency of photocatalytic processes is determined by the electron/hole pair life, which is around $10^{-9} \mathrm{~s}$ for $\mathrm{TiO}_{2}$ alone [54]. The time needed for chemical interaction with organic matter is in the $10^{-8}-10^{-3} \mathrm{~s}$ order; therefore a decrease of the photocatalytic efficiency is observed. In this sense, G materials act as conducting materials and enable the effective electron/hole separation due to their conducting patways. In this way, the lifetime of the electron/hole pair is increased, as does the photocatalytic efficiency of these materials. Other advantage is that G materials can also extend light absorption, acting as an electron donor to produce more $\mathrm{O}_{2}{ }^{-}$radical species. In addition, $G$ materials can also act as adsorbants of organic matter, thus facilitating the contact between the photcatalytic material and the pollutants, organic matter, bacteria, etc. [54].

Karimi et al. [54] coated cotton fabrics with GO and PU. Therafter $\mathrm{TiCl}_{3}$ was added, and acted as a reductant of $\mathrm{GO}$ and at the same time, $\mathrm{TiO}_{2} \mathrm{NPs}(8-13 \mathrm{~nm})$ were formed due to the oxidation of $\mathrm{Ti}^{3+}$. Authors performed a series of experiments varying the GO and $\mathrm{TiCl}_{3}$ concentrations. The effect of these parameters on the photocatalytic efficiency (in the degradation of MB dye solution) was measured and optimized with a mathematical model. The modified fabrics were also employed as antimicrobial (Escherichia coli and Staphylococcus aureus) and antifungal materials (Candida albicans). Cytotoxicity tests were performed and showed no hazard for health. In [56] authors published a similar study.

Molina et al. [57] developed RGO-coated PES fabrics and coated them with commercial $\mathrm{TiO}_{2} \mathrm{NPs}$. An increase in the number of RGO coatings applied, produced an increase of the conductivity and a decrease of the charge transfer resistance of the fabrics in solution. 
Consequently, an increase in the photocatalytic efficiency (in Rhodamine B degradation) was also observed.

\subsubsection{Fabric sensors}

Taking advantage of their high surface area and conductivity, G coated fabrics/fibers have also been employed as sensors for different purposes: electrodes for heart rate monitoring [59], strain sensor [60], $\mathrm{H}_{2} \mathrm{O}_{2}$ sensor [61], glucose sensor [61], $\mathrm{NO}_{2}$ gas sensor [62], and acetone and methanol sensor [63].

Yapici et al. [59] coated nylon fabrics with RGO to produce electrodes for obtaining electrocardiograms. The performance was very similar to the conventional electrodes employed for such purpose and presented several advantages over traditional electrodes (Ag/AgCl) such as: They alleviate the need for gel, provide comfort, wearability, reusability and easy integration to personal clothing.

Gan et al. [60] coated cotton fabrics with GNRs obtained from MWCNTs unzipping by strong oxidants. Bending, stress-strain and washing experiments showed no significant degradation of the conductivity of the fabrics. A linear dependence of the resistance on the strain was observed when elongation was lower than $20 \%$, indicating that the fabric could be employed as a strain sensor in smart textiles. GWFs have been more widely applied for this purpose due to its high sensitivity as will be seen in section 2.4.1.

Liang et al. [61] coated silk fiber mats with GO via vacuum filtration. Later GO was reduced to RGO chemically. The morphology of the composite showed a loose structure on the top of the film and a compact structure at the bottom of the film, due to the accumulation of RGO sheets. The porous structure helped in the diffusion of analytes to the electrode. The composite material also showed capacitative properties due to the high surface area of the silk/RGO composite. Thereafter, PtNPs were deposited on the 
RGO/silk fiber mats via CV electrodeposition (Fig. 10-a,b), a spiky structure in the form of flowers was obtained. Fig. 10-c shows the EDX analysis which corroborates the presence of PtNPs on the surface of the fibers. The modified fibers were employed as electrode materials for $\mathrm{H}_{2} \mathrm{O}_{2}$ sensor (Fig. 10-d). $\mathrm{H}_{2} \mathrm{O}_{2}$ is a by-product of many analytespecific enzymes, as well as a known brain neuromodulator. After modification with glucose oxidase enzyme, the conducting fibers were also employed as glucose sensing material that could be employed for diabetes diagnosis.

Yun et al. [62] coated cotton and PES fibers with BSA to facilitate GO adsorption. After chemical reduction, the conductive fibers were embroidered in commercial fabrics and employed as gas sensors. The obtained sensors were 3-fold more sensitive to $\mathrm{NO}_{2}$ than when obtained in the form of flat RGO films, which can be attributed to the high surface area of the yarns. When exposed to $\mathrm{NO}_{2}$ as an oxidizing gas, the resistance of the RGO sensor decreases owing to the increased hole concentrations resulting in the negative sign of the response. Washing and bending (1000 tests) did not affect the performance of the fibers and provided a constant response for 7 days monitoring ( $0.13 \%$ variation). Ethanol, ethylene, acetone, and $\mathrm{CO}_{2}$ gases in 10 -fold concentrations did not cause interference in the $\mathrm{NO}_{2}$ determination. 

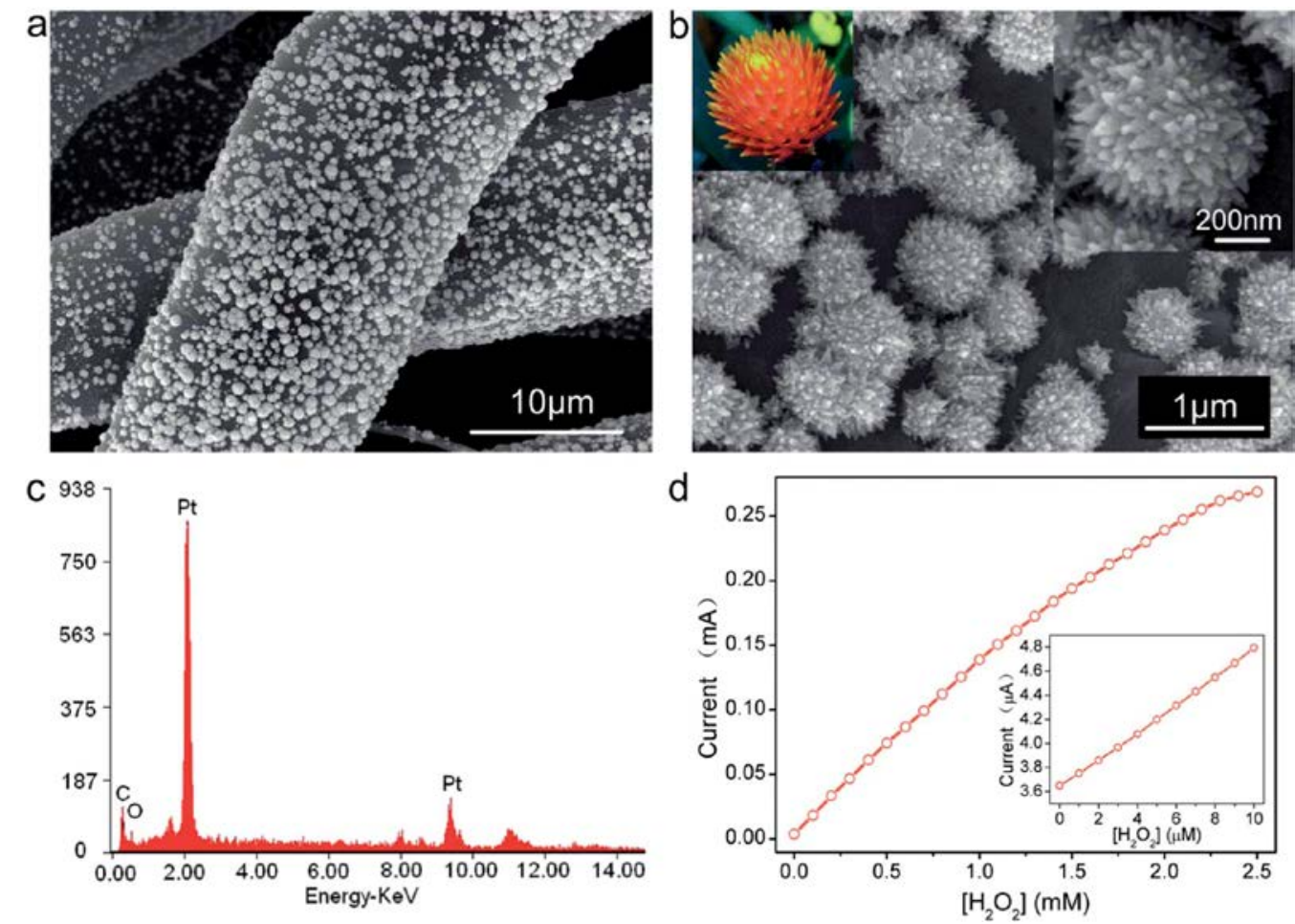

Fig. 10. (a) An SEM image of a G/silk film decorated with Pt nanospheres. (b) A highmagnification SEM image of the G/silk film decorated with Pt nanosphere. The right inset right shows a Pt spiky nanosphere and the left inset shows a photograph of a spiky flower head that is similar to the Pt nanosphere. (c) EDX spectrum of the Pt nanosphere decorated G/silk film. (d) Calibration curve of $\mathrm{H}_{2} \mathrm{O}_{2}$ detection by the Pt nanosphere decorated G/silk film at $0.65 \mathrm{~V}$ vs. Ag/AgCl. The inset shows a magnified calibration curve at low $\mathrm{H}_{2} \mathrm{O}_{2}$ concentration (1 $\mathrm{mM}$ to $10 \mathrm{mM}$ ). Reprinted from [61] with permission from The Royal Society of Chemistry.

Skrzetuska et al. [63] coated cotton fabrics with $\mathrm{G}$ pellets (23 nm of thickness, $68 \mathrm{G}$ layers on average,) and MWCNTs by screen printing technique and the developed fabrics were employed as gas sensors. The change of the electrical resistance of the fabrics when exposed to different vapor gases was employed as an indication of the gas concentration. Methanol and acetone gases were employed to test sensing properties of the screen printed electrodes, being more sensitive to methanol than towards acetone. The differences could 
be attributed to differences in the dipole moment that is lower in the case of methanol (1.61 D vs. $2.91 \mathrm{D}$ for acetone).

\subsubsection{Electrocatalytic materials}

G materials are also electrochemically active and have been employed for producing fabric electrodes for different electrochemical applications such as anodes for microbial fuel cells [64], cathodes in dye sensitized solar cells [65] cathode membranes for dye degration [66] or photoelectrode materials [74].

Liu et al. [64] deposited electrochemically ERGO on carbon cloth. The fabrics were employed as anode materials for a Pseudomonas aeruginosa mediatorless microbial fuel cell. ERGO promoted the growth of bacteria growth due to its biocompatibility and enhanced electron transfer rate due to two mechanisms: direct electron transfer and through cell-excreted mediator-enabled electron transfer pathways. Pseudomonas aeruginosa produces pyocyanin, phenazine-1-carboxamide or phenazine-1-carboxylic acid that can function as redox mediators for the transfer of electrons between the bacteria and the anode electrode. The ERGO modification improved power density and energy conversion by 2.7 and 3 times, respectively.

Sahito et al. [65] obtained RGO coated fabrics and employed them as counter electrode in dye sensitized solar cells. The counter electrode in this type of cells is usually coated with Pt to increase its electroactivity, the counter electrode with RGO is Pt free and hence is cheaper. The energy conversion efficiency obtained with the RGO/cotton fabric was lower than that for Pt counter electrode. However, there are several with these type of electrodes, such as: the low cost, the simple production method, flexibility and biodegradability of the materials, which make these type of electrodes promising candidates for future technology of textile structured solar cells. 
Zhao et al. [66] developed PPy/RGO coated PES filter cloth membranes and employed them at the same time as membrane and cathode material. AQSA was employed as a dopant to improve the conductivity of the membrane and the generation of radicals. The filtration effect enhanced the contact between the membrane and the pollutants. The membrane was employed in an electro-Fenton system to degrade pollutants (MB). $\mathrm{H}_{2} \mathrm{O}_{2}$ was produced on the cathode through $\mathrm{O}_{2}$ reduction, which reacted with $\mathrm{Fe}^{2+}$ to produce hydroxyl and hydroperoxyl radicals that were responsible for oxidizing organic matter. Hydroxyl radicals could also be directly produced on the cathode. RGO acted as an effective bridge between PPy and the catalyst.

Tian et al. [74] wrapped CNT fibers with GO by means of $\pi-\pi$ interaction, and later reduced to RGO. $\mathrm{TiO}_{2}$ was also deposited by CVD to produce photoelectrode materials. When depositing $\mathrm{TiO}_{2} / \mathrm{RGO}$ on CNTs, the photocurrents obtained were multiplied by a 5 factor when compared with $\mathrm{TiO}_{2} / \mathrm{CNT}\left(132\right.$ vs. $\left.25 \mu \mathrm{A} \cdot \mathrm{cm}^{-2}\right)$. This was due to the deposition of more $\mathrm{TiO}_{2} \mathrm{NPs}$ and the creation of donor-acceptor interfaces due to tight binding between $\mathrm{RGO}$ and $\mathrm{TiO}_{2} \mathrm{NPs}$.

\subsubsection{Field emission fabrics}

Roy et al. [67] deposited RGO and CNTs on carbon cloth/PET substrate for increasing field emission for flexible device applications. A decrease in the turn-on field and in the current density at the threshold field was observed and was due to an enhanced edge effect of RGO caused by the synergy between RGO and CNTs. In [68] a similar study for the same application was performed. RGO was deposited on carbon cloth and was etched with plasma to produce $G$ nanocones that acted as cold electron emitters. The effect of the time of plasma etching was studied, obtaining the best results with 3 min etching. The thermal conductivity of G minimized resistive heating and allowed stable emission. As 
examples of application authors pointed out rolled-up field emission displays, bendable X-ray generators, etc.

\subsubsection{Capacitors and energy storage}

Carbon materials are of interest for the production of capacitors since its high surface area allow them to adsorb more electrolyte ions, which increases the capacitance of the doublelayer capacitor. In this sense, $\mathrm{G}$ and derivatives have a high surface area $\left(2630 \mathrm{~m}^{2} \cdot \mathrm{g}^{-1}\right)$ [20] which make them ideal candidates for such purpose. In addition, its conductivity enhances the performance of the capacitors and reduces their internal resitance, thus improving the rate performance. This is why the use of $\mathrm{G}$ derivatives for supercapacitors is on the increase. The same happens in the field of fabrics, where the applications of $G$ materials allows to obtain flexible supercapacitors [61,69-85]. Fig. 11 displays a diagram showing the double layer capacitative performance of a carbon fiber electrode before and after ERGO deposit. An increase in the surface area allows the material to adsorb more ions. Fabric supercapacitors have also the advantage that they are highly porous and facilitate electrolyte access. However, the capacitance obtained by carbon materials is low and other pseudo-capacitative materials are usually added on top of them to increase their capacitance. These materials include conducting polymers suc as PPy [70,71,80,81,83], Pani [74,85], PEDOT [73] and metal oxides such as $\mathrm{MnO}_{2}$ [72,73,83], $\mathrm{V}_{2} \mathrm{O}_{5}$ [75]. The use of MWCNTs has also been reported to increase double layer capacitance and conductivity [75,81]. The design of the supercapacitor has been studied as a key factor for enhancing the electrolyte-accessible surface area and increase the capacitance of the system when compared with traditional configurations [77]. Following, the most interesting works related to G-based fabrics for supercapacitor applications will be briefly summarized. 


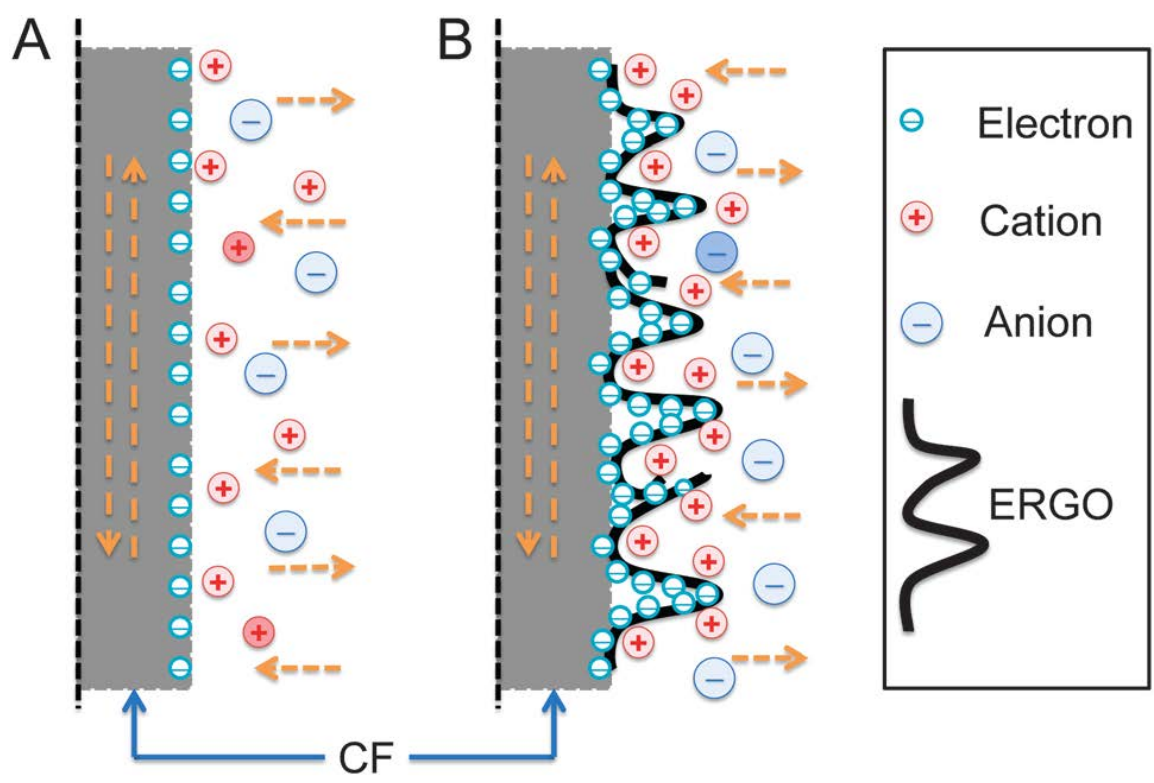

Fig. 12. Schematic diagram of the mechanism that, by stably attaching ERGO additives, increased specific surface area featuring a unique wrinkled structure for adsorption of electrolyte ions contributing to the excellent electrochemical double-layers. (A) Pure carbon fiber electrode. (B) ERGO-carbon fiber electrode. Reprinted from [82] with permission from The Royal Society of Chemistry.

Yaghoubidoust et al. [70] coated cotton fabrics with GO and later with PPy obtained by chemical oxidation, obtaining a double layer coating. The previous GO deposit enhanced conductivity of the fabric, it should be taken into account that GO could be partially reduced to RGO during the oxidation process of pyrrole to PPy. Specific capacitance was also improved by the GO coating as measured by cyclic voltammetry. Xu et al. [71] employed a similar approach to [70], however in this case authors reduced GO to RGO to obtain more conductive coatings. Although the presence of RGO produced a thinner PPy coating $\left(1.5 \mathrm{mg} \cdot \mathrm{cm}^{-2}\right.$ vs. $\left.6 \mathrm{mg} \cdot \mathrm{cm}^{-2}\right)$, the capacitance was higher in the case of PPy/RGO coating. This can be attributed to a higher surface area, yielding increased electrode/electrolyte interface areas. In addition, RGO formed a conducting layer below the PPy layer, which facilitated the electron transfer between RGO and PPy. The presence 
of RGO coating stabilized PPy and increased its cycling stability due to the interaction between RGO and PPy ( $\pi-\pi$ interaction) which limited the swelling and shrinking of the PPy coating. A similar effect of stabilization of the conducting polymers has been observed by other authors [85]. Zhao et al. [80] coated nylon-lycra fabrics with RGO and later a PPy film was also deposited on the surface of the fabrics. In this case, the capacitative performance was even better under $50 \%$ stretching, since allowed a better contact between RGO sheets.

Liu et al. [81] coated PES non-woven fabrics with RGO, PPy and MWCNTs and studied its performance as supercapacitor material. A synergistic effect was observed among all the components of the flexible fabric. The presence of RGO increased the surface area of PPy and MWCNTs increased the conductivity, high rate performance and the stability. Yu et al. [85] deposited Pani nanowire array coating on nitrogen-doped carbon fiber cloth. Thereafter RGO was deposited on top of the Pani coating to buffer the volume change of Pani that suffers in the oxidation/reduction process, which contributed to enhance the long term stability of the supercapacitor. Strong $\pi-\pi$ interaction allowed gooed electron transfer between Pani and the basal plane of RGO. Nanostructured Pani allowed a high electrode/electrolyte interface area and short diffusion lengths and RGO decreased the internal resistance of the electrode.

Huang et al. [83] deposited $\mathrm{RGO}, \mathrm{MnO}_{2}$ and PPy successively on the surface of stainless steel fibers. The obtained fibers could be knitted into fabrics for wearable energy storage textiles. RGO improved charge transfer with $\mathrm{MnO}_{2}$ and increased capacitance. $\mathrm{MnO}_{2}$ contributted to the capacitance and PPy improved electron transfer and also participated in the pseudocapacitative charge storage. The yarns could be assembled in series and in parallel to meet the voltage and current requirements in real applications. In addition, the yarns could be knitted into patterns without loosing their properties. 
$\mathrm{Yu}$ et al. [72,73] published two works in which they coated fabrics with $\mathrm{GNS} / \mathrm{MnO}_{2}$ coatings. Fabrics were previously coated with exfoliated GNS and after this, electrochemical deposition of $\mathrm{MnO}_{2}$ was performed. Materials with high specific capacitance were obtained $\left(315 \mathrm{~F} \cdot \mathrm{g}^{-1}\right) \cdot \mathrm{MnO}_{2}$ was employed as a typical active pseudocapacitive material which uses fast and reversible redox reactions at the surface of electroactive materials. GNS acted as a conductor which facilitated the electrochemical synthesis of $\mathrm{MnO}_{2} \mathrm{NPs}$ and facilitated fast electron transport between GNS and $\mathrm{MnO}_{2} \mathrm{NPs}$. The morphology of the $\mathrm{MnO}_{2} \mathrm{NPs}$ (flower-like) enhanced the surface area and reduced ion diffusion length during charging/discharging. In addition, GNS acted as a double layer capacitor, accumulating electrical charges arising from ion absorption (double layer capacitance). In [73] authors employed a conductive wrapping of PEDOT/PSS or SWCNTs on the GNS- $\mathrm{MnO}_{2} / \mathrm{PES}$ fabrics. This wrapping further increased the specific capacitance (till $380 \mathrm{~F} \cdot \mathrm{g}^{-1}$ ) and the rate capability, which can be attributed to shorter ion diffusion path and increased electronic conductivity. The additional conductive wrapping created a new electron transport path and also participated in increasing the capacitance through double layer capacitance (SWCNTs) or pseudocapacitance (PEDOT).

Shakier et al. [75] obtained supercapacitor electrodes based on layer-by-layer assembly of $\mathrm{G}$ layers acting as conductive spacers between layers of $\mathrm{V}_{2} \mathrm{O}_{5}$ coated-MWCNTs. The G coatings provided an extra conductive pathway, avoided the agglomeration of MWCNTs and enhanced the specific capacitance by a $67 \%$, till values as high as 2590 F. $\mathrm{g}^{-1}$. Electrodes stored charge through electric double layer capacitance (MWCNTs) and through pseudocapacitative mechanism $\left(\mathrm{V}_{2} \mathrm{O}_{5}\right)$. The optimal thickness of the $\mathrm{V}_{2} \mathrm{O}_{5}$ coating on MWCNTs was $3 \mathrm{~nm}$, a higher thickness decreased the ratio of utilization which decreased the specific capacitance. 
Wang et al. [76] employed nanofabrics of electrospun polyamide coated with RGO to produce supercapacitative materials. The nanofabrics increased the surface area of the fabric and avoided the aggregation of RGO, thus being advantageous when compared to microfabrics (capacitance when employing nanofabrics was 4.4 times higher than with microfabrics). GO with different sizes was coated on the fabrics to study the influence of this parameter on the capacitative behavior (diameters: < $200 \mathrm{~nm}(\mathrm{~S}), 200-450 \mathrm{~nm}(\mathrm{M})$, $>450 \mathrm{~nm}(\mathrm{~L})$ ). GO was fixed on polyamide through hydrogen bonding between GO functional groups and the amide groups of polyamide 66. The optimal size of GO nanosheets was 200-450 nm, because they had a size that could wrap the fibers and maintained the pores of the fabric. The lowest size $(<200 \mathrm{~nm})$ did not produce proper coatings due to an incomplete coverage of the fibers, and the highest size (>450 nm) blocked the pores of the fabric due to the larger size of GO nanosheets. Medium size GO nanosheets improved GO loading and fixation, surface area, conductivity and electrolyte could easily access, thus obtaining the highest capacitance values. Fig. 11 shows micrographs of the coatings obtained on the nanofabrics depending on the size of the GO sheets. A schematic representation is also included to clarify the effect of the GO sheets size.

Ramadoss et al. [79] coated carbon fabrics with GO and later reduced it to RGO by thermal treatment at low temperature. High values of specific capacitance were achieved $\left(414 \mathrm{~F} \cdot \mathrm{g}^{-1}\right)$ and a good rate capability was also observed, which was attributed to a shorter diffusion path for electrolyte and electrons, a highly activated surface and improved electrical conductivity. Two pieces of the conducting fabric, were separated by filter paper separator and a flexible solid state supercapcitor was obtained employing a $\mathrm{H}_{3} \mathrm{PO}_{4} / \mathrm{PVA}$ gel as electrolyte. Bending did not cause significant change in its properties. 5 supercapacitors were mounted and charged and they powered a LED for more than 15 
minutes. A nanogenerator was also integrated to harvest the energy from vibrational and mechanical deformation to charge the capacitor and this one supplied power to a photosensor. This demonstrates their application for wearable and portable devices.

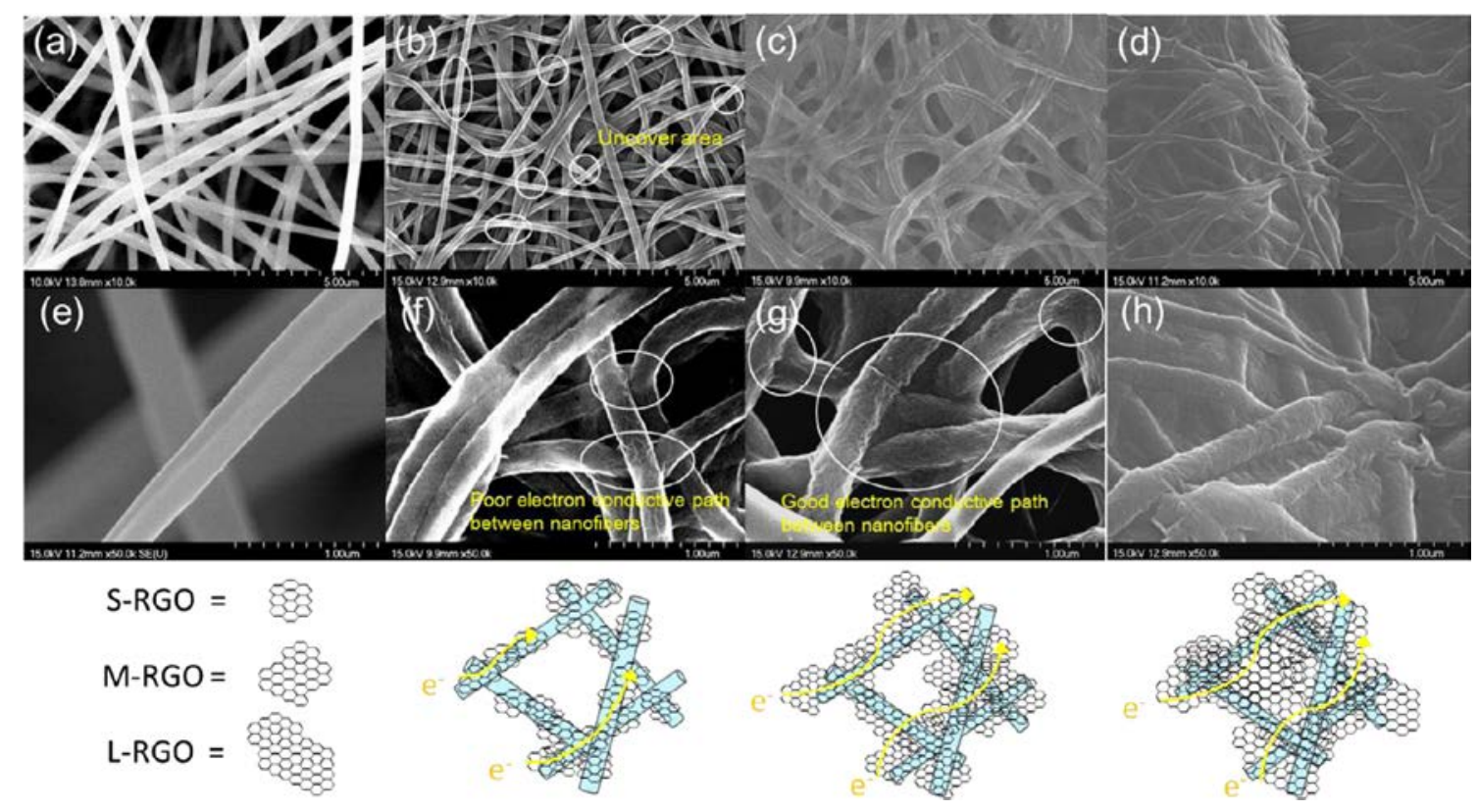

Fig. 11. The SEM images of (a, e) PA66 nanofibers, (b, f) S-RGO/PA66-nano, (c, g) MRGO/PA66-nano, and (d, h) L-RGO/PA66-nano. Reprinted from [76] with permission from Elsevier.

Liu et al. [84] coated cotton yarns with Ni by a polymer-assisted metal deposition method. Later ERGO was deposited by means of electrochemical methods and was further reduced with hydrazine. The fibers obtained showed high capacitance values and could be embroidered or weft due to the enhanced mechanical resistance provided by $\mathrm{Ni}$ coating. The fibers could be connected in series, in parellell or in a combination of both to meet operational voltage or power requirements. 
Table 1. Work performed with fabrics and graphene coatings by wet methods.

\begin{tabular}{|c|c|c|c|c|c|}
\hline $\begin{array}{l}\text { Material } \\
\text { composition }\end{array}$ & Properties & Method of synthesis & Reductant & Application & Ref. \\
\hline $\begin{array}{l}\text { GNS- } \\
\text { chitosan/cotton } \\
\text { fabrics }\end{array}$ & $\begin{array}{l}\text { UPF: } 465.8 \text { (chitosan-GNS/Cotton), } 7.31 \text { (cotton) } \\
\text { UPF after laundering } 10 \text { times: } 432.7 \text { (chitosan-GNS/Cotton), } 7.28 \\
\text { (cotton) }\end{array}$ & $\begin{array}{l}\text { GNS coating: Dip coating }(0.2 \% \text { wt. chitosan }+2 \% \mathrm{v} / \mathrm{v} \\
\text { acetic acid }+0.1-1 \% \text { wt. GNS, } 2 \mathrm{~h}) . \text { Padding } 2 \text { times, } \\
\text { drying } 70^{\circ} \mathrm{C}(10 \mathrm{~min}) \text {, curing } 110^{\circ} \mathrm{C}(10 \mathrm{~min})\end{array}$ & - & UV-blocking & [28] \\
\hline $\begin{array}{l}\text { GNPs- } \\
\text { WPU/cotton } \\
\text { fabrics }\end{array}$ & $\begin{array}{l}\text { UPF: } 356.74 \text { (GNPs-WPU/cotton), } 32.71 \text { (cotton) } \\
\text { UPF after laundering } 10 \text { times: } 5 \% \text { decrease }\end{array}$ & $\begin{array}{l}\text { GNP coating: Dip coating (WPU + 0.05- } 0.4 \% \text { wt. GNP, } 1 \\
\text { h). Padding } 2 \text { times, drying } 65^{\circ} \mathrm{C}(5 \mathrm{~min}) \text {, curing } 110^{\circ} \mathrm{C}(5 \\
\text { min) }\end{array}$ & - & UV-blocking & {$[29]$} \\
\hline $\begin{array}{l}\text { PEDOT-G- } \\
\text { PSS/chitosan- } \\
\text { PEI/cotton fabric }\end{array}$ & $\begin{array}{l}\text { UPF: } 312 \text { (PEDOT-G-PSS/chitosan/PEI/cotton), } 92.4 \text { (PEDOT-PSS- } \\
\text { chitosan-PEI/cotton), } 9.37 \text { (cotton) } \\
\text { UPF after laundering } 10 \text { times: } 301.39 \text { (PEDOT-G-PSS- } \\
\text { chitosan/cotton) } \\
\text { Electrical resistivity: } 2.29 \Omega \cdot \mathrm{m} \text { (PEDOT-G-PSS-chitosan/cotton), } 208.4 \\
\Omega \cdot \mathrm{m} \text { (PEDOT-PSS-chitosan-PEI/cotton), } 7.79 \cdot 10^{8} \Omega \cdot \mathrm{m} \text { (cotton) }\end{array}$ & $\begin{array}{l}\text { PEI coating: Dip coating }\left(0.01 \mathrm{M} \text { PEI, } 2 \mathrm{~h}, 75^{\circ} \mathrm{C}\right) \\
\text { Chitosan coating: Dip coating ( } 3 \% \text { wt. chitosan in } 2 \% \\
\text { acetic acid) } \\
\text { PEDOT/PSS/GNS coating: Dip coating }(1 \% \text { wt. PEDOT } \\
+0.5 \% \text { wt. PSS }+10 \mathrm{mg} \cdot \mathrm{L}^{-1}(\sim 1 \% \text { wt) GNS, } 20 \text { min }) \\
\text { ( } 1 \text { to } 6 \text { coatings applied alternatively by layer-by-layer self- } \\
\text { assembly: } 1-6 \text { coatings of PEDOT/PSS/GNS and } 1-6 \\
\text { coatings of chitosan) }\end{array}$ & - & $\begin{array}{l}\text { UV blocking, } \\
\text { electrical } \\
\text { conductivity }\end{array}$ & {$[30]$} \\
\hline $\begin{array}{l}\text { GNPs- } \\
\text { WPU/cotton } \\
\text { fabrics }\end{array}$ & $\begin{array}{l}\text { UPF: } 500 \text { (GNPs-WPU/cotton), } 8.19 \text { (cotton) } \\
\text { UPF after laundering } 10 \text { times: } 2 \% \text { increase } \\
\text { Electrical resistivity: } 2.94 \cdot 10^{-1} \Omega \cdot \mathrm{m} \text { (GNPs-WPU/cotton) } 1.15 \cdot 10^{7} \Omega \cdot \mathrm{m} \\
\text { (cotton) } \\
\text { Far-infrared emissivity: } 0.911 \text { (wavelength } 4-18 \mu \mathrm{m} \text { ) (GNPs- } \\
\text { WPU/cotton) } \\
\text { Thermal conductivity: } 50.633 \mathrm{~W} / \mathrm{mK} \times 10^{-3}\left(0.48 \mathrm{~g} \cdot \mathrm{m}^{-2} \mathrm{GNPs}\right), 38.5 \\
\mathrm{~W} / \mathrm{mK} \times 10^{-3}\left(0 \mathrm{~g} \cdot \mathrm{m}^{-2} \mathrm{GNPs}\right)\end{array}$ & $\begin{array}{l}\text { GNP coating: Dip coating (WPU }+0.8 \% \text { wt. GNP, } 100 \\
\text { min). Padding } 2 \text { times, drying } 70^{\circ} \mathrm{C}(10 \mathrm{~min}) \text {, curing } 120^{\circ} \mathrm{C} \\
(5 \mathrm{~min}) \\
\text { GNP content on fabrics: } 240,320,480 \mathrm{mg} \cdot \mathrm{m}^{-2}(1,2,3 \\
\text { coating cycles) }\end{array}$ & - & $\begin{array}{l}\text { UV-blocking, far- } \\
\text { infrared emission, } \\
\text { electrical } \\
\text { conductivity, } \\
\text { thermal conductivity }\end{array}$ & [31] \\
\hline $\begin{array}{l}\text { Pani-GO/cotton } \\
\text { fabric }\end{array}$ & $\begin{array}{l}\text { UPF: } 445.21 \text { (Pani-GO/cotton), } 424.88 \text { (GO/cotton), } 29.43 \text { (Pani/cotton), } \\
6.86 \text { (cotton) } \\
\text { UPF after laundering } 10 \text { times: } 412.63 \text { (Pani-GO/cotton), } 380.95 \\
\text { (GO/cotton), } 29.21 \text { (Pani/cotton), } 6.82 \text { (cotton) } \\
\text { Electrical resisitivity: } 48.35 \Omega \cdot \mathrm{cm} \text { (Pani-GO/cotton), } 2084.91 \Omega \cdot \mathrm{cm} \\
\text { (Pani/cotton) } \\
\text { Electrical resisitivity after laundering } 10 \text { times: } 52.37 \Omega \cdot \mathrm{cm} \text { (Pani- } \\
\text { GO/cotton), } 2108.78 \Omega \cdot \mathrm{cm} \text { (Pani/cotton) }\end{array}$ & $\begin{array}{l}\text { GO coating: Vacuum filtration deposition }\left(5 \mathrm{~g} \cdot \mathrm{L}^{-1} \mathrm{GO}\right) \\
\text { Pani coating: Adsorption }(20 \mathrm{~mL} \text { aniline }+80 \mathrm{~mL} \text { ethanol, } \\
90 \text { min), oxidation by APS, } 120 \mathrm{~min}(\mathrm{APS} \text { ratio } 1: 1, \mathrm{HCl} \\
\text { ratio 1:0.5, ratio respect aniline) }\end{array}$ & - & $\begin{array}{l}\text { UV-blocking, } \\
\text { electrical } \\
\text { conductivity }\end{array}$ & [32] \\
\hline $\begin{array}{l}\text { RGO/wool fabric } \\
\text { RGO/cotton fabric }\end{array}$ & $\begin{array}{l}\text { Surface resistivity: } 45 \mathrm{k} \Omega / \text { square (RGO/wool fabric), } 100.8 \mathrm{k} \Omega / \mathrm{square} \\
\text { (RGO/cotton fabric) } \\
\text { UPF: } 5 \text { (cotton), > } 50 \text { (RGO/cotton fabric) }\end{array}$ & $\begin{array}{l}\text { GO coating: Brush coating }\left(2 \mathrm{~g} \cdot \mathrm{L}^{-1} \mathrm{GO}, \mathrm{pH} 4.5\right) \text {. Drying: } \\
90^{\circ} \mathrm{C}, 10 \text { min. } \\
\text { (Process repeated } 5 \text { times to increase } \mathrm{GO} \text { adsorption) }\end{array}$ & $\begin{array}{l}\text { UV light (8 passes } \\
\text { UV irradiation } \\
\text { line) }\end{array}$ & $\begin{array}{l}\text { UV blocking, } \\
\text { electrical } \\
\text { conductivity }\end{array}$ & [33] \\
\hline $\begin{array}{l}\text { GO-NCPCl/PES } \\
\text { fibers }\end{array}$ & $\begin{array}{l}\text { GO weight uptake: } 0.38 \mathrm{mg} \mathrm{GO} / \mathrm{g} \text { PES ( } \mathrm{pH} 3), 0.14 \mathrm{mg} \mathrm{GO} / \mathrm{g} \text { PES (pH } \\
\text { 4.5), negligible deposition }(\mathrm{pH} 9)\end{array}$ & $\begin{array}{l}\text { NCPCl coating: Dip coating }\left(10^{-4} \mathrm{M} \text { NCPCl, } 293 \mathrm{~K}, 24 \mathrm{~h}\right) \\
\text { GO coating: Dip coating }\left(0.4 \mathrm{~g} \cdot \mathrm{L}^{-1} \mathrm{GO}, 293 \mathrm{~K}, 12000 \mathrm{~s}\right)\end{array}$ & - & - & [34] \\
\hline GO/cotton fabric & $\begin{array}{l}\text { Water contact angle: } 143^{\circ}\left(0.4 \mathrm{~g} \cdot \mathrm{L}^{-1} \mathrm{GO}\right), 135^{\circ}\left(0.2 \mathrm{~g} \cdot \mathrm{L}^{-1} \mathrm{GO}\right), 121^{\circ} \\
\left(0.1 \mathrm{~g} \cdot \mathrm{L}^{-1} \mathrm{GO}\right), 60^{\circ}\left(0.05 \mathrm{~g} \cdot \mathrm{L}^{-1} \mathrm{GO}\right), 0^{\circ} \text { (cotton) }\end{array}$ & GO coating: Dip coating $\left(0.05-0.4 \mathrm{~g} \cdot \mathrm{L}^{-1} \mathrm{GO}, 45 \mathrm{~min}\right)$ & - & Hydrophobicity & [35] \\
\hline $\begin{array}{l}\text { PMS-RGO/cotton } \\
\text { RGO/cotton }\end{array}$ & $\begin{array}{l}\text { Surface resistance: } 91.8 \mathrm{k} \Omega / \mathrm{square} \text { (RGO/cotton), } 112.5 \mathrm{k} \Omega / \mathrm{square} \\
\text { (PMS-RGO/cotton) }\end{array}$ & $\begin{array}{l}\text { GO coating: Dip coating }\left(0.2 \mathrm{~g} \cdot \mathrm{L}^{-1} \mathrm{GO}, 30 \mathrm{~min} \text {, repeated } 3\right. \\
\text { times. } \\
\text { (Multiple coatings, } 1 \text { to } 20) .\end{array}$ & $\begin{array}{l}0.05 \mathrm{M} \mathrm{C}_{6} \mathrm{H}_{8} \mathrm{O}_{6} \\
95^{\circ} \mathrm{C}, 60 \mathrm{~min}\end{array}$ & $\begin{array}{l}\text { Hydrophobicity, } \\
\text { electrical } \\
\text { conductivity }\end{array}$ & [36] \\
\hline
\end{tabular}




\begin{tabular}{|c|c|c|c|c|c|}
\hline & $\begin{array}{l}\text { Surface resistance of RGO/cotton with number of RGO coatings: } 1 \\
(400.2 \mathrm{k} \Omega \text { /square), } 5 \text { (12.6 } \mathrm{k} \Omega / \text { square }), 10(3.4 \mathrm{k} \Omega / \mathrm{square}), 20(0.84 \\
\mathrm{k} \Omega \text { /square) } \\
\text { Water contact angle: } 143.2^{\circ} \text { (RGO/cotton), } 163^{\circ} \text { (PMS-RGO/cotton) }\end{array}$ & $\begin{array}{l}\text { PMS coating: Dip coating (methyltrichlorosilane in hexane, } \\
15 \text { min). Curing } 110^{\circ} \mathrm{C}, 60 \mathrm{~min} .\end{array}$ & & & \\
\hline $\begin{array}{l}\text { RGO-BSA/nylon- } \\
6 \text { yarns and } \\
\text { fabrics (or PES or } \\
\text { cotton yarns) }\end{array}$ & Conductivity: $1040 \mathrm{~S} \cdot \mathrm{m}^{-1}$ (RGO-BSA/nylon-6 fabric) & $\begin{array}{l}\text { BSA coating: Dip coating ( } 0.5 \% \text { wt. BSA, } 10 \text { min), drying } \\
1 \text { hour, washing. } \\
\text { GO coating: Dip coating }\left(1 \mathrm{~g} \cdot \mathrm{L}^{-1} \mathrm{GO}\right)\end{array}$ & $\begin{array}{l}\mathrm{HI}(2 \mathrm{~mL} \mathrm{HI}+5 \\
\mathrm{mL} \text { acetic acid, } 15 \\
\text { min) }\end{array}$ & $\begin{array}{l}\text { Electrical } \\
\text { conductivity }\end{array}$ & [37] \\
\hline $\begin{array}{l}\text { RGO/cotton } \\
\text { fabrics }\end{array}$ & $\begin{array}{l}\text { Surface resistance of RGO/cotton as function of reductant: } \mathrm{NaBH}_{4} \\
\left(34600 \mathrm{k} \Omega \cdot \mathrm{cm}^{-1}\right), \mathrm{NaOH}\left(23300 \mathrm{k} \Omega \cdot \mathrm{cm}^{-1}\right), \mathrm{N}_{2} \mathrm{H}_{4}\left(62.7 \mathrm{k} \Omega \cdot \mathrm{cm}^{-1}\right), \mathrm{C}_{6} \mathrm{H}_{8} \mathrm{O}_{6} \\
\left(31.2 \mathrm{k} \Omega \cdot \mathrm{cm}^{-1}\right), \mathrm{Na}_{2} \mathrm{~S}_{2} \mathrm{O}_{4}\left(19.4 \mathrm{k} \Omega \cdot \mathrm{cm}^{-1}\right) \text {. } \\
\text { Surface resistance with number of RGO coatings }\left(\mathrm{Na}_{2} \mathrm{~S}_{2} \mathbf{O}_{4}\right. \\
\text { reductant): } 1\left(201.1 \mathrm{k} \Omega \cdot \mathrm{cm}^{-1}\right), 10\left(1.27 \mathrm{k} \Omega \cdot \mathrm{cm}^{-1}\right), 20\left(0.374 \mathrm{k} \Omega \cdot \mathrm{cm}^{-1}\right)\end{array}$ & $\begin{array}{l}\text { GO coating: Dip coating ( } 0.05 \% \text { wt. GO, } 30 \text { min) } \\
\text { (Multiple coatings, } 1 \text { to 20) }\end{array}$ & $\begin{array}{l}\mathrm{NaBH}_{4}, \mathrm{~N}_{2} \mathrm{H}_{4}, \\
\mathrm{C}_{6} \mathrm{H}_{8} \mathrm{O}_{6}, \mathrm{Na}_{2} \mathrm{~S}_{2} \mathrm{O}_{4} \\
\text { and } \mathrm{NaOH}(25 \\
\text { mM, } 95^{\circ} \mathrm{C}, 60 \\
\text { min. Best } \\
\text { reductor: } \mathrm{Na}_{2} \mathrm{~S}_{2} \mathrm{O}_{4} \\
\left(30 \text { min, } 95^{\circ} \mathrm{C}\right)\end{array}$ & $\begin{array}{l}\text { Electrical } \\
\text { conductivity }\end{array}$ & {$[38]$} \\
\hline $\begin{array}{l}\text { RGO/polyarylate } \\
\text { yarns }\end{array}$ & $\begin{array}{l}\text { Electrical resistivity: } 92.52 \Omega \cdot \mathrm{cm}^{-1} \text { (it could be tuned from } 10^{2} \Omega \cdot \mathrm{cm}^{-1} \text { to } \\
10^{9} \Omega \cdot \mathrm{cm}^{-1} \text { depending on the RGO content). } \\
\text { GO weight uptake: } 8 \mathrm{mg} \mathrm{GO} / \mathrm{g} \text { fiber }\end{array}$ & GO coating: Dip coating ( $0.3 \%$ wt. GO, pH 2.13, 15 min) & $\begin{array}{l}0.5 \% \text { wt. } \\
\mathrm{Na}_{2} \mathrm{~S}_{2} \mathrm{O}_{4}, 363 \mathrm{~K} \\
30 \mathrm{~min}\end{array}$ & $\begin{array}{l}\text { Electrical } \\
\text { conductivity }\end{array}$ & [39] \\
\hline $\begin{array}{l}\text { RGO-BSA/silk } \\
\text { fabrics } \\
\text { RGO-BSA/silk } \\
\text { yarns }\end{array}$ & $\begin{array}{l}\text { Surface resistance: } 386.6 \mathrm{k} \Omega / \mathrm{square} \text { (1 coating), } 1.5 \mathrm{k} \Omega / \mathrm{square} \text { (5 } \\
\text { coatings) (RGO-BSA/silk fabrics) } \\
\text { Electrical conductivity: } 3595 \mathrm{~S} \cdot \mathrm{m}^{-1} \text { (RGO-BSA/silk yarns) }\end{array}$ & $\begin{array}{l}\text { BSA coating: Dip coating ( } 0.5 \% \text { wt BSA, } 10 \mathrm{~min} \text { ). Drying } \\
30^{\circ} \mathrm{C}, 15 \mathrm{~min} \\
\text { GO coating: Dip coating }\left(2 \mathrm{~g} \cdot \mathrm{L}^{-1} \mathrm{GO}, 30 \mathrm{~min}\right) \\
\text { (Multiple coatings, } 1 \text { to } 7 \text { ) }\end{array}$ & $\begin{array}{l}\text { Hydrazine, } \\
\text { overnight }\end{array}$ & $\begin{array}{l}\text { Electrical } \\
\text { conductivity }\end{array}$ & [40] \\
\hline $\begin{array}{l}\text { PPy-GO/PES } \\
\text { fabrics }\end{array}$ & $\begin{array}{l}\text { Surface resistivity: } 177 \Omega / \text { square ( } 10 \% \text { wt. GO in solution), } 385 \\
\Omega / \text { square ( } 20 \% \text { wt. GO in solution), } 472 \Omega / \text { square ( } 30 \% \text { wt. GO in } \\
\text { solution) }\end{array}$ & $\begin{array}{l}\text { PPy/GO coating: Dip coating }(0.02 \mathrm{M} \text { pyrrole + GO }(10 \% \text {, } \\
20 \% \text {, } 30 \% \text { wt. respect to pyrrole mass }), 30 \text { min adsorption. } \\
\text { Pyrrole oxidation: } 0.05 \mathrm{M} \mathrm{FeCl}_{3}, 150 \mathrm{~min}\end{array}$ & - & $\begin{array}{l}\text { Electrical } \\
\text { conductivity }\end{array}$ & {$[41]$} \\
\hline $\begin{array}{l}\text { G/PP fibers } \\
\text { G/PLA fibers }\end{array}$ & $\begin{array}{l}\text { Sheet resistance: } 1 \mathrm{k} \Omega / \mathrm{square}(\mathrm{G} / \mathrm{PP}) \\
\text { Optical transparency: } 89 \%(\mathrm{G} / \mathrm{PP}), 92 \%(\mathrm{PP})\end{array}$ & $\begin{array}{l}\text { G coating: Monolayer G grown by CVD and transferred to } \\
\text { the fibers by wet methods }\end{array}$ & - & $\begin{array}{l}\text { Electrical } \\
\text { conductivity }\end{array}$ & {$[42]$} \\
\hline RGO/PES fabrics & $\begin{array}{l}\text { Resistance: } 26 \mathrm{k} \Omega \cdot \mathrm{cm}^{2} \text { (1 RGO coating), } 700 \Omega \cdot \mathrm{cm}^{2} \text { (2 RGO coatings), } \\
23.15 \Omega \cdot \mathrm{cm}^{2} \text { (3 RGO coatings), }>10^{11} \Omega \cdot \mathrm{cm}^{2} \text { (PES) }\end{array}$ & $\begin{array}{l}\text { GO coating: Dip coating }\left(3 \mathrm{~g} \cdot \mathrm{L}^{-1} \mathrm{GO}, 30 \mathrm{~min}\right) \text {. } \\
\text { (Multiple coatings, } 1 \text { to } 4 \text { ) }\end{array}$ & $\begin{array}{l}0.5 \% \mathrm{wt} \mathrm{Na}_{2} \mathrm{~S}_{2} \mathrm{O}_{4} \text {, } \\
90{ }^{\circ} \mathrm{C}, 30 \mathrm{~min}\end{array}$ & $\begin{array}{l}\text { Electrical } \\
\text { conductivity, } \\
\text { antistatic material }\end{array}$ & [43] \\
\hline RGO/PES fabrics & $\begin{array}{l}\text { Impedance modulus: } 10^{5} \Omega \text { (1 RGO coating), } 19450 \Omega(2 \mathrm{RGO} \\
\text { coatings), } 2157 \Omega \text { (3 RGO coatings), } 667 \Omega \text { (4 RGO coatings), }>10^{10} \Omega \\
\text { (PES) }\end{array}$ & $\begin{array}{l}\text { GO coating: Dip coating }\left(3 \mathrm{~g} \cdot \mathrm{L}^{-1} \mathrm{GO}, 30 \mathrm{~min}\right) \text {. } \\
\text { (Multiple coatings, } 1 \text { to } 4 \text { ) }\end{array}$ & $\begin{array}{l}0.5 \% \text { wt. } \\
\mathrm{Na}_{2} \mathrm{~S}_{2} \mathrm{O}_{4}, 90{ }^{\circ} \mathrm{C}, \\
30 \mathrm{~min}\end{array}$ & $\begin{array}{l}\text { Electrical } \\
\text { conductivity, } \\
\text { antistatic material }\end{array}$ & {$[44]$} \\
\hline $\begin{array}{l}\text { RGO- } \\
\text { BSA/plasma } \\
\text { treated PES } \\
\text { fabrics }\end{array}$ & $\begin{array}{l}\text { Impedance modulus: } 73 \Omega \text { (RGO-BSA/PES plasma treated), } 4.6 \cdot 10^{5} \Omega \\
\text { (RGO/PES-plasma + chemical reduction) } 2.1 \cdot 10^{7} \Omega \text { (RGO/PES), }>10^{11} \Omega \\
\text { (RGO/PES-plasma) }>10^{11} \Omega \text { (PES) }\end{array}$ & $\begin{array}{l}\text { BSA coating: Dip coating ( } 0.5 \% \text { wt BSA, } \mathrm{pH} 7,15 \mathrm{~min} \text { ). } \\
\text { Washing to remove BSA excess } \\
\left.\text { GO coating: Dip coating ( } 3 \mathrm{~g} \cdot \mathrm{L}^{-1} \mathrm{GO}, 30 \mathrm{~min}\right) \text {. } \\
\text { (Multiple coatings, } 1 \text { to } 10)\end{array}$ & $\begin{array}{l}50 \mathrm{mM} \mathrm{Na}_{2} \mathrm{~S}_{2} \mathrm{O}_{4} \\
90^{\circ} \mathrm{C}, 30 \mathrm{~min}\end{array}$ & $\begin{array}{l}\text { Electrical } \\
\text { conductivity, } \\
\text { antistatic material }\end{array}$ & {$[45]$} \\
\hline $\begin{array}{l}\text { RGO/(PES, nylon, } \\
\text { cotton, Kevlar } \\
\text { mats; wool and } \\
\text { glass fibers) }\end{array}$ & $\begin{array}{l}\text { Electrical conductivity: } 13 \mathrm{~S} \cdot \mathrm{cm}^{-1} \text { (RGO/Kevlar), } 4.5 \mathrm{~S} \cdot \mathrm{cm}^{-1} \\
(\mathrm{RGO} / \mathrm{nylon}), 0.6 \mathrm{~S} \cdot \mathrm{cm}^{-1}\left(\mathrm{RGO} / \mathrm{glass}^{-}\right), 0.1 \mathrm{~S} \cdot \mathrm{cm}^{-1}(\mathrm{RGO} / \mathrm{PES}), 40 \\
\mathrm{mS} \cdot \mathrm{cm}^{-1} \text { (RGO/cotton), } 10 \mathrm{mS} \cdot \mathrm{cm}^{-1} \text { (RGO/wool) }\end{array}$ & GO coating: Dip coating $\left(0.37 \mathrm{~g} \cdot \mathrm{L}^{-1} \mathrm{GO}, 80^{\circ} \mathrm{C}\right)$ & $\begin{array}{l}\text { HI or hydrazine } \\
\text { solution, } 30 \text { min }\end{array}$ & $\begin{array}{l}\text { Electrical } \\
\text { conductivity }\end{array}$ & {$[46]$} \\
\hline $\begin{array}{l}\text { FLG- } \\
\text { graphite/PET } \\
\text { fabric }\end{array}$ & $\begin{array}{l}\text { Sheet resistance: } 77.9 \mathrm{M} \Omega / \text { square ( } 2.5 \% \text { wt. FLG), } 3.6 \mathrm{k} \Omega / \text { square (7.4 } \\
\% \text { wt. FLG), } 2.5 \mathrm{k} \Omega / \text { square (10.7 \% wt. FLG) }\end{array}$ & $\begin{array}{l}\text { FLG coating: Dip coating (graphite + heptane + water, } \\
\text { sonication, } 1 \text { h) (Kinetic trapping method) }\end{array}$ & - & $\begin{array}{l}\text { Electrical } \\
\text { conductivity }\end{array}$ & [47] \\
\hline
\end{tabular}




\begin{tabular}{|c|c|c|c|c|c|}
\hline RGO/cotton fabric & $\begin{array}{l}\text { Resistance: } 4.1 \cdot 10^{15} \Omega \text { (cotton), } 8.45 \cdot 10^{10} \Omega \text { (cotton/GO), } 2.01 \cdot 10^{7} \\
\text { (cotton/RGO) }\end{array}$ & $\begin{array}{l}\text { GO coating: Dip coating }\left(4 \mathrm{~g} \cdot \mathrm{L}^{-1} \mathrm{GO} \text {, ultrasonication, } 30\right. \\
\text { min) }\end{array}$ & $\begin{array}{l}27 \% \text { wt. } \\
\text { hydrazine } \\
\text { solution, } 100^{\circ} \mathrm{C} \text {, } \\
24 \text { h, reflux } \\
\end{array}$ & $\begin{array}{l}\text { Electrical } \\
\text { conductivity }\end{array}$ & {$[48]$} \\
\hline $\begin{array}{l}\text { RGO-BSA/PES } \\
\text { fibers } \\
\text { RGO-BSA/cotton } \\
\text { fibers } \\
\end{array}$ & Conductivity: $10^{-1} \mathrm{~S} \cdot \mathrm{m}^{-1}$ & $\begin{array}{l}\text { BSA coating: Dip coating } \\
\text { GO coating: Dip coating }\end{array}$ & $\begin{array}{l}\text { HI solution }(2 \mathrm{~mL} \\
\mathrm{HI}+5 \mathrm{~mL} \text { acetic } \\
\text { acid), } 40^{\circ} \mathrm{C}, 1-20 \\
\text { min }\end{array}$ & $\begin{array}{l}\text { Electrical } \\
\text { conductivity }\end{array}$ & {$[49]$} \\
\hline $\begin{array}{l}\text { RGO-PU/PET } \\
\text { fabric (nonwoven) }\end{array}$ & $\begin{array}{l}\text { Surface conductivity: } 2.0 \cdot 10^{-5} \mathrm{~S} / \text { square (RGO-PU/PET fabric, } 0.08 \% \\
\text { wt. RGO in solution), } 2.2 \cdot 10^{-14} \mathrm{~S} / \text { square (PET fabrics) }\end{array}$ & $\begin{array}{l}\text { PU coating: Dip coating ( } 0.1 \% \text { wt. PU in DMF, } 60 \text { s) } \\
\text { RGO coating: Dip coating }(0.001-15 \% \text { wt. RGO, } 10 \text { min, } \\
0^{\circ} \mathrm{C} \text {, ultrasonication) }\end{array}$ & $\begin{array}{l}1 \mathrm{~mL} / \mathrm{L} \text { hydrazine } \\
\text { hydrate }\end{array}$ & $\begin{array}{l}\text { Electrical } \\
\text { conductivity, heat } \\
\text { generation }\end{array}$ & {$[50]$} \\
\hline $\begin{array}{l}\text { Thiofenol/AgNPs- } \\
\text { RGO/PU } \\
\text { (electrospun PU } \\
\text { fiber mats) }\end{array}$ & $\begin{array}{l}\text { Surface resistivity: } 3.5 \cdot 10^{2} \Omega / \text { square (RGO/PU), } 10 \Omega / \text { square } \\
\text { (Thiofenol/AgNPs-RGO/PU) }\end{array}$ & $\begin{array}{l}\text { GO coating: Dip coating }\left(500 \mathrm{mg} \cdot \mathrm{L}^{-1} \mathrm{GO}, 2 \mathrm{~h}\right) \\
\text { AgNPs coating: Dip coating }(0.5-3 \% \text { wt. AgNPs, } 30 \mathrm{~min}) \\
\text { (diameter AgNPs } \sim 20 \mathrm{~nm} \text { ) }\end{array}$ & $\mathrm{HI}, 100^{\circ} \mathrm{C}, 10 \mathrm{~s}$ & $\begin{array}{l}\text { Electrical } \\
\text { conductivity, } \\
\text { thermal stability }\end{array}$ & {$[51]$} \\
\hline $\begin{array}{l}\text { G-resin/cotton } \\
\text { fabrics } \\
\text { MWCNTs- } \\
\text { resin/cotton } \\
\text { fabrics } \\
\text { BN-resin/cotton } \\
\text { fabrics }\end{array}$ & $\begin{array}{l}\text { Thermal conductivity: } 0.047 \mathrm{~W} / \mathrm{mK} \text { (cotton), } 0.078 \mathrm{~W} / \mathrm{mK}(11.1 \% \mathrm{G}) \text {, } \\
0.10 \mathrm{~W} / \mathrm{mK}(20.0 \% \mathrm{G}), 0.14 . \mathrm{W} / \mathrm{mK}(33.3 \% \mathrm{G}), 0.29 \mathrm{~W} / \mathrm{mK}(50.0 \% \mathrm{G})\end{array}$ & $\begin{array}{l}\text { GO coating: Dip coating ( } 0.5,1,2,4 \% \mathrm{G} \text { in } 4 \% \text { wt. } \\
\text { Hercosett XC resin and } 1.2 \% \text { wt. } 3 \text {-(N, N- } \\
\text { dimethylmyristylammonio)-propanesulfonate) (11.1, 20.0, } \\
33.3,50 \% \text { final content of G filler in the coatings, } \\
\text { respectively) } \\
\text { Drying and curing: } 120^{\circ} \mathrm{C}, 10 \text { min }\end{array}$ & - & $\begin{array}{l}\text { Thermal } \\
\text { conductivity }\end{array}$ & {$[52]$} \\
\hline $\begin{array}{l}\text { Intumescent flame } \\
\text { retardant- } \\
\text { polyacrylamide } \\
\text { GO/cotton fabrics }\end{array}$ & $\begin{array}{l}\text { Temperature of decomposition: } 324^{\circ} \mathrm{C} \text { (cotton), } 351^{\circ} \mathrm{C} \text { (intumescent } \\
\text { flame-retardant polyacrylamide-GO/cotton, } 20 \text { coatings) } \\
\text { Time to ingnition: } 41 \mathrm{~s} \text { (cotton), } 64 \mathrm{~s} \text { ((intumescent flame-retardant } \\
\text { polyacrylamide-GO/cotton, } 20 \text { coatings) } \\
\text { Peak heat release rate: } 77 \mathrm{~kW} / \mathrm{m}^{2} \text { (cotton), } 153 \mathrm{~kW} / \mathrm{m}^{2} \text { (intumescent } \\
\text { flame-retardant polyacrylamide-GO/cotton, } 20 \text { coatings) }\end{array}$ & $\begin{array}{l}\text { Polyacrylamide coating: Dip coating }(0.1 \mathrm{~g} \cdot \mathrm{L}-1 \\
\text { intumescent flame retardant-polyacrylamide, } 10 \mathrm{~s}) \\
\text { GO coating: Dip coating }\left(0.02 \mathrm{~g} \cdot \mathrm{L}^{-1} \mathrm{GO}, 30 \mathrm{~s}\right) \\
\text { (Multiple coatings) }\end{array}$ & & Flame retardant & [53] \\
\hline $\begin{array}{l}\mathrm{TiO}_{2} \text {-PVP- } \\
\mathrm{GO} / \text { cotton fabric }\end{array}$ & $\begin{array}{l}\text { Photocatalytic activity (degradation } \mathbf{M B} \mathbf{1 0} \mathbf{~ m} \cdot \mathbf{L}^{-1} \text {, } \mathbf{U V} \text { irradiation): } \\
87.14 \% \\
\text { Antibacterial activity: } 99 \% \text { (E. coli and S. aureus) } \\
\text { Antifungal activity: } 99 \% \text { (C. albicans) }\end{array}$ & $\begin{array}{l}\text { GO coating: Dip coating }\left(0.42 \% \text { wt. GO, } 45 \mathrm{~min}, 70^{\circ} \mathrm{C}\right) \\
\text { PVP coating: Dip coating }\left(2 \mathrm{~g} \cdot \mathrm{L}^{-1} \mathrm{PVP}, 10 \mathrm{~min}\right) \\
\text { TiO }_{2} \text { coating: Dip coating }\left(1.53 \mathrm{~mL} \mathrm{TiCl} 3,100 \mathrm{~mL} \mathrm{H} \mathrm{H}_{2} \mathrm{O}, 95\right. \\
\left.{ }^{\circ} \mathrm{C}, 60 \text { min }\right) \\
\text { Curing: } 130^{\circ} \mathrm{C}, 3 \mathrm{~min}\end{array}$ & $\begin{array}{l}1.53 \mathrm{~mL} \mathrm{TiCl}_{3} \\
/ 100 \mathrm{~mL} \mathrm{H}_{2} \mathrm{O}\end{array}$ & $\begin{array}{l}\text { Photocatalytic } \\
\text { activity, } \\
\text { antibacterial, } \\
\text { antifungal }\end{array}$ & {$[54]$} \\
\hline GO/cotton fabrics & $\begin{array}{l}\text { Photocatalytic activity: Measured in } 1.5 \mathrm{mg} \cdot \mathrm{L}^{-1} \text { resazurin dye under UV } \\
\text { light irradiation. } \\
\text { Antibacterial activity: } 46 \%, 62 \%, 74 \% \text { (gram-negative bacteria for } 6 \\
\text { h, } 12 \mathrm{~h} \text { and } 24 \mathrm{~h} \text {, respectively). } 68 \%, 86 \%, 100 \% \text { (gram-positive } \\
\text { bacteria for } 6 \mathrm{~h}, 12 \mathrm{~h} \text { and } 24 \mathrm{~h} \text {, respectively) }\end{array}$ & $\begin{array}{l}\text { GO coating: Dip coating ( } 0.25 \mathrm{~g} \text { in water, stirring } 300 \mathrm{rpm}, \\
24 \text { h) }\end{array}$ & - & $\begin{array}{l}\text { Antibacterial, } \\
\text { photocatalyic fabrics }\end{array}$ & {$[55]$} \\
\hline $\begin{array}{l}\mathrm{TiO}_{2} \text {-PVP- } \\
\mathrm{GO} / \text { cotton fabric }\end{array}$ & 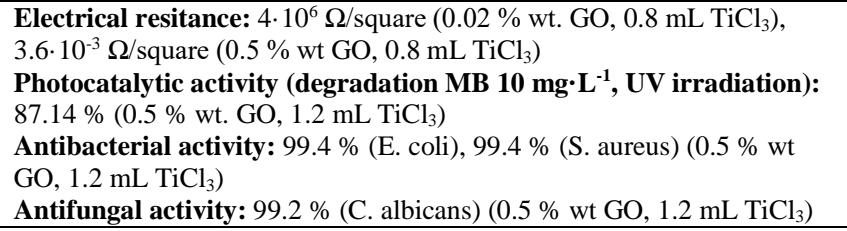 & $\begin{array}{l}\text { GO coating: Dip coating }\left(0.5 \% \text { wt. GO, } 45 \mathrm{~min}, 70^{\circ} \mathrm{C}\right) \\
\text { PVP coating: Dip coating }\left(2 \mathrm{~g} \cdot \mathrm{L}^{-1} \mathrm{PVP}, 10 \mathrm{~min}\right) \\
\text { TiO }_{2} \text { coating: Dip coating }\left(0.8 / 1.2 \mathrm{~mL} \mathrm{TiCl}{ }_{3} \text { in } 100 \mathrm{~mL}\right. \\
\left.\mathrm{H}_{2} \mathrm{O}, 95^{\circ} \mathrm{C}, 60 \mathrm{~min}\right) \\
\text { Curing: } 130^{\circ} \mathrm{C}, 3 \mathrm{~min}\end{array}$ & $\begin{array}{l}0.8 \mathrm{~mL} / 1.2 \mathrm{~mL} \\
\mathrm{TiCl}_{3}\left(15 \% \mathrm{TiCl}_{3}\right. \\
\text { in } 10 \% \mathrm{HCl})\end{array}$ & $\begin{array}{l}\text { Electrical } \\
\text { conductivity, } \\
\text { photocatalytic } \\
\text { activity, } \\
\text { antibacterial, } \\
\text { antifungal }\end{array}$ & {$[56]$} \\
\hline
\end{tabular}




\begin{tabular}{|c|c|c|c|c|c|}
\hline $\begin{array}{l}\mathrm{TiO}_{2} \text {-RGO- } \\
\text { BSA/plasma } \\
\text { treated PES } \\
\text { fabrics }\end{array}$ & $\begin{array}{l}\text { Impedance modulus: } 2102 \Omega(1 \text { RGO-BSA/PES plasma treated), } 112 \Omega \\
\text { (4 RGO-BSA/PES-plasma treated), >10 } 11 \Omega \text { (PES) } \\
\text { Charge transfer resistance: } 727.3 \Omega(1 \mathrm{RGO}-\mathrm{BSA} / \mathrm{PES} \text { plasma treated), } \\
197.3 \Omega \text { (4RGO-BSA/PES-plasma treated) } \\
\text { Photocatalytic activity (degradation Rhodamine B } \mathbf{1 0} \mathbf{~ m g} \cdot \mathbf{L}^{-\mathbf{1}} \text {, UV } \\
\text { irradiation): } 70.4 \% \text { (1 RGO coating), } 77.9 \% \text { (4 RGO coatings) }\end{array}$ & 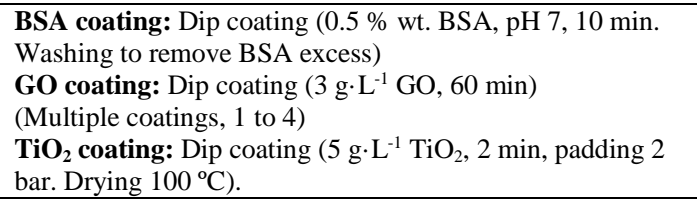 & $\begin{array}{l}50 \mathrm{mM} \mathrm{Na}_{2} \mathrm{~S}_{2} \mathrm{O}_{4}, \\
90^{\circ} \mathrm{C}, 30 \mathrm{~min}\end{array}$ & $\begin{array}{l}\text { Electrical } \\
\text { conductivity, } \\
\text { photocatalytic } \\
\text { activity }\end{array}$ & [57] \\
\hline $\begin{array}{l}\text { RGO-BSA/cotton } \\
\text { fabric }\end{array}$ & $\begin{array}{l}\text { Surface resistance: } 40 \Omega / \text { square (RGO-BSA/cotton), } 510 \Omega / \text { square } \\
\text { (RGO/cotton) } \\
\text { Photocatalytic activity (degradation } \mathbf{1 0 ~} \mathbf{~ m g} \cdot \mathbf{L}^{-1} \mathbf{~ M B}, \mathbf{1 0 0} \text { min } \\
\text { irradiation): } 27 \% \text { (RGO/cotton), } 45 \% \text { (RGO-BSA/cotton) }\end{array}$ & $\begin{array}{l}\text { BSA coating: Dip coating }\left(0.15 \mathrm{~g} \cdot \mathrm{L}^{-1} \mathrm{BSA}, 5 \mathrm{~min}\right), 30 \mathrm{~min} \\
\text { drying } 60^{\circ} \mathrm{C}, 3 \text { washings. } \\
\text { GO coating: Dip coating }\left(0.1 \% \mathrm{wt} \text {. GO, } 30 \mathrm{~min}, 80^{\circ} \mathrm{C} \text { ) }\right. \\
\text { (Multiple coatings, } 1 \text { to } 10 \text { ) }\end{array}$ & $\begin{array}{l}40 \mathrm{mM} \text { hydrazine, } \\
100^{\circ} \mathrm{C}, 30 \mathrm{~min}\end{array}$ & $\begin{array}{l}\text { Electrical } \\
\text { conductivity, } \\
\text { photocatalytic } \\
\text { activity }\end{array}$ & [58] \\
\hline RGO/nylon fabric & Electrical conductivity: $4.5 \mathrm{~S} \cdot \mathrm{cm}^{-1}$ (RGO/nylon) $6 \cdot 10^{-12} \mathrm{~S} \cdot \mathrm{cm}^{-1}$ (nylon) & GO coating: Dip coating $\left(0.37 \mathrm{~g} \cdot \mathrm{L}^{-1}\right)$. & $\begin{array}{l}\text { HI solution, } \\
\text { hydrazine solution }\end{array}$ & $\begin{array}{l}\text { Electrical } \\
\text { conductivity, } \\
\text { electrocardiogram } \\
\text { monitoring }\end{array}$ & [59] \\
\hline GNR/cotton fabric & Resistance: $80 \Omega$ & $\begin{array}{l}\text { GNR coating: Dip coating }\left(0.25 \mathrm{~g} \cdot \mathrm{L}^{-1} \mathrm{GNR}+2.5 \mathrm{~g} \cdot \mathrm{L}^{-1}\right. \\
\text { SDS) }\end{array}$ & - & $\begin{array}{l}\text { Electrical } \\
\text { conductivity, strain } \\
\text { sensor }\end{array}$ & [60] \\
\hline $\begin{array}{l}\text { RGO/silk fibers } \\
\text { (capacitor) } \\
\text { PtNPs-RGO/silk } \\
\text { fibers }\left(\mathrm{H}_{2} \mathrm{O}_{2}\right. \\
\text { sensor) } \\
\text { Enzyme-PtNPs- } \\
\text { RGO/silk fiber } \\
\text { mat (glucose } \\
\text { sensor) }\end{array}$ & $\begin{array}{l}\text { Conductivity: } 57.9 \mathrm{~S} \cdot \mathrm{m}^{-1}(\mathrm{RGO} / \mathrm{silk}) \\
\text { Sheet resistivity: } 90 \Omega / \mathrm{square}(\mathrm{RGO} / \mathrm{silk}) \\
\text { Capacitance: } 17.75 \mathrm{mF} \cdot \mathrm{cm}^{-2}(\mathrm{RGO} / \mathrm{silk}) \\
\mathbf{H}_{2} \mathbf{O}_{2} \text { sensor: } 0-2.5 \mathrm{mM} \text { (linear range), } 0.2 \mu \mathrm{M} \text { (detection limit), } 0.56 \\
\mathrm{~mA} \cdot \mathrm{mM}^{-1} \cdot \mathrm{cm}^{-2} \text { (sensitivity) } \\
\text { Glucose sensor: } 10 \mu \mathrm{M}-10 \mathrm{mM} \text { (linear range), } 1 \mu \mathrm{M} \text { (detection limit), } \\
150.8 \mu \mathrm{A} \cdot \mathrm{mM}^{-1} \cdot \mathrm{cm}^{-2} \text { (sensitivity) }\end{array}$ & $\begin{array}{l}\text { GO coating: Dip coating ( } 50 \mathrm{mg} \text { silk fibers, } 10 \mathrm{mg} \mathrm{GO} \text {, } \\
\text { ultrasonication } 15 \text { min, filtering) } \\
\text { PtNPs synthesis: Electrochemical synthesis }(\mathrm{CV}, 0 \rightarrow-0.6 \\
\left.\mathrm{V}, 50 \mathrm{mV} \cdot \mathrm{s}^{-1}, 10 \mathrm{mM} \mathrm{H}_{2} \mathrm{PtCl}_{6}+0.1 \mathrm{M} \mathrm{HCl} \mathrm{solution}\right) \\
\text { Glucose oxidase fixation: Dip coating }\left(10 \mathrm{~g} \cdot \mathrm{L}^{-1} \text { glucose }\right. \\
\text { oxidase }+30 \mathrm{~g} \cdot \mathrm{L}^{-1} \mathrm{BSA}+0.01 \mathrm{M} \mathrm{PBS}(\mathrm{pH} 7.4) \text {. Exposure } \\
\text { to glutaraldehyde }\left(50 \mu \mathrm{L}, 25 \%, 35^{\circ} \mathrm{C}, 3 \mathrm{~h}\right) \text { for cross-linking } \\
\text { glucose oxidase to } \mathrm{BSA}\end{array}$ & $\begin{array}{l}10 \mathrm{~g} \cdot \mathrm{L}^{-1} \text { ascorbic } \\
\text { acid, } 100^{\circ} \mathrm{C}, 2 \mathrm{~h}\end{array}$ & $\begin{array}{l}\text { Sensor }\left(\mathrm{H}_{2} \mathrm{O}_{2}\right. \\
\text { glucose) } \\
\text { Capacitor }\end{array}$ & [61] \\
\hline $\begin{array}{l}\text { RGO-BSA/cotton } \\
\text { yarns } \\
\text { RGO-BSA/PES } \\
\text { yarns }\end{array}$ & $\begin{array}{l}\text { Current sensitivity to } 0.25 \text { ppm NO} \mathbf{N O}_{2}:-7 \text { \% (RGO/cotton), }-6 \% \\
\text { (RGO/PES) } \\
\text { Current sensitivity to } 1.25 \text { ppm NO}_{2}:-12 \% \text { (RGO/cotton), }-12 \% \\
\text { (RGO/PES) }\end{array}$ & $\begin{array}{l}\text { BSA coating: Dip coating ( } 0.5 \% \text { wt. BSA, } 30 \text { min. Drying } \\
1 \text { h. Washing) } \\
\text { GO coating: Dip coating }\left(2 \mathrm{~g} \cdot \mathrm{L}^{-1} \mathrm{GO}\right)\end{array}$ & $\begin{array}{l}\mathrm{HI}(2 \mathrm{~mL} \mathrm{HI}+5 \\
\mathrm{mL} \text { acetic acid }) 40 \\
{ }^{\circ} \mathrm{C}, 10 \mathrm{~min}\end{array}$ & $\mathrm{NO}_{2}$ gas sensor & [62] \\
\hline $\begin{array}{l}\text { G } \\
\text { pellets/MWCNTs- } \\
\text { cotton fabric }\end{array}$ & $\begin{array}{l}\text { Surface electrical resistivity: } 4.7 \mathrm{k} \Omega(3 \% \text { wt. G), } 9.1 \mathrm{k} \Omega(1 \% \text { wt. G), } \\
12.8 \mathrm{k} \Omega(0.5 \% \text { wt. G), } 13 \mathrm{k} \Omega(0 \% \text { wt. G) } \\
\text { Relative change in resistance: } 50 \% \text { (methanol exposure) } 15 \% \text { (acetone } \\
\text { exposure) }\end{array}$ & $\begin{array}{l}\text { GO coating: Screen printing (G pellets } 0.5,1,3 \% \text { wt. + } \\
\text { MWCNTs } 3 \% \text { wt + aliphatic urethane acrylate + Esacure } \\
\text { DP250 photoinitiator. Mechanical stirring } 30 \text { min. } \\
\text { Application of the paste to the fabric. Curing } 30 \text { min with IR } \\
\text { light) }\end{array}$ & - & $\begin{array}{l}\text { Vapor sensor } \\
\text { (acetone and } \\
\text { methanol) }\end{array}$ & [63] \\
\hline $\begin{array}{l}\text { ERGO/carbon } \\
\text { cloth }\end{array}$ & $\begin{array}{l}\text { Charge transfer resistance: } 2.5 \Omega \text { (carbon cloth), } 0.6 \Omega \text { (ERGO/carbon } \\
\text { cloth) } \\
\text { Plateau discharge rates: } 15.8 \mu \mathrm{A} \cdot \mathrm{cm}^{-2} \text { (carbon cloth), } 24.5 \mu \mathrm{A} \cdot \mathrm{cm}^{-2} \\
\text { (ERGO/carbon cloth) } \\
\text { Discharge life: } 230 \mathrm{~h} \text { (carbon cloth), } 330 \mathrm{~h} \text { (ERGO/carbon cloth) } \\
\text { Maximum power density: } 19.5 \mathrm{~mW} \cdot \mathrm{m}^{-2} \text { (carbon cloth), } 52.5 \mathrm{~mW} \cdot \mathrm{m}^{-2} \\
\text { (ERGO/carbon cloth) } \\
\text { Electrical energy converted: } 1.75 \mathrm{~J} \text { (carbon cloth), } 5.34 \mathrm{~J} \\
\text { (ERGO/carbon cloth) }\end{array}$ & $\begin{array}{l}\text { GO coating: Electrophoresis on carbon cloth }\left(0.2 \mathrm{~g} \cdot \mathrm{L}^{-1} \mathrm{GO} \text {, }\right. \\
0.3 \mathrm{~mA} \cdot \mathrm{cm}^{-2}, 30 \text { min. Reduction. } \\
\text { Drying and UV sterilization, } 3 \mathrm{~h}\end{array}$ & $\begin{array}{l}\text { Electrochemical } \\
\text { reduction, }-0.6 \\
\mathrm{~mA} \cdot \mathrm{cm}^{-2}, 90 \mathrm{~s}\end{array}$ & $\begin{array}{l}\text { Anode for microbial } \\
\text { fuel cell }\end{array}$ & [64] \\
\hline
\end{tabular}




\begin{tabular}{|c|c|c|c|c|c|}
\hline RGO/cotton fabric & $\begin{array}{l}\text { Surface resistance: } 114 \Omega / \mathrm{square} \text { ( } 20 \mathrm{GO} \text { coatings), } 55 \Omega / \mathrm{square} \text { (20 GO } \\
\text { coatings after acid treatment) } \\
\text { Charge transfer resistance: } 9.68 \Omega \cdot \mathrm{cm}^{2} \text { (RGO/cotton), } 6.74 \Omega \cdot \mathrm{cm}^{2} \text { (Pt- } \\
\text { coated electrode) } \\
\text { Conversion efficiency } \mathrm{I}_{3}{ }^{-}: 2.52 \% \text { (RGO/cotton), } 7.20 \% \text { (Pt-coated } \\
\text { electrode) } \\
\text { Short circuit current: } 9.08 \mathrm{~mA} \cdot \mathrm{cm}^{-2} \text { (RGO/cotton), } 14.88 \mathrm{~mA} \cdot \mathrm{cm}^{-2} \text { (Pt- } \\
\text { coated electrode) } \\
\text { Open circuit voltage: } 0.64 \mathrm{~V}(\mathrm{RGO} / \mathrm{cotton}), 0.66 \mathrm{~V} \text { (Pt-coated electrode) } \\
\text { Fill factor: } 42.97 \text { (RGO/cotton), } 71.18 \text { (Pt-coated electrode) }\end{array}$ & $\begin{array}{l}\text { GO coating: Dip coating ( } 1 \% \mathrm{wt} \mathrm{GO}, 80^{\circ} \mathrm{C}, 30 \mathrm{~min} \text { ). } \\
\text { (Multiple coatings, } 1 \text { to } 20 \text { ) }\end{array}$ & $\begin{array}{l}0.1 \mathrm{M} \mathrm{HI}, 90^{\circ} \mathrm{C} \text {, } \\
\text { vapor reduction }\end{array}$ & $\begin{array}{l}\text { Cathode in dye } \\
\text { sensitized solar cells }\end{array}$ & [65] \\
\hline $\begin{array}{l}\text { PPy/AQSA- } \\
\text { RGO/PES filter } \\
\text { cloth }\end{array}$ & $\begin{array}{l}\text { Electrical conductivity: } 0.7 \mathrm{k} \Omega \cdot \mathrm{cm}^{-1}(\mathrm{PPy} / \mathrm{RGO}), 2 \mathrm{k} \Omega \cdot \mathrm{cm}^{-1}(\mathrm{PPy}) \\
\text { Degradation rate of MB: } 59.2 \% \text { (PPy), } 64.0 \% \text { (PPy/RGO), } 74.6 \% \\
\left(\mathrm{PPy} / \mathrm{RGO} \text { with } \mathrm{Fe}^{2+} \text { in solution) (Conditions: }-1 \mathrm{~V} \text { (cathode), } 0.2 \mathrm{mM}\right. \\
\mathrm{Fe}^{2+}, 5 \mathrm{mg} \cdot \mathrm{L}^{-1} \mathrm{MB}, 0.05 \mathrm{M} \mathrm{Na}_{2} \mathrm{~S}_{2} \mathrm{O}_{4} \text { supporting electrolyte, after } 120 \mathrm{~min} \\
\text { of reaction). }\end{array}$ & $\begin{array}{l}\text { RGO coating: Dip coating }\left(0.02 \mathrm{~g} \cdot \mathrm{L}^{-1} \mathrm{RGO}, 10 \mathrm{~min}\right) \\
\text { RGO/AQSA coating: Dip coating }\left(0.02 \mathrm{~g} \cdot \mathrm{L}^{-1} \mathrm{RGO}, 0.25\right. \\
\text { mM AQSA, } 10 \mathrm{~min}) \\
\text { Sprying: APS solution }\left(20 \mathrm{mg} \cdot \mathrm{L}^{-1}, 50 \mathrm{~mL}\right) \\
\text { PPy coating: } 0.5 \mathrm{~mL}, 90^{\circ} \mathrm{C}, 15 \mathrm{~min} \text { (vapor phase } \\
\text { polymerization) }\end{array}$ & - & $\begin{array}{l}\text { Electrocatalytic } \\
\text { membrane (acting as } \\
\text { cathode) }\end{array}$ & {$[66]$} \\
\hline $\begin{array}{l}\text { RGO- } \\
\text { CNTs/carbon } \\
\text { cloth-PET }\end{array}$ & $\begin{array}{l}\text { Turn-on field at } 10 \mu \mathrm{\mu A} \cdot \mathrm{cm}^{-2}: 0.26 \mathrm{~V} \cdot \mu \mathrm{m}^{-1}(\mathrm{RGO}-\mathrm{CNTs}), 0.49 \mathrm{~V} \cdot \mu \mathrm{m}^{-1} \\
(\mathrm{CNTs}), 0.43 \mathrm{~V} \cdot \mu \mathrm{m}^{-1}(\mathrm{RGO}) \\
\text { Current density at threshold field }\left(\mathbf{0 . 5 5} \mathbf{V} \cdot \boldsymbol{\mu} \mathrm{m}^{-1}\right): 1 \mathrm{~mA} \cdot \mathrm{cm}^{-2}(\mathrm{RGO}- \\
\text { CNTs), } 60 \mu \mathrm{A} \cdot \mathrm{cm}^{-2}(\mathrm{CNTs}), 250 \mu \mathrm{A} \cdot \mathrm{cm}^{-2}(\mathrm{RGO})\end{array}$ & $\begin{array}{l}\text { RGO/CNTs coating: Electrophoretic deposition }\left(1 \mathrm{~mA} \cdot \mathrm{cm}^{-}\right. \\
\left.{ }^{2}, 10 \mathrm{~min}(\mathrm{CNTs}) ; 2.5 \mathrm{~mA} \cdot \mathrm{cm}^{-2}, 10 \mathrm{~min}(\mathrm{RGO})\right) 1 \mathrm{~g} \cdot \mathrm{L}^{-1} \mathrm{GO}\end{array}$ & $\begin{array}{l}\text { Reduction with } \\
\text { hydrazine hydrate } \\
\text { ( } 35 \% \text { wt), } \\
\text { ammonium } \\
\text { hydroxide ( } 25 \% \\
\text { wt), } 90^{\circ} \mathrm{C}, 1 \mathrm{~h}\end{array}$ & $\begin{array}{l}\text { Field emission } \\
\text { device }\end{array}$ & [67] \\
\hline $\begin{array}{l}\text { RGO/carbon cloth } \\
+ \text { Ar plasma } \\
\text { treatment }\end{array}$ & $\begin{array}{l}\text { Turn-on field at } 10 \mu \mathrm{A} \cdot \mathbf{c m}^{-2}: 0.78 \mathrm{~V} \cdot \mu \mathrm{m}^{-1}(0 \mathrm{~s} \text { plasma }), 0.59 \mathrm{~V} \cdot \mu \mathrm{m}^{-1}(40 \\
\text { s plasma), } 0.41 \mathrm{~V} \cdot \mu \mathrm{m}^{-1}\left(3 \mathrm{~min}^{-1} \text { plasma }\right) \\
\text { Threshold field: } 0.96 \mathrm{~V} \cdot \mu \mathrm{m}^{-1}\left(1 \mathrm{~mA} \cdot \mathrm{cm}^{-2}\right)(40 \mathrm{~s} \text { plasma }), 0.81 \mathrm{~V} \cdot \mu \mathrm{m}^{-1}(1 \\
\left.\mathrm{mA} \cdot \mathrm{cm}^{-2}\right)(3 \text { min plasma). For } 0 \mathrm{~s} \text { plasma treatment, emission dos not } \\
\text { achieve the threshold value. }\end{array}$ & $\begin{array}{l}\text { RGO coating: Electrophoretic deposition }\left(2.4 \mathrm{~mA} \cdot \mathrm{cm}^{-2}, 5\right. \\
\text { s- } 10 \mathrm{~min}) \\
\text { Plasma etching: Ar gas, } 0.2 \mathrm{mbar}, 150 \mathrm{~W}, 50 \mathrm{~s}-5 \mathrm{~min}\end{array}$ & $\begin{array}{l}\text { Hydrazine hydrate } \\
(80 \%)(1: 7 \text { weight } \\
\text { ratio with GO), } 90 \\
{ }^{\circ} \mathrm{C}, 6 \text { hours }\end{array}$ & $\begin{array}{l}\text { Field emission } \\
\text { device }\end{array}$ & [68] \\
\hline $\begin{array}{l}\text { RGO/cotton } \\
\text { fabrics }\end{array}$ & $\begin{array}{l}\text { Sheet resistance: } 560 \Omega / \mathrm{square}^{-1} \\
\text { Specific capacitance: } 40 \mathrm{~F} \cdot \mathrm{g}^{-1}\left(5 \mathrm{mV} \cdot \mathrm{s}^{-1}, 0 \mathrm{~V} \rightarrow 1 \mathrm{~V}\right) \\
\text { Capacitance rentention: } 90 \%\left(1000 \text { cycles at } 0.85 \mathrm{~A} \cdot \mathrm{g}^{-1}\right)\end{array}$ & $\begin{array}{l}\text { GO coating: Dip coating }\left(2 \mathrm{~g} \cdot \mathrm{L}^{-1} \mathrm{GO}, 30 \mathrm{~min}\right) \\
\text { ( } 20 \text { coatings) }\end{array}$ & $\begin{array}{l}0.5 \mathrm{M} \mathrm{NaBH}_{4}, 12 \\
\mathrm{~h}\end{array}$ & Capacitor & [69] \\
\hline $\begin{array}{l}\mathrm{PPy} / \mathrm{GO} / \mathrm{cotton} \\
\text { fabrics }\end{array}$ & $\begin{array}{l}\text { Electrical conductivity: } 0.9 \mathrm{~S} \cdot \mathrm{cm}^{-1} \text { (PPy/cotton), } 1.12 \mathrm{~S} \cdot \mathrm{cm}^{-1} \\
\text { (PPy/GO/cotton) } \\
\text { Capacitance }\left(\mathbf{5 0} \mathbf{~ m V} \cdot \mathrm{s}^{-1}\right): 24.3 \mathrm{~F} \cdot \mathrm{g}^{-1} \text { (PPy/cotton), } 35.7 \mathrm{~F} \cdot \mathrm{g}^{-1} \\
\text { (PPy/GO/Cotton) }\end{array}$ & $\begin{array}{l}\text { GO coating: Dip coating }\left(5 \mathrm{~g} \cdot \mathrm{L}^{-1} \mathrm{GO}, 30 \mathrm{~min}\right) \\
\text { PPy coating: Dip coating ( } 2 \mathrm{mM} \text { pyrrole, } 2 \mathrm{~h} \text { (pyrrole } \\
\text { adsorption), } 0.08 \mathrm{M} \mathrm{FeCl}_{3} \text { addition (oxidation, } 4 \mathrm{~h}, 0-5{ }^{\circ} \mathrm{C} \text {, } \\
\mathrm{N}_{2} \text { gas flow) }\end{array}$ & - & $\begin{array}{l}\text { Capacitor, electrical } \\
\text { conductivity }\end{array}$ & {$[70]$} \\
\hline $\begin{array}{l}\text { PPy/RGO/cotton } \\
\text { fabrics }\end{array}$ & $\begin{array}{l}\text { Electrical conductivity: } 1.2 \mathrm{~S} \cdot \mathrm{cm}^{-1}(\mathrm{PPy} / \mathrm{RGO} / \mathrm{cotton}) \\
\text { Capacitance: } 336 \mathrm{~F} \cdot \mathrm{g}^{-1}(\mathrm{PPy} / \mathrm{RGO} / \mathrm{cotton}), 234 \mathrm{~F} \cdot \mathrm{g}^{-1}(\mathrm{PPy} / \mathrm{Cotton}) \\
\text { Energy density: } 21.1 \mathrm{~W} \cdot \mathrm{h} \cdot \mathrm{kg}^{-1}\left(\mathrm{at} 0.6 \mathrm{~mA} \cdot \mathrm{cm}^{-2}\right) \\
\text { Capacitance rentention: } 64 \%(\mathrm{PPy} / \mathrm{RGO} / \mathrm{cotton}), 35 \%(\mathrm{PPy} / \mathrm{cotton}) \\
\left(500 \text { cycles at } 0.6 \mathrm{~mA} \cdot \mathrm{cm}^{-2}\right)\end{array}$ & $\begin{array}{l}\text { GO coating: Dip coating }\left(2 \mathrm{~g} \cdot \mathrm{L}^{-1} \mathrm{GO}, 30 \mathrm{~min},\right. \\
\text { ultrasonication). Reduction. } \\
\text { PPy coating: Dip coating }(1 \mathrm{M} \text { pyrrole, } 30 \mathrm{~min} \\
\text { (adsorption), } 0.5 \mathrm{M} \mathrm{FeCl}_{3} \text { adding (oxidation, } 2 \mathrm{~h} \text {, ice bath)) }\end{array}$ & $\begin{array}{l}\text { Thermal } \\
\text { reduction, } 250^{\circ} \mathrm{C} \text {, } \\
2 \mathrm{~h}, \mathrm{~N}_{2} \\
\text { atmosphere }\end{array}$ & $\begin{array}{l}\text { Supercapacitor, } \\
\text { electrical } \\
\text { conductivity }\end{array}$ & [71] \\
\hline $\begin{array}{l}\mathrm{MnO}_{2} \text {-GNS/PES } \\
\text { fabrics }\end{array}$ & $\begin{array}{l}\text { Sheet resistance: } 700 \Omega / \text { square }(35 \text { cycles of deposition) } \\
\text { Specific capacitance: } 315 \mathrm{~F} \cdot \mathrm{g}^{-1}\left(2 \mathrm{mV} \cdot \mathrm{s}^{-1}, 0 \mathrm{~V} \rightarrow 0.85 \mathrm{~V}\right) \\
\text { Maximum power density: } 110 \mathrm{~kW} \cdot \mathrm{kg}^{-1} \\
\text { Energy density: } 12.5 \mathrm{~W} \cdot \mathrm{h} \cdot \mathrm{kg}^{-1} \\
\text { Capacitance rentention: } 95 \%\left(5000 \text { cycles at } 2.2 \mathrm{~A} \cdot \mathrm{g}^{-1}\right)\end{array}$ & 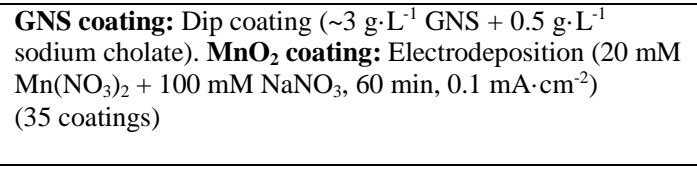 & - & Supercapacitor & {$[72]$} \\
\hline
\end{tabular}




\begin{tabular}{|c|c|c|c|c|c|}
\hline $\begin{array}{l}\text { PEDOT/PSS- } \\
\mathrm{MnO}_{2} \text {-GNS/PES } \\
\text { fabrics } \\
\text { SWCNTs-MnO } \\
\text { GNS/PES fabrics }\end{array}$ & $\begin{array}{l}\text { Sheet resitance: } 700 \Omega / \mathrm{square}^{-1} \\
\text { Specific capacitance: } 380 \mathrm{~F} \cdot \mathrm{g}^{-1}\left(0.1 \mathrm{~mA} \cdot \mathrm{cm}^{-2}\right)\left(\mathrm{PEDOT} / \mathrm{PSS}-\mathrm{MnO}_{2^{-}}\right. \\
\text {GNS/PES fabrics) } \\
\text { Capacitance rentention after: } 93 \%\left(\mathrm{MnO}_{2} \text {-GNS/PES fabrics), } 95 \%\right. \\
\text { (PEDOT/PSS-MnO }{ }_{2} \text {-GNS/PES fabrics), } 96 \% \text { (SWCNTs-MnO } 2^{-} \\
\text {GNS/PES fabrics) }\left(3000 \text { cycles at } 1 \mathrm{~mA} \cdot \mathrm{cm}^{-2}\right)\end{array}$ & 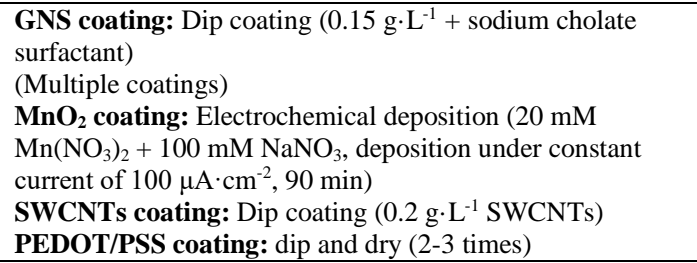 & - & Supercapacitor & [73] \\
\hline $\begin{array}{l}\text { Pani-GO/CNT } \\
\text { fibers } \\
\mathrm{TiO}_{2} \text {-RGO/CNT } \\
\text { fibers }\end{array}$ & 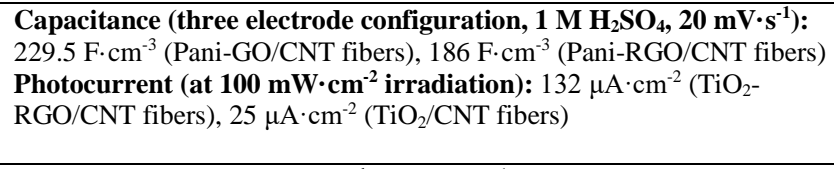 & $\begin{array}{l}\text { GO coating: Dip coating }\left(0.05 \mathrm{~g} \cdot \mathrm{L}^{-1} \mathrm{GO}+1-2 \% \mathrm{DMF}, 2 \mathrm{~h},\right. \\
2 \text { times }) \\
\text { Pani coating: Electrosynthesis }(0.05 \mathrm{M} \text { aniline }+1 \mathrm{M} \\
\left.\mathrm{H}_{2} \mathrm{SO}_{4}, 0.75 \mathrm{~V}, 10 \mathrm{~min}\right) \\
\mathrm{TiO}_{2} \text { coating: Metal-organic } \mathrm{CVD}(10 \mathrm{~min})\end{array}$ & $\begin{array}{l}\text { Hydrazine }\left(95^{\circ} \mathrm{C},\right. \\
1 \text { h, hydrazine:GO } \\
\text { wt. ratio }(7: 10)\end{array}$ & $\begin{array}{l}\text { Capacitor, } \\
\text { photoelectrode }\end{array}$ & [74] \\
\hline $\begin{array}{l}\text { (G- } \\
\left.\mathrm{V}_{2} \mathrm{O}_{5} / \mathrm{MWCNTs}\right)_{1} \\
{ }_{0} / \mathrm{PES} \text { fabrics } \\
\text { coated with } \\
\mathrm{Ni} / \mathrm{Cu} / \mathrm{Ni} / \mathrm{Au}\end{array}$ & $\begin{array}{l}\text { Specific capacitance }\left(1 \mathbf{~ m V} \cdot \mathrm{s}^{-1}\right): 2590 \mathrm{~F} \cdot \mathrm{g}^{-1}\left(\mathrm{G}-\mathrm{V}_{2} \mathrm{O}_{5} / \mathrm{MWCNTs}\right), 1600 \\
\mathrm{~F} \cdot \mathrm{g}^{-1}\left(\mathrm{~V}_{2} \mathrm{O}_{5} / \mathrm{MWCNTs}\right)\left(3 \mathrm{~nm} \mathrm{~V} \mathrm{~V}_{2} \mathrm{O}_{5}\right), 510 \mathrm{~F} \cdot \mathrm{g}^{-1}\left(\mathrm{~V}_{2} \mathrm{O}_{5} / \mathrm{MWCNTs}\right)(20 \mathrm{~nm} \\
\left.\mathrm{V}_{2} \mathrm{O}_{5}\right) \\
\text { Power density: } 800 \mathrm{~W} \cdot \mathrm{kg}^{-1} \\
\text { Energy density: } 96 \mathrm{~W} \cdot \mathrm{h} \cdot \mathrm{kg}^{-1} \\
\text { Capacitance rentention: }>97 \%\left(5000 \mathrm{cycles}, 20 \mathrm{mV} \cdot \mathrm{s}^{-1}\right)\end{array}$ & $\begin{array}{l}\text { G coating: G transfer method } \\
\mathbf{V}_{2} \mathbf{O}_{5} / \mathbf{M W C N T s} \text { coating: spray coating } \\
\text { (Multiple coatings, } 1 \text { to } 10 \text { ) }\end{array}$ & - & Supercapacitor & {$[75]$} \\
\hline $\begin{array}{l}\text { RGO/polyamide } \\
66 \text { nanofibers } \\
\text { (electrospun) }\end{array}$ & $\begin{array}{l}\text { Volume resistance: } 330 \Omega \cdot \mathrm{cm}(\mathrm{d} \mathrm{GO}<200 \mathrm{~nm}), 1.1 \Omega \cdot \mathrm{cm}(\mathrm{d} \mathrm{GO} 200- \\
450 \mathrm{~nm}), 14.3 \Omega \cdot \mathrm{cm}(\mathrm{d} \mathrm{GO}>450 \mathrm{~nm}), 1670 \Omega \cdot \mathrm{cm}(\mathrm{d} \mathrm{GO} 200-450 \mathrm{~nm} \text {, } \\
\text { microfiber fabric, } 1 \text { coating }), 0.5 \Omega \cdot \mathrm{cm}(\mathrm{d} \mathrm{GO} 200-450 \mathrm{~nm} \text {, microfiber } \\
\text { fabric, } 5 \text { coatings) } \\
\text { Specific capacitance: } 280 \mathrm{~F} \cdot \mathrm{g}^{-1}(\mathrm{~d} \mathrm{GO} 200-450 \mathrm{~nm}), 65.4 \mathrm{~F} \cdot \mathrm{g}^{-1}(\mathrm{~d} \mathrm{GO} \\
<200 \mathrm{~nm}), 95.3 \mathrm{~F} \cdot \mathrm{g}^{-1}(\mathrm{~d} \mathrm{GO}>450 \mathrm{~nm}), 130 \mathrm{~F} \cdot \mathrm{g}^{-1}(\mathrm{~d} \mathrm{GO} 200-450 \mathrm{~nm}, \\
\text { micrometer fabric, } 5 \mathrm{GO} \text { coatings }\left(10 \mathrm{mV} \cdot \mathrm{s}^{-1}\right) \\
\text { Specific energy: } 10 \mathrm{~W} \cdot \mathrm{h}^{-1}\left(\mathrm{at} 0.5 \mathrm{~A} \cdot \mathrm{g}^{-1}\right)(\mathrm{d} \mathrm{GO} 200-450 \mathrm{~nm}) \\
\text { Specific power: } 1500 \mathrm{~W} \cdot \mathrm{kg}^{-1}\left(3 \mathrm{~A} \cdot \mathrm{g}^{-1}\right)(\mathrm{d} \mathrm{GO} 200-450 \mathrm{~nm})\end{array}$ & $\begin{array}{l}\text { GO coating: Dip coating }\left(0.5 \mathrm{~g} \cdot \mathrm{L}^{-1} \mathrm{GO} \text { (diameter } \mathrm{GO}<200\right. \\
\mathrm{nm}, 200-450 \mathrm{~nm} \text { or }>450 \mathrm{~nm}) \text {, ultrasonication } 2 \mathrm{~h})\end{array}$ & $\begin{array}{l}\text { Hydrazine vapor, } \\
120^{\circ} \mathrm{C} \text {. Oven } 200 \\
{ }^{\circ} \mathrm{C} \text {, 2h (to remove } \\
\mathrm{C}-\mathrm{N} \text { bonding) }\end{array}$ & Supercapacitor & [76] \\
\hline $\begin{array}{l}\text { RGO/cotton } \\
\text { fabrics }\end{array}$ & $\begin{array}{l}\text { Sheet resistance: } 910 \Omega / \mathrm{square}(\mathrm{RGO} / \mathrm{cotton}), 1.09 \cdot 10^{8} \Omega / \mathrm{square} \\
\text { (GO/cotton) } \\
\text { Capacitance: } 87.53 \mathrm{mF} \cdot \mathrm{cm}^{-2}\left(2 \mathrm{mV} \cdot \mathrm{s}^{-1}\right), 81.4 \mathrm{~F} \cdot \mathrm{g}^{-1}\left(2 \mathrm{mV} \cdot \mathrm{s}^{-1}\right) \\
\text { Capacitance rentention: } 89.82 \% \mathrm{after} 1000 \mathrm{cycles}\left(2 \mathrm{mV} \cdot \mathrm{s}^{-1}\right), 90.5 \% \\
\text { after } 100 \text { bending cycles }\left(2 \mathrm{mV} \cdot \mathrm{s}^{-1}\right) \\
\text { Volumetric capacitance: } 5.53 \mathrm{~F} \cdot \mathrm{cm}^{-3}\left(62.5 \mathrm{~mA} \cdot \mathrm{cm}^{-3}\right) \\
\text { Energy density: } 767.36 \mu \mathrm{W} \cdot \mathrm{h} \cdot \mathrm{cm}^{-2}\left(31.26 \mathrm{~mW} \cdot \mathrm{cm}^{-3}\right)\end{array}$ & $\begin{array}{l}\text { GO coating: Dip coating }\left(4 \mathrm{~g} \cdot \mathrm{L}^{-1} \mathrm{GO}\right) \\
\text { (5 coatings) }\end{array}$ & $\begin{array}{l}\text { Thermal reduction } \\
\text { and carbonization } \\
\text { of cotton fabrics, } \\
300^{\circ} \mathrm{C}, 2 \mathrm{~h}, \mathrm{Ar} \\
\text { atmosphere }\end{array}$ & Supercapacitor & {$[77]$} \\
\hline $\begin{array}{l}\text { RGO/cotton } \\
\text { fabrics }\end{array}$ & $\begin{array}{l}\text { Electrical resistance: } 225 \Omega \cdot \mathrm{cm}^{-1} \\
\text { Mass loading: } 1.08 \mathrm{mg} \cdot \mathrm{cm}^{-2} \\
\text { Specific capacitance: } 326.8 \mathrm{~F} \cdot \mathrm{g}^{-1}\left(10 \mathrm{mV} \cdot \mathrm{s}^{-1}\right) \\
\text { Power density: } 1.5 \mathrm{~kW} \cdot \mathrm{kg}^{-1}\left(3 \mathrm{~A} \cdot \mathrm{g}^{-1}\right) \\
\text { Energy density: } 7.13 \mathrm{~W} \cdot \mathrm{h} \cdot \mathrm{kg}^{-1}\left(3 \mathrm{~A} \cdot \mathrm{g}^{-1}\right) \\
\text { Capacitance rentention: } 93.8 \%(\mathrm{atter} 1500 \text { cycles }) \\
\end{array}$ & $\begin{array}{l}\text { GO coating: brush coating }\left(2 \mathrm{~g} \cdot \mathrm{L}^{-1} \mathrm{GO}\right) \\
\text { (50 coatings) }\end{array}$ & $\begin{array}{l}\text { Thermal reduction } \\
\text { and carbonization } \\
\text { of cotton fabrics, } \\
300^{\circ} \mathrm{C}, 2 \mathrm{~h}, \mathrm{Ar} \\
\text { atmosphere }\end{array}$ & Supercapacitor & [78] \\
\hline $\begin{array}{l}\text { RGO/carbon } \\
\text { fabrics }\end{array}$ & $\begin{array}{l}\text { Mass loading: } 0.6-0.8 \mathrm{mg} \cdot \mathrm{cm}^{-2} \\
\text { Specific capacitance: } 414 \mathrm{~F} \cdot \mathrm{g}^{-1}\left(5 \mathrm{mV} \cdot \mathrm{s}^{-1}\right) \\
\text { Device capacitance: } 70.4 \mathrm{~F} \cdot \mathrm{g}^{-1}\left(5 \mathrm{mV} \cdot \mathrm{s}^{-1}\right) \\
\text { Energy density: } 5.8 \mathrm{~W} \cdot \mathrm{h} \cdot \mathrm{kg}^{-1}\left(27.7 \mathrm{~kW} \cdot \mathrm{kg}^{-1}\right)\end{array}$ & $\begin{array}{l}\text { GO coating: Dip coating } \\
\text { (5 coatings) }\end{array}$ & $\begin{array}{l}\text { Thermal } \\
\text { reduction, } 160^{\circ} \mathrm{C} \text {, } \\
2 \mathrm{~h}, \mathrm{Ar} \\
\text { atmosphere }\end{array}$ & Supercapacitor & [79] \\
\hline
\end{tabular}




\begin{tabular}{|c|c|c|c|c|c|}
\hline & Capacitance rentention: $93 \%$ (after 1000 cycles) & & & & \\
\hline $\begin{array}{l}\text { RGO/nylon lycra } \\
\text { fabrics } \\
\text { PPy-RGO/nylon } \\
\text { lycra fabrics }\end{array}$ & $\begin{array}{l}\text { Surface resistivity: } 240 \Omega / \mathrm{square}^{(25 \mathrm{cycles})} \\
\text { RGO loading ( } 25 \mathrm{cycles}): 2.3 \mathrm{mg} \cdot \mathrm{cm}^{-2} \\
\text { Capacitance: } 12.3 \mathrm{~F} \cdot \mathrm{g}^{-1}(\mathrm{RGO}), 15.5 \mathrm{~F} \cdot \mathrm{g}^{-1}(\mathrm{RGO}, 50 \% \mathrm{strain}), 114 \mathrm{~F} \cdot \mathrm{g}^{-1} \\
\left(\text { PPy-RGO), } 125 \mathrm{~F} \cdot \mathrm{g}^{-1}(\mathrm{PPy}-\mathrm{RGO}, 50 \% \mathrm{strain})\left(5 \mathrm{mV} \cdot \mathrm{s}^{-1}\right)\right. \\
\text { PPy loading: } 2.8 \mathrm{mg} \cdot \mathrm{cm}^{-2} \\
\text { Capacitance rentention: } 76 \%(\mathrm{RGO}), 89 \%(\mathrm{RGO}, 50 \% \mathrm{strain}), 74 \% \\
\text { (PPy/RGO), } 79 \%(\mathrm{PPy} / \mathrm{RGO}, 50 \% \mathrm{strain})\left(\text { after } 2000 \mathrm{cycles}, 0.1 \mathrm{~A} \cdot \mathrm{g}^{-1}\right) \\
\text { Energy density: } 2.53 \mathrm{~W} \cdot \mathrm{h} \cdot \mathrm{kg}^{-1}\left(5 \mathrm{mV} \cdot \mathrm{s}^{-1}\right)\end{array}$ & $\begin{array}{l}\text { Plasma treatment of the fabric: Previous to GO coating } \\
\left.\text { GO coating: Dip coating ( } 3 \mathrm{~g} \cdot \mathrm{L}^{-1} \mathrm{GO}, 30 \mathrm{~min}\right) \\
\text { ( } 25 \text { coatings) } \\
\text { PPy coating: Dip coating (Pyrrole }+\mathrm{Na}_{2} \mathrm{NDS}(30 \mathrm{~min} \text {, ice } \\
\text { bath). Addition of APS (oxidation). Reaction time: } 2 \mathrm{~h} \text { ) }\end{array}$ & $\begin{array}{l}0.1 \mathrm{M} \text { L-ascorbic } \\
\text { acid, } 95^{\circ} \mathrm{C}, 60 \\
\text { min }\end{array}$ & Supercapacitor & [80] \\
\hline $\begin{array}{l}\text { MWCNTs-PPy- } \\
\text { RGO/PES non- } \\
\text { woven fabrics }\end{array}$ & $\begin{array}{l}\text { Conductivity: } 0.4 \mathrm{~S} \cdot \mathrm{cm}^{-1}(\mathrm{RGO} / \mathrm{PES}) \\
\text { Capacitance: } 305 \mathrm{~F} \cdot \mathrm{g}^{-1}(\mathrm{MWCNTs}-\mathrm{PPy}-\mathrm{RGO} / \mathrm{PES}) 290 \mathrm{~F} \cdot \mathrm{g}^{-1}(\mathrm{PPy}- \\
\text { RGO/PES), } 118 \mathrm{~F} \cdot \mathrm{g}^{-1}(\mathrm{RGO} / \mathrm{PES}), 72.6 \mathrm{~F} \cdot \mathrm{g}^{-1}(\mathrm{PPy} / \mathrm{PES}), 222.9 \mathrm{~F} \cdot \mathrm{g}^{-1} \\
\text { (MWCNTs/PES) }\left(5 \mathrm{mV} \cdot \mathrm{s}^{-1}\right) \\
\text { Capacitance rentention: } 83.4 \% \text { (PPy-RGO/PES), } 94.5 \% \text { (MWCNTs- } \\
\left.\text { PPy-RGO/PES) (after } 1000 \mathrm{cycles}, 80 \mathrm{mV} \cdot \mathrm{s}^{-1}\right)\end{array}$ & $\begin{array}{l}\text { GO coating: Dip coating ( } \mathrm{GO} 5 \mathrm{~g} \cdot \mathrm{L}^{-1}+\text { hydroxylamine } \\
\text { hydrochloride } 0.125 \mathrm{M}, 5 \mathrm{~min}) \\
\text { PPy coating: Dip coating }\left(\mathrm{FeCl}_{3} \cdot 6 \mathrm{H}_{2} \mathrm{O} \text { solution, } 5 \mathrm{~min}\right) \text {. } \\
\text { Exposure to pyrrole vapor (polymerization during } 5 \mathrm{~h} \text { ). } \\
\text { MWCNTs: Dip coating ( }\left(\mathrm{g} \cdot \mathrm{L}^{-1} \text { MWCNTs, } 5 \mathrm{~min}\right)\end{array}$ & $\begin{array}{l}\text { Hydroxylamine } \\
\text { hydrochloride, } \\
130^{\circ} \mathrm{C}, 30 \mathrm{~min}\end{array}$ & Supercapacitor & [81] \\
\hline $\begin{array}{l}\text { ERGO/carbon } \\
\text { fibers }\end{array}$ & $\begin{array}{l}\text { Specific capacitance: } 10.3 \mu \mathrm{F} \cdot \mathrm{cm}^{-2}, 22.6 \mu \mathrm{F} \cdot \mathrm{cm}^{-1}\left(10 \mathrm{mV} \cdot \mathrm{s}^{-1}\right)(\text { single } \\
\text { fiber), } 307 \mathrm{mF} \cdot \mathrm{cm}^{-2}, 13.5 \mathrm{mF} \cdot \mathrm{cm}^{-1}\left(250 \text { fibers }\left(0.05 \mathrm{~mA} \cdot \mathrm{cm}^{-1}\right)\right. \\
\text { Capacitance rentention: } 85 \% \text { ( } 250 \text { fibers }) \text { after } 5000 \mathrm{cycles}(0.05 \\
\left.\mathrm{mA} \cdot \mathrm{cm}^{-1}\right) \\
\text { Energy density: } 1.09 \mu \mathrm{W} \cdot \mathrm{h} \cdot \mathrm{cm}^{-1}\left(27.2 \mu \mathrm{W} \cdot \mathrm{cm}^{-1}\right) \\
\text { Power densitiy: } 748.6 \mu \mathrm{W} \cdot \mathrm{cm}^{-1}\end{array}$ & $\begin{array}{l}\text { Carbon fiber treatment: } \mathrm{H}_{2} \mathrm{SO}_{4} / \mathrm{HNO}_{3}(3: 1 \mathrm{in} \text { volume, } 10 \\
\text { h). } \\
\text { GO coating: Electrochemical deposition }\left(3 \mathrm{~g} \cdot \mathrm{L}^{-1} \mathrm{GO}, 0.1 \mathrm{M}\right. \\
\left.\mathrm{LiClO}_{4},-1.2 \mathrm{~V}, 10 \mathrm{~min}\right)\end{array}$ & $\begin{array}{l}\text { Electrochemical } \\
\text { reduction }\end{array}$ & Supercapacitor & [82] \\
\hline $\begin{array}{l}\mathrm{PPy}-\mathrm{MnO}_{2^{-}} \\
\mathrm{RGO} / \text { stainless } \\
\text { steel yarns }\end{array}$ & $\begin{array}{l}\text { Three-electrode configuration }\left(1 \mathrm{M} \mathrm{Na}_{2} \mathrm{SO}_{4}\right) \\
\text { Specific capacitance: } 36.6 \mathrm{mF} \cdot \mathrm{cm}^{-1}, 486 \mathrm{mF} \cdot \mathrm{cm}^{-2} \\
\text { Two-electrode configuration }\left(\text { solid state } \mathbf{P V A}-\mathbf{H}_{3} \mathbf{P O}_{4} \text { electrolyte) }\right. \\
\text { Specific capacitance: } 31 \mathrm{mF} \cdot \mathrm{cm}^{-1}, 411 \mathrm{mF} \cdot \mathrm{cm}^{-2} \\
\text { Energy density: } 0.0092 \mathrm{~mW} \cdot \mathrm{h} \cdot \mathrm{cm}^{-2}, 1.1 \mathrm{~mW} \cdot \mathrm{h} \cdot \mathrm{cm}^{-3} \\
\text { Capacitance rentention: } 92 \%\left(\text { after } 4950 \mathrm{cycles}, 80 \mathrm{~mA} \cdot \mathrm{cm}^{-3}\right)\end{array}$ & 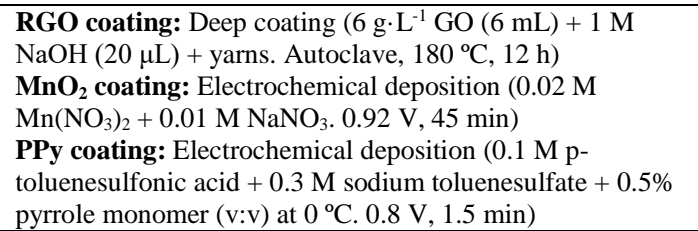 & $\mathrm{NaOH}$ & Supercapacitor & [83] \\
\hline $\begin{array}{l}\text { ERGO-Ni/cotton } \\
\text { yarns }\end{array}$ & $\begin{array}{l}\text { Electrical resistance: } 1.6 \Omega \cdot \mathrm{cm}^{-1} \\
\text { Two electrode configuration }\left(1 \mathrm{M} \mathrm{Na}_{2} \mathrm{SO}_{4}\right) \\
\text { Capacitance: } 292.3 \mathrm{~F} \cdot \mathrm{cm}^{-3}, 311 \mathrm{~F} \cdot \mathrm{g}^{-1}\left(87.9 \mathrm{~mA} \cdot \mathrm{cm}^{-3}\right) \\
\text { Two electrode configuration }(\mathbf{P V A} / \mathrm{LiCl} \text { gel, solid state) } \\
\text { Capacitance: } 0.11 \mathrm{~F} \cdot \mathrm{cm}^{-1} \\
\text { Maximum energy density: } 6.1 \mathrm{~mW} \cdot \mathrm{h} \cdot \mathrm{cm}^{-3} \\
\text { Maximum power density: } 1400 \mathrm{~mW} \cdot \mathrm{cm}^{-3} \\
\text { Capacitance rentention: } 82 \%\left(\mathrm{after} 10000 \mathrm{cycles}, 439.6 \mathrm{~mA} \cdot \mathrm{cm}^{-3}\right)\end{array}$ & $\begin{array}{l}\text { Ni coating: Electroless deposition ( } 60 \mathrm{~min}) \\
\text { GO coating: Electrochemical deposition }\left(3 \mathrm{~g} \cdot \mathrm{L}^{-1} \mathrm{GO}+0.1\right. \\
\left.\mathrm{M} \mathrm{LiClO}_{4},-1.2 \mathrm{~V}, 10 \mathrm{~min}\right)\end{array}$ & $\begin{array}{l}\text { Electrochemical } \\
\text { reduction }+ \\
\text { hydrazine vapor } \\
\text { reduction, } 60^{\circ} \mathrm{C}, 3 \\
\text { h }\end{array}$ & Supercapacitor & [84] \\
\hline $\begin{array}{l}\text { RGO- } \\
\text { Pani/nitrogen- } \\
\text { doped carbon } \\
\text { fiber cloth }\end{array}$ & $\begin{array}{l}\text { Three-electrode configuration }\left(\mathbf{~ M ~ H}_{2} \mathbf{S O}_{4}\right) \\
\text { Specific capacitance: } 1145 \mathrm{~F} \cdot \mathrm{g}^{-1}(\mathrm{RGO}-\mathrm{Pani} / \mathrm{N}-\mathrm{doped} \text { carbon cloth), } \\
1050 \mathrm{~F} \cdot \mathrm{g}^{-1} \text { (Pani/ } / \mathrm{N}-\text { doped carbon cloth), } 940 \mathrm{~F} \cdot \mathrm{g}^{-1}(\mathrm{GO}-\mathrm{Pani} / \mathrm{N}-\text { doped } \\
\text { carbon cloth), } 520 \mathrm{~F} \cdot \mathrm{g}^{-1}(\text { Pani) } \\
\left.\text { Maximum energy density: } 25.4 \mathrm{~W} \cdot \mathrm{h} \cdot \mathrm{kg}^{-1} \text { (at } 52.5 \mathrm{~kW} \cdot \mathrm{kg}^{-1}\right) \\
\left.\text { Maximum power density: } 92.2 \mathrm{~kW} \mathrm{~kg}^{-1} \text { (at } 20.3 \mathrm{~W} \cdot \mathrm{h} \cdot \mathrm{kg}^{-1}\right) \\
\text { Capacitance rentention: } 94 \% \text { (after } 5000 \text { cycles) }\end{array}$ & $\begin{array}{l}\text { Nitrogen doping carbon fiber cloth: Cold plasma } \\
\text { treatment } \mathrm{N}_{2} / \mathrm{O}_{2}, 2 \text { min } \\
\left.\text { Pani coating: Dip coating (aniline }+1 \mathrm{M} \mathrm{H}_{2} \mathrm{SO}_{4}, 10 \mathrm{~min}\right) \\
\text { APS oxidation }(24 \mathrm{~h} \text {, ratio aniline:APS }(4: 1)) \\
\text { GO coating: Dip coating }\left(0.5 \mathrm{~g} \cdot \mathrm{L}^{-1}, 15 \mathrm{~min}\right)\end{array}$ & HI reduction & Supercapacitor & [85] \\
\hline
\end{tabular}




\subsection{Graphene woven fabrics}

Another method that has been applied for the synthesis of G-based fabrics is the production of graphene woven fabrics [86-101]. This method consists in growing G coating on a metallic mesh (normally Cu) by CVD (Fig. 13-a) [86]. During the growth, $\mathrm{Cu}$ wires interconnect due to the high temperature employed in CVD growth $\left(\sim 1000^{\circ} \mathrm{C}\right)$. Thereafter, the $\mathrm{Cu}$ mesh is removed by $\mathrm{FeCl}_{3} / \mathrm{HCl}$ treatment and the $\mathrm{G}$ structure collapses (upper and lower part of the wires) to produce graphene micron-ribbons. The resulting structure has the form of the Cu mesh employed (Fig. 13-b). Fig. 13-c shows a photograph of the resulting GFWs structure. Fig. 13-d shows a TEM micrograph and the diffraction pattern which shows a hexagonal symmetry. Two sets of the hexagonal spots can be observed with a rotation of $26^{\circ}$ between them. This is due that the two sides of the GWF that collapsed are analyzed at the same time. The GWF structure obtained is polycrystalline with several G layers and surface wrinkles are present. The sheet resistance of GWFs can be tuned by varying the coverage of G simply varying the parameters of the supporting $\mathrm{Cu}$ mesh (width of wires and distance between wires).

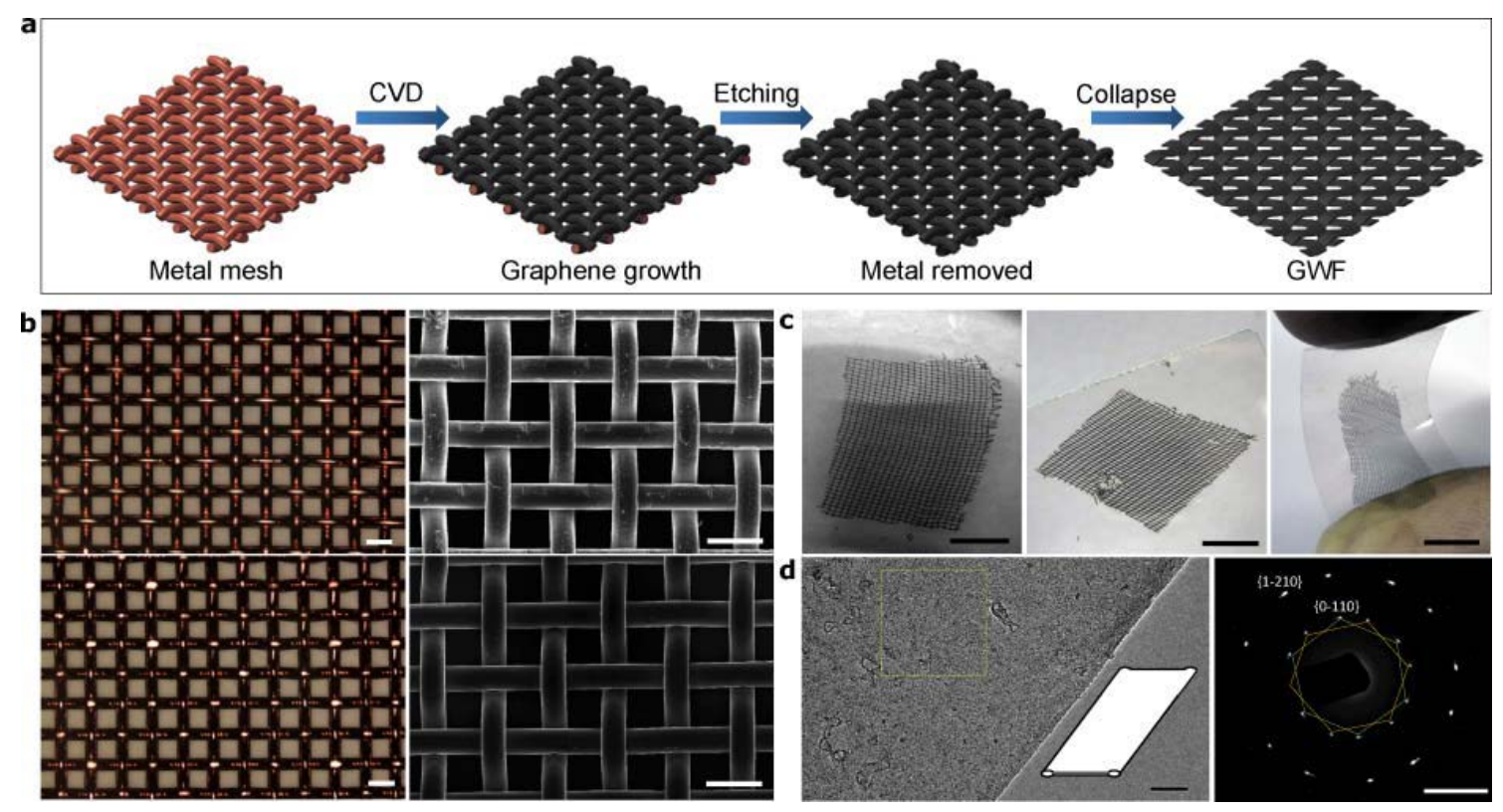

Fig. 13. Fabrication of GWFs by CVD using copper wire meshes as substrates. (a) Schematic of steps for GWF preparation. (b) Macroscopic optical images (left), top-view 
SEM images (right) of copper meshes before (top) and after (bottom) graphene growth. Scale bars, $200 \mathrm{~mm}$. (c) Optical images of GWF films floating on water and deposited on glass and PET. Scale bars, $5 \mathrm{~mm}$. (d) TEM image of a GMR and selected area electron diffraction pattern from the region marked with a yellow box. Scale bars, $50 \mathrm{~nm}$ (left), 5 (1/nm) (right). Reprinted from [86] with permission from Nature.

\subsection{Applications of graphene woven fabrics}

\subsubsection{Sensors for strain, torsion, movement, acoustic, pulse, etc. monitoring}

GWFs have been widely employed for the production of strain sensors due to the high sensitivity of its structure to deformation. Li et al. [86] coated the obtained GWFs with PDMS to produce composites that were employed as strain sensors. The sensors were more sensitive when the strain was applied in the direction of the fibers (x direction) rather than when a combined stress was applied (x and y directions) (Fig. 14-a). The strain range was limited to $5 \%$ to avoid irreversible tensile strain that provoked breakage of the G structure. Under this limit, the sensor was reversible (Fig. 14-b). Fig. 14-c shows the application of the sensor for monitoring the movement of a finger.
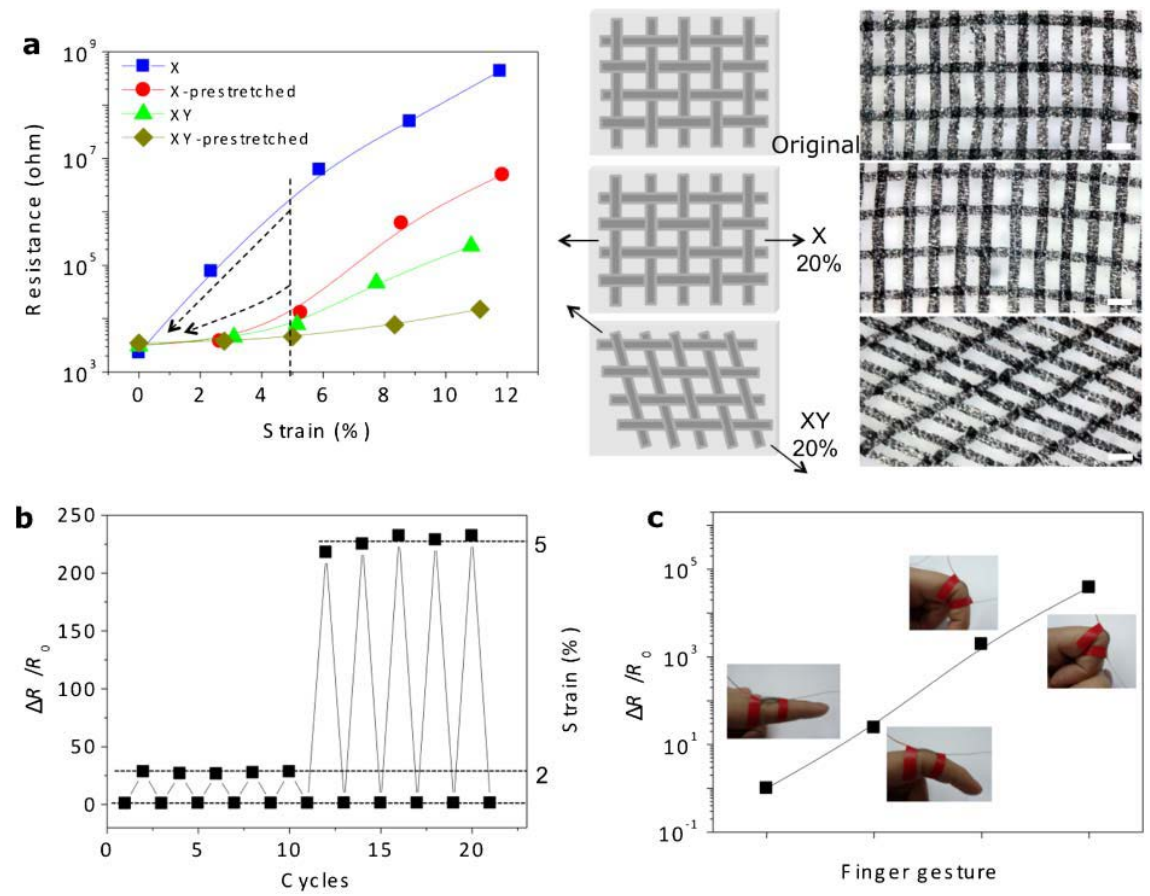
Fig. 14. GWF/polymer hybrid films. (a) Resistance-strain curves for GWF/PDMS hybrids along different directions. Inset shows the schematics and corresponding optical images. Scale bars, $300 \mathrm{~mm}$. (b) Electromechanical properties of the GWF/PDMS films. Resistance change relative to the original value $\left(\Delta R / R_{0}\right)$ recorded for a number of cycles at tensile strains of $2 \%$ and $5 \%$. (c) Stretchable sensor fixed to a finger, and relative changes in resistance for finger motion. Insets show corresponding photographs. Reprinted from [86] with permission from Nature.

In [87], the same authors performed a similar study and explained the mechanism underlying for such good performance of GWFs as strain sensors. Under strain, cracks in the structure begin to form at weak points. The crack length and crack density propagate with the increasing strain (Fig. 15). After removing the external force, the cracks disappear and the fractured GWF recovers to its initial position since it is stuck to PDMS substrate. These cracks are responsible for the change in resistance of the sensor. In this paper, very high gauge factors for GWF/PDMS were reported $\left(10^{6}\right.$ for strain $\left.>7 \%\right)$. The sensors were also employed for compression, torsion and shearing strain sensing, although the response was much lower. Wang et al. [88] applied bio-inspired Voronoi polycrystalline micromechanics model and experimental validations to explain such high gauge factors. It was demonstrated that the successive cracking, the "fish-scale” like network structure of GWFs (overlapping of G crystals on the grain boundary), and the superlubricity between overlapped G flakes play a crucial paper.

Lee et al. [89] produced piezoresistors by assembling GWF on PDMS where Ti-Au electrodes had been previously deposited (round and band type) to produce touch sensors. 
The method employed for producing GWFs has also been employed for producting G fibers by Wang et al. [90]. The G fibers were coated with PVA to produce protected conducting fibers that were mounted on PDMS film to construct a strain sensor.

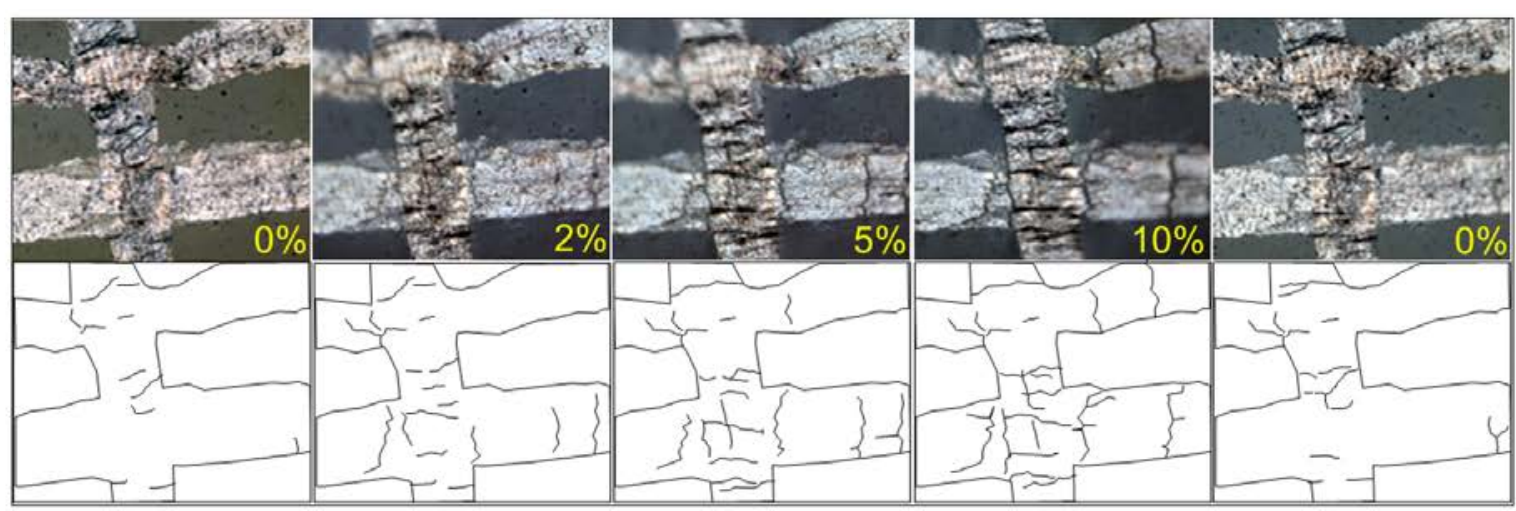

Fig. 15. A series of optical images showing the formation of crack and their evolution in GWF under different strain, and corresponding schematics. Reprinted from [87] with permission from Nature.

Yang et al. [91] employed GWFs as strain sensors for human monitoring (human skin movement, pulse, jugular venous pressure, body movement), acoustic signal acquisition, and spatially resolved monitoring of external stress distribution. Fig. 16 shows some of the applications and the experiments performed. Thicker G coatings produced GWFs with a larger stretching range (> $20 \%$ ), however sensitivity was sacrificed (lower gauge factor). The higher stretching limit would allow to employ these sensors for monitoring activities such as walking, running and grasping. Wang et al. [92] applied the GWFs for similar body motion monitoring (clenching, phonation, expression change, blink, breath, and pulse). Authors pointed out applications such as lie detectors based on muscle deformation amplitude, or evaluation of the degree of fatigue by measuring the frequency and amplitude of the blinks, etc.

Torsion sensors have also been reported by Yang et al. [93] by wrapping GWF/PDMS around a PDMS rod and applying torsion to the polymeric rod. Differences were observed 
when pre-stretching to the PDMS film was applied or not. When applying a $20 \%$ prestretching, the sensor could withstand torsions of up to $800 \mathrm{rad} \cdot \mathrm{m}^{-1}$ because waving of the GWFs was avoided and their tolerance to high strains was improved. Lower pretensions favoured the sensitivity due to a large gauge factor. The sensor could discriminate among forward and backward torsion by the change in resistance and the response it was not dependent on the frequency of the applied load.
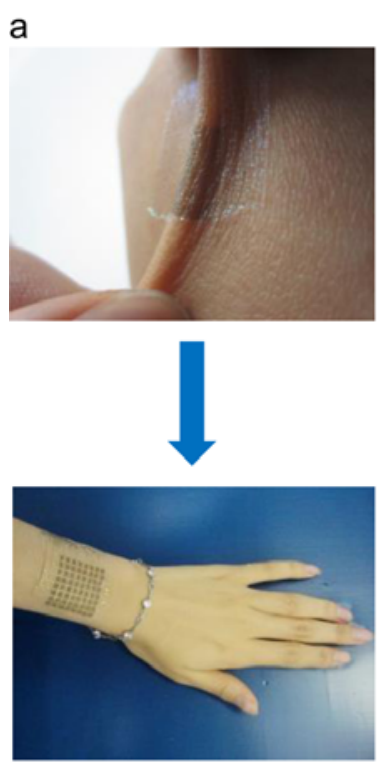
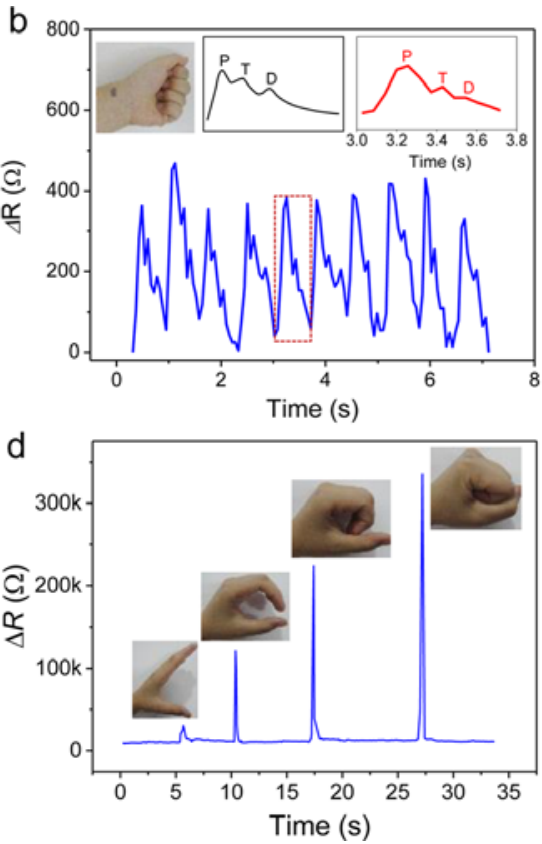
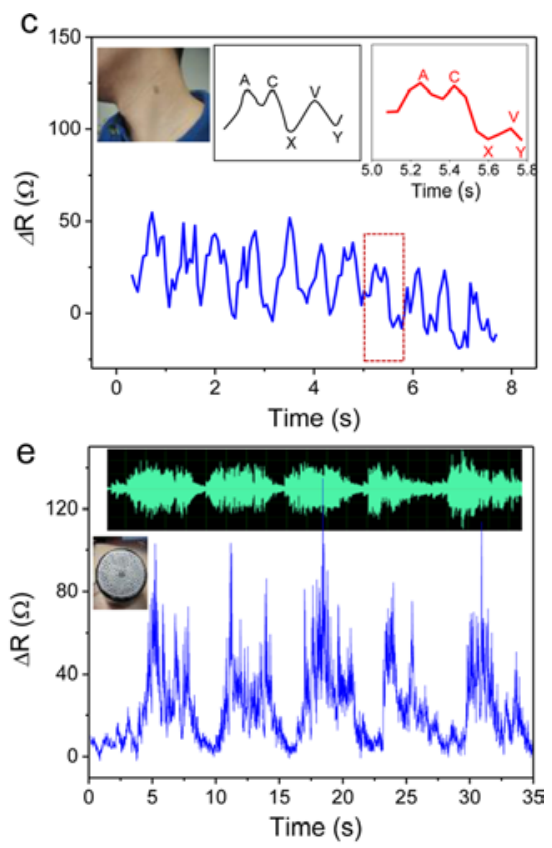

Figure 16. (a) Conformal adhesion of a GWF-based strain sensor on the human skin. (b) Measured relative resistances of pulse (insets: photograph, typical pulse waveform, measured profile) and (c) jugular venous pressure measured in real time (insets: photograph, a typical jugular venous pulse, measured profile). (d) Resistance response at the successive stages of making a fist. (e) Recognition of a sound signal using the GWF strain sensor. The insets show the sensor on an earphone and the sound wave profile. Reprinted from [91] with permission from American Chemical Society.

Wang et al. [94] employed GWFs for sound signal acquisition and recognition. The sensor, which was very sensitive to tiny strains and vibrations, was located on a human 
throat and it was employed to register the muscular movement/vibration. It was used for collecting and recognizing the 26 English letters, some typical Chinese characters, phrases and animal sounds. The waveforms were specific of each letter and showed similar key features when performed by different people. The same signal wave forms were obtained without vocalization, which could help patients with problems in vocalization. In addition, authors pointed out the employment of these sensors in earthquake monitoring, animal communication and robotic voice development. The sensor was also employed to perform measurements with a loudspeaker, where the sensor was located on the loudspeaker membrane. The audio frequency and the collected signal had a matching synchronization.

\subsubsection{Solar cells}

GWFs have been also employed in solar cells where GWF functioned as the transparent electrode in Schottky junction with Si to allow enhanced photovoltaic conversion [86]. In addition GWF allowed electron/hole separation and hole transport, while electrons were driven into silicon, which allowed the production of electricity. Different additives were employed to improve solar energy conversion $\left(\mathrm{HNO}_{3}\right.$, $\mathrm{PEDOT}$ and $\mathrm{HBr} / \mathrm{Br}_{2}$ redox mediator). Kang et al. [95] deposited PtNPs on GWFs for producing hybrid Shottky junctions and photoelectrochemical solar cells. The deposition of Pt increased the work function of GWFs and reduced the sheet resistance. The optical pathlength was also increased by PtNPs absorption of light and more carriers were photogenerated. However, an excessive amount of PtNPs was detrimental since it hindered light transmittance. Fig. 17 shows a scheme of the solar cell configuration (Fig. 17-a), as well as the synthesis of PtNPs (Fig. 17-b) and the final cell configuration with PtNPs (Fig. 17-c). The presence of PtNPs improved the open circuit voltage and the short circuit current density. 
Photoexcited charge carriers generated in n-Si were separated by the built-in field, electrons were directed to the n-Si region and holes moved towards GWF. The solid electrolyte, acted as a redox mediator and holes were captured by $\mathrm{NO}_{3}{ }^{-}$that diffused to the GWF and was reduced again to $\mathrm{NO}_{3}{ }^{-}$. This redox reaction forms a photoelectrochemical channel for hole carriers. Both effects were synergistic and contributed to enhance the power conversion efficiency. In addition, the solid electrolyte acted as an anti-reflection layer and as a chemical carrier.

(a)

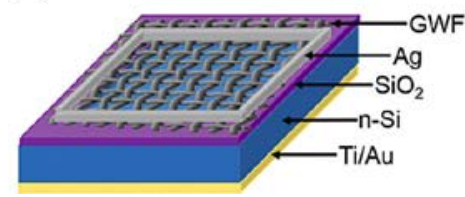

(b)

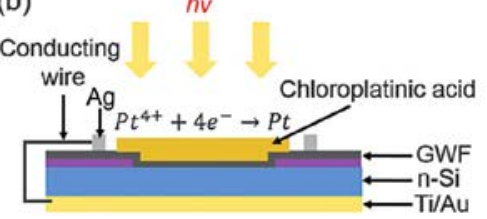

(c)

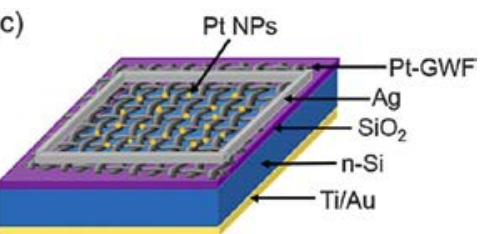

Fig. 17. Schematic diagrams of (a) pristine GWF/n-Si solar cell, (b) in situ galvanic synthesis of Pt-GWF, and (c) Pt-GWF/n-Si solar cell. Reprinted from [95] with permission from The Royal Society of Chemistry.

\subsubsection{Electromagnetic shielding}

Han et al. [96] employed the GWFs for obtaining IR transparent and conducting materials that were applied for electromagnetic shielding. The influence of square aperture and wire width of the mesh on the optical transmittance, electromagnetic shielding and conductivity was evaluated. An increase in the square aperture caused an increase of the transmittance, however conductivity and electromagnetic shielding followed the inverse trend. The thickness of the ribbons was around $6 \mathrm{~nm}$, and $12 \mathrm{~nm}$ in the intersections. The dominant shielding mechanism of GWFs was microwave absorption to electromagnetic radiation in the frequency range of 9.2-15 GHz. The high surface area of GWFs caused multiple reflections of the radiation in the GWFs that enhanced its absorption. 


\subsubsection{Supercapacitative materials}

GWFs have been also employed as flexible supercapacitative materials, alone $[97,98]$ or combined with pseudocapacitative materials such as $\mathrm{MnO}_{2}$ [98] or Pani $[99,100]$.

Zang et al. [97] obtained GWFs and deposited them on different substrates (polishing cloth, polyethylene, PET and filter paper) and studied their capacitative behavior. Supercapacitors with very low thickness $(<1 \mathrm{~mm})$ were mounted with $\mathrm{PVA}-\mathrm{H}_{3} \mathrm{PO}_{4}$ as polymer gel electrolyte and the best results were obtained on polishing cloth. Deformation of the devices (fold, twist, knead, and curl) increased capacitance due to a better contact between the electrode and the gel electrolyte. Therefore, the supercapacitors could be shaped into different forms without loss in their capacitance.

Li et al. [98] obtained GWFs composed of G layers and porous carbon on the core, hence integrating the conductivity of $G$ and the porous characteristics of porous carbon. Depending on the synthesis conditions and cooling rate, the composition of the material could be adjusted. Thinner multilayer $\mathrm{G}$ films provided a larger specific surface area and voids for high-performance supercapacitor electrodes. Thicker deposits provided a better skeleton structure to be filled with other functional materials. The mean pore size of the material was in the 2-3 nm range, favouring the formation of an electrical double layer. $\mathrm{N}$-doping enhanced the pseudocapacitative effect and improved the specific capacitance by a $150 \%$. Capacitance could be further increased depositing other materials such as $\mathrm{MnO}_{2}$ on the surface of the GWFs.

Zang et al. [99] coated GWFs with Pani obtained by potentiostatic deposition and employed the Pani/GWFs composite as supercapacitor material. GWF acted as support material onto which Pani could be deposited and also as a current collector for capacitance measurements. In addition, GWFs also acted as a double layer capacitor and Pani acted as a pseudo-capacitor material. The presence of Pani improved greatly the capacitance of 
GWFs (from $2 \mathrm{mF} \cdot \mathrm{cm}^{-2}$ to $23 \mathrm{mF} \cdot \mathrm{cm}^{-2}$ ) (Fig. 18). The supercapacitor showed great stability after 2000 cycles with no appreciable loss of capacitance; what is more, bending and curling even improved the areal capacitance since a better contact between the polymer gel electrolyte and the electrode was favored.

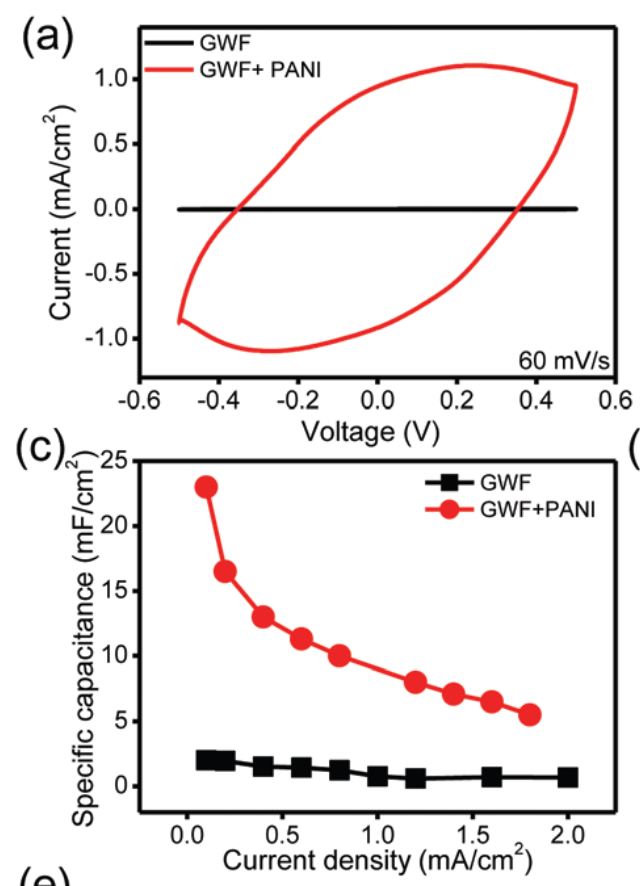

(e)
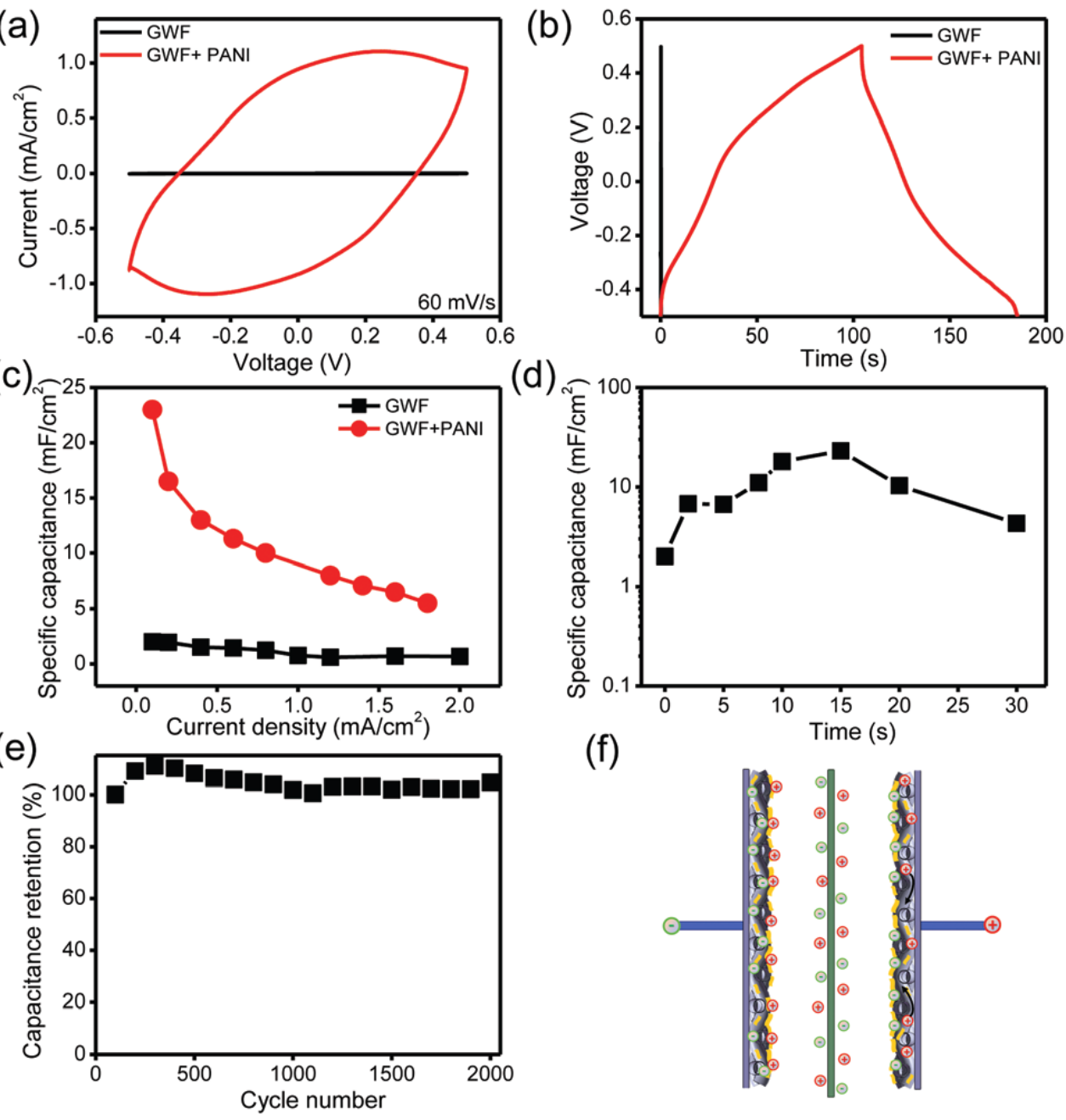

(f)

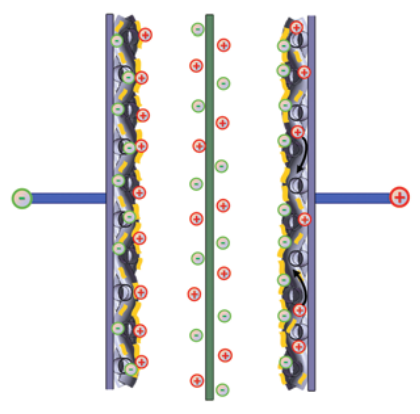

Fig. 18. Electrochemical performance of the GWF + PANI (15 min) film supercapacitor. (a) CV curves $\left(60 \mathrm{mV} \cdot \mathrm{s}^{-1}\right)$, (b) galvanostatic charge-discharge curves $\left(0.1 \mathrm{~mA} \cdot \mathrm{cm}^{-2}\right)$, (c) areal capacitances $\left(0.1\right.$ to $\left.2 \mathrm{~mA} \cdot \mathrm{cm}^{-2}\right)$ of GWF and GWF + PANI. (d) Areal capacitance versus electropolymerization time. (e) Cycling stability of the flexible GWF + PANI supercapacitor. (f ) Schematic diagram of the GWF electrodes. Reprinted from [99] with permission form The Royal Society of Chemistry. 
In [100] the same authors employed the same approach to produce supercapacitors and tested the static and dynamic performance under strain. The GWFs were assembled on pre-stretched polymer substrates in order to improve flexibility and enlarge the strain range of the supercapacitors. Till a $30 \%$ strain, no change in the capacitance was observed. Pani was also electropolymerized on GWFs as explained previously in order to increase capacitance [99]. No change in the capacitance was neither observed till a $30 \%$ strain. According to this, the maximum strain for the dynamic tests was restricted to 30 $\%$. The supercapacitors could withstand high rates of dynamic stretching (60\%/s, strain frequency $1 \mathrm{~Hz}$ ). The GWFs increased the surface area and the robustness, being more suitable for dynamic stretching deformation.

\subsubsection{Mechanical properties}

GWFs also confer enhanced mechanical strength. Liu et al. [101] reinforced epoxy resin with GWF which provided exceptional electrical, mechanical and fracture toughness to the composite. The mechanical properties of epoxy resin were improved by the presence of GWF. When the force was applied at $45^{\circ}$ respect the direction of the fibers, the composite had better mechanical properties than when it was applied at $0^{\circ}$. In the latter case, only the fibers that are parallel to the force play a role in mechanical resistance. On the other hand, at $45^{\circ}$, both the weave and weft of the GWF make a contribution towards the improvement of its mechanical properties.

Zhang et al. [102] performed an interesting analysis of the mechanical properties and behavior of GWFs by computational modelling. Authors provided guidelines for the theoretical mechanical analysis of GWFs and concluded that the mechanical properties of GWFs can be adjusted by varying the weave density. 
Table 2. Work performed with graphene woven fabrics.

\begin{tabular}{|c|c|c|c|c|}
\hline Material composition & Properties & Method of synthesis & Application & Reference \\
\hline $\begin{array}{l}\text { GWF/PDMS (sensor) } \\
\text { GWF (solar cells) }\end{array}$ & $\begin{array}{l}\text { Surface resistivity: } 500-2500 \Omega / \text { square (GWF), } 200-1200 \Omega / \text { square (GWF + } \\
\mathrm{HNO}_{3} \text { treatment) } \\
\text { Optical transparency: } 50-90 \% \\
\text { Linearity as strain sensor: strain < } 5 \% \text { (reversible) } \\
\text { Change of electrical resistance under strain: } 25 \text {-fold ( } 2 \% \text { strain), } 230 \text {-fold ( } 5 \% \\
\text { strain) } \\
\text { Efficiency, solar energy conversion: } 2.5 \% \text { GWF, } 3 \%(\mathrm{GWF} / \mathrm{Si}), 3.6 \% \\
(\mathrm{GWF} / \mathrm{PEDOT}), 3.8 \% \text { (GWF/Si-HBr-Br }), 6.1 \%\left(\mathrm{GWF} / \mathrm{Si}-\mathrm{HNO}_{3}\right)\end{array}$ & $\begin{array}{l}\text { CVD synthesis on Cu mesh followed } \\
\text { by Cu etching }\end{array}$ & $\begin{array}{l}\text { GWF/polymer composites as strain sensors } \\
\text { GWF/semiconductor in solar cells }\end{array}$ & [86] \\
\hline GWF/PDMS & $\begin{array}{l}\text { Change of electrical resistance under strain: 1-fold ( } 0.5 \% \text { strain), } 5 \text {-10-fold (2 } \\
\% \text { strain), } 10^{3}-10^{4} \text {-fold ( } 8 \% \text { strain). } \\
\text { Gauge factor: } 10^{3}\left(2-6 \% \text { strain), } 10^{6}(>7 \% \text { strain) }\right. \\
\text { Linearity as strain sensor: strain }<10 \% \text { (reversible) } \\
\text { Stability: }>100 \text { cycles }\end{array}$ & $\begin{array}{l}\text { CVD synthesis on Cu mesh followed } \\
\text { by Cu etching }\end{array}$ & GWF/polymer composites as strain sensors & [87] \\
\hline GWF/Ti-Au-PDMS & $\begin{array}{l}\text { Sheet resistance: } 1840 \Omega / \mathrm{square} \\
\text { Transmittance: } 92.4 \%(550 \mathrm{~nm}) \\
\text { Linearity as strain sensor: } 3.025 \% \text { (warp), } 0.727 \% \text { (weft) (round electrodes) } \\
\text { Change of electrical resistance under strain: } 60 \% \text { on average }\end{array}$ & $\begin{array}{l}\text { CVD synthesis on Cu mesh followed } \\
\text { by Cu etching }\end{array}$ & GWF/polymer composites as strain sensors & [89] \\
\hline $\begin{array}{l}\text { G fibers/PVA } \\
\mathrm{G} \text { fibers/PVA-PDMS }\end{array}$ & $\begin{array}{l}\text { Conductivity: } 9.6 \cdot 10^{3} \mathrm{~S} \cdot \mathrm{m}^{-1} \text { (for } 10 \% \text { wt PVA) } \\
\text { Tensile strength: } 590 \mathrm{MPa}(16 \% \text { elongation) } \\
\text { Limit of strain: } 7.1 \% \text { (to maintain conductivity) } \\
\text { Gauge factor: } 5.02(1-6.3 \% \text { strain) } \\
\text { Stability: } 200 \text { cycles, bending radius } 5.5 \mathrm{~mm} .200 \text { cycles, elongation } 6 \% \text {. }\end{array}$ & $\begin{array}{l}\text { CVD synthesis on Cu wires followed } \\
\text { by Cu etching } \\
\text { PVA coating: } 1,3,5,10 \% \text { PVA } \\
\text { solutions. Drying: } 3 \text { h, room } \\
\text { temperature }\end{array}$ & Strain sensor & [90] \\
\hline GWF/PDMS & $\begin{array}{l}\text { Change of electrical resistance under strain: } 1 \text {-2-fold (1 \% strain), 5-10-fold (2 } \\
\% \text { strain), } 10^{3}-10^{4} \text {-fold ( } \% \text { strain) } \\
\text { Gauge factor: } 500 \text { ( } 2 \% \text { strain), } 10000 \text { ( }>8 \% \text { strain) } \\
\text { Stability: } 24 \% \text { decrease of initial response after applying } 2 \% \text { strain for } 1000 \\
\text { cycles. } 20 \% \text { strain can be achieved by adjusting growth parameters or } 40 \% \text { by } \\
\text { changing growth and adopting oblique direction stretching }\end{array}$ & $\begin{array}{l}\text { CVD synthesis on Cu mesh followed } \\
\text { by Cu etching }\end{array}$ & $\begin{array}{l}\text { Sensor for human motion detection, sound } \\
\text { signal acquisition, spatially resolved } \\
\text { monitoring of external stress distribution }\end{array}$ & [91] \\
\hline $\begin{array}{l}\text { GWF/PDMS-medical } \\
\text { tape }\end{array}$ & $\begin{array}{l}\text { Sheet resistance: } 400-500 \Omega / \text { square } \\
\text { Change of electrical resistance under strain: } 10 \text {-fold ( } 2 \% \text { strain), } 10^{4} \text {-fold ( } 8 \% \\
\text { strain). } \\
\text { Reversibility: }<30 \% \text { strain }\end{array}$ & $\begin{array}{l}\text { CVD synthesis on Cu mesh followed } \\
\text { by Cu etching }\end{array}$ & $\begin{array}{l}\text { Sensor for human motion detection: } \\
\text { clenching, phonation, expression change, } \\
\text { blink, breath, and pulse }\end{array}$ & [92] \\
\hline GWF/PDMS & $\begin{array}{l}\text { Detection limit: } 0.3 \mathrm{rad} \cdot \mathrm{m}^{-1}(0 \% \text { pre-stretching of PDMS film }) \\
\text { Ratio of tolerance limit: } 1000\left(100 \mathrm{rad} \cdot \mathrm{m}^{-1}\right) \\
\text { Limit: } 800 \mathrm{rad} \cdot \mathrm{m}^{-1}(20 \% \text { pre-stretching of PDMS film }) \\
\text { Stability: } 1000 \text { cycles }\left(0-100 \mathrm{rad} \cdot \mathrm{m}^{-1}\right)\left(10 \% \text { pre-strain, } 45^{\circ} \text { winding angle }\right)\end{array}$ & $\begin{array}{l}\text { CVD synthesis on Cu mesh followed } \\
\text { by Cu etching }\end{array}$ & Torsion sensor & [93] \\
\hline GWF/PDMS-tape & Change of electrical resistance for letters registration: $>4 \%$ & $\begin{array}{l}\text { CVD synthesis on } \mathrm{Cu} \text { mesh followed } \\
\text { by } \mathrm{Cu} \text { etching }\end{array}$ & Acoustic sensor & [94] \\
\hline PtNPs/GWF/n-Si & $\begin{array}{l}\text { Efficiency, solar energy conversion: 3-5 \% (GWF/n-Si), 7.51 \% (GWFs/n-Si + } \\
\text { solid electrolyte), } 7.94 \% \text { (PtNPs/GWF/n-Si), } 10.02 \% \text { (PtNPs/GWF/n-Si + solid } \\
\text { electrolyte) }\end{array}$ & $\begin{array}{l}\text { CVD synthesis on Cu mesh followed } \\
\text { by Cu etching }\end{array}$ & Solar cells & [95] \\
\hline
\end{tabular}




\begin{tabular}{|c|c|c|c|c|}
\hline & & $\begin{array}{l}\text { PtNPs synthesis: } \mathrm{H}_{2} \mathrm{PtCl}_{6} 10 \mathrm{mM} \text {, } \\
\text { irradiation } 82 \mathrm{~mW} \cdot \mathrm{cm}^{-2}, 3-15 \mathrm{~min} \text {. } \\
\text { Solid electrolyte: } \mathrm{PVA} / \mathrm{HNO}_{3}\end{array}$ & & \\
\hline GWF & $\begin{array}{l}\text { Electrical conductivity: } 66.7-127{\mathrm{~S} \cdot \mathrm{cm}^{-1}}^{-1} \\
\text { Electromagnetic shielding effectiveness: } 12.86 \mathrm{~dB}(10 \mathrm{GHz}) \\
\text { Lowest IR Transmittance: } 70.85 \%(4500 \mathrm{~nm})(120 \text { mesh }) \\
\text { Highest IR transmittance: } 87.85 \%(2500-6500 \mathrm{~nm})(40 \text { mesh })\end{array}$ & $\begin{array}{l}\text { CVD synthesis on } \mathrm{Cu} \text { mesh followed } \\
\text { by Cu etching }\end{array}$ & Electromagnetic shielding & [96] \\
\hline $\begin{array}{l}\text { GWF/polishing cloth } \\
\text { GWF/polyethylene } \\
\text { GWF/PET } \\
\text { GWF/filter paper }\end{array}$ & $\begin{array}{l}\left.\text { Areal capacitance (at } 60 \mathrm{mV}^{\cdot-1} \mathrm{~s}^{-1}\right): 9 \mathrm{mF} \cdot \mathrm{cm}^{-2}\left(\mathrm{GWF} / \mathrm{polishing} \text { cloth), } 3 \mathrm{mF} \cdot \mathrm{cm}^{-2}\right. \\
(\mathrm{GWF} / \text { filter paper }), 2 \mathrm{mF} \cdot \mathrm{cm}^{-2}(\mathrm{GWF} / \mathrm{polyethylene}), 1 \mathrm{mF} \cdot \mathrm{cm}^{-2}(\mathrm{GWF} / \mathrm{PET}) \\
\text { Specific capacitance: } 267 \mathrm{~F} \cdot \mathrm{g}^{-1}(\mathrm{GWF} / \text { polishing cloth) } \\
\text { Stability: } 100 \% \text { after } 1000 \text { cycles of charge/discharge (GWF/polishing cloth, } \\
\text { GWF/filter paper, GWF/PET) }\end{array}$ & $\begin{array}{l}\text { CVD synthesis on Cu mesh followed } \\
\text { by Cu etching }\end{array}$ & Supercapacitor & [97] \\
\hline $\begin{array}{l}\text { GWF/porous carbon } \\
\text { core } \\
\text { GWF/porous carbon } \\
\text { core N-doped } \\
\mathrm{MnO}_{2} \text {-GWF/porous } \\
\text { carbon core N-doped }\end{array}$ & $\begin{array}{l}\text { Sheet resitance: } 10 \Omega / \mathrm{square} \\
\text { Specific surface area: } 688 \mathrm{~m}^{2} \cdot \mathrm{g}^{-1} \\
\text { Total pore volume: } 435 \mathrm{~m}^{3} \cdot \mathrm{g}^{-1} \\
\text { Areal capacitance: } 44 \mathrm{mF} \cdot \mathrm{cm}^{-2} \\
\text { Specific capacitance: } 173 \mathrm{~F} \cdot \mathrm{g}^{-1} \text { (N-doped), } 225 \mathrm{~F} \cdot \mathrm{g}^{-1}\left(\mathrm{~N}-\mathrm{doped} / \mathrm{MnO}_{2}\right) \\
\text { Stability: } 95 \% \text { after } 1000 \mathrm{cycles} \text { of charge/discharge at } 20 \mathrm{~A} \cdot \mathrm{g}^{-1}\end{array}$ & $\begin{array}{l}\text { CVD synthesis on Ni mesh followed } \\
\text { by Ni etching }\end{array}$ & Supercapacitor & [98] \\
\hline Pani/GWF & $\begin{array}{l}\text { Areal capacitance }\left(\mathbf{0 . 1} \mathbf{~ m A} \cdot \mathrm{cm}^{-2}\right): 23 \mathrm{mF} \cdot \mathrm{cm}^{-2}\left(\text { Pani-GWF), } 2 \mathrm{mF} \cdot \mathrm{cm}^{-2}(\mathrm{GWF})\right. \\
\text { Specific capacitance }\left(\mathbf{0 . 1} \mathbf{~ m A} \cdot \mathrm{cm}^{-2}\right): 771 \mathrm{~F} \cdot \mathrm{g}^{-1}(\mathrm{Pani}-\mathrm{GWF}), 66.7 \mathrm{~F} \cdot \mathrm{g}^{-1}(\mathrm{GWF}) \\
\text { Highest energy density: } 15 \mathrm{~mW} \cdot \mathrm{h}^{-} \mathrm{m}^{-2}\left(0.33 \mathrm{~mW} \cdot \mathrm{cm}^{-2} \text {, Pani-GWF), } 1.4\right. \\
\mathrm{mW} \cdot \mathrm{h} \cdot \mathrm{m}^{-2}\left(0.03 \mathrm{~mW} \cdot \mathrm{cm}^{-2}, \mathrm{GWF}\right) \\
\text { Highest power density: } 1 \mathrm{~mW} \cdot \mathrm{cm}^{-2}\left(2.6 \mathrm{~mW} \cdot \mathrm{h} \cdot \mathrm{m}^{-2} \text {, Pani-GWF), } 0.3 \mathrm{~mW} \cdot \mathrm{cm}^{-2}\right. \\
\left(0.8 \mathrm{~mW} \cdot \mathrm{h} \cdot \mathrm{m}^{-2}, \mathrm{GWF}\right) \\
\text { Stability: } 100 \% \text { after } 2000 \mathrm{cycles} \text { of charge/discharge }\end{array}$ & $\begin{array}{l}\text { CVD synthesis on } \mathrm{Cu} \text { mesh followed } \\
\text { by Cu etching } \\
\text { Pani coating: } 0.5 \mathrm{M} \text { aniline }+0.1 \mathrm{M} \\
\mathrm{HCl} \text {, potentiostatic synthesis at }+0.8 \\
\mathrm{~V}, 15 \text { min }\end{array}$ & Supercapacitor & [99] \\
\hline Pani-GWF/PDMS & $\begin{array}{l}\text { Maximum static strain: } 30 \% \\
\text { Maximum dynamic stretching rate: } 60 \% / \mathrm{s} \\
\text { Maximum specific capacitance }\left(\mathbf{6 0} \mathbf{~ m V} \cdot \mathrm{s}^{-1}\right): 8 \mathrm{mF} \cdot \mathrm{cm}^{-2}(20 \% \text { pre-stretching, } \\
\text { Pani-GWF/PDMS), } 17 \mu \mathrm{F} \cdot \mathrm{cm}^{-2}\left(\text { no pre-stretching, GWF/PDMS), } 26 \mu \mathrm{F} \cdot \mathrm{cm}^{-2}(20\right. \\
\% \text { pre-stretching, GWF/PDMS) } \\
\text { Stability: } 100 \% \text { after } 1000 \text { cycles of charge/discharge }\end{array}$ & $\begin{array}{l}\text { CVD synthesis on } \mathrm{Cu} \text { mesh followed } \\
\text { by Cu etching } \\
\text { Pani coating: } 0.5 \mathrm{M} \text { aniline }+0.1 \mathrm{M} \\
\text { HCl, potentiostatic synthesis at }+0.8 \\
\mathrm{~V}, 15 \text { min }\end{array}$ & Supercapacitor & [100] \\
\hline $\begin{array}{l}\text { GWF/epoxy } \\
\text { composite }\end{array}$ & $\begin{array}{l}\text { Electrical conductivity: } 2.9 \mathrm{~S} \cdot \mathrm{cm}^{-1}(\mathrm{GWFs}), 0.15 \mathrm{~S} \cdot \mathrm{cm}^{-1}(\mathrm{GWF} / \mathrm{epoxy})(0.19 \% \\
\text { wt. G), } 10^{-12} \mathrm{~S} \cdot \mathrm{cm}^{-1} \text { (epoxy) } \\
\text { Fracture toughness: } 1.67 \mathrm{MPa} \cdot \mathrm{m}^{1 / 2} \text { (application force at } 0^{\circ} \text { in the direction of the } \\
\text { fibers) and } 1.78 \mathrm{MPa} \cdot \mathrm{m}^{1 / 2}\left(45^{\circ} \text { direction fibers }(0.62 \% \text { wt. G) }\right.\end{array}$ & $\begin{array}{l}\text { CVD synthesis on Ni mesh followed } \\
\text { by Ni etching } \\
\text { Epoxy application: } 80^{\circ} \mathrm{C}, 0.5 \text { h. } 120 \\
{ }^{\circ} \mathrm{C}, 2 \mathrm{~h}\end{array}$ & $\begin{array}{l}\text { Composite materials with conductivity and } \\
\text { enhanced mechanical properties }\end{array}$ & [101] \\
\hline
\end{tabular}




\section{Conclusions and perspectives}

Textile fabrics present different advantages when compared with sheet materials, such as its high surface area, flexibility, mechanical properties, etc. that make them attractive substrates onto which deposit functional materials. On the other hand, graphene (G) has emerged as a revolutionary material in the field of materials science and physics due to its extraordinary properties. G materials provide a conductive platform that can be integrated into textiles by means of chemical deposition, by producing graphene woven fabrics (GWFs) or by integrating conductive fibers of G in the fabrics. A lot of work has been performed with G-based fibers and there are several reviews that deal with this topic [21-24]. For this reason, this subject has not been included in the present review. The present review is focused on the chemical deposition of $G$ materials on fabrics/yarns and the synthesis of GWFs and their applications.

The chemical method is simple and can be scaled up by means of traditional techniques employed in textile industry such as soaking, drying, reducing with chemical compounds, etc. Graphene oxide (GO) is employed as the main G source since it is cheap and it can be produced in great quantitities and for the moment is the only G derivative that could meet the great requirements of $G$ for textile industry if this technology were to be established. GO is simply adsorbed on the surface of the fabrics by means of chemical interactions (electrostatic, hydrogen bonds, $\pi-\pi$ interactions, etc.). GO is an insulating material, however, its conductivity is partially restored by means of chemical reduction, thermal reduction, electrochemical or UV reduction to produce reduced graphene oxide (RGO). However, the conductivity obtained with this procedure is lower than in the case of GWFs since RGO retains some degree of oxidation (functional groups) after reduction. The applications for these type of fabrics (composed only of $G$ or other with other functional materials) can be: UV protection, conducting fabrics, antistatic fabrics, IR 
emission, hydrophobicity, sensors for electrocardiogram acquisition, heat generation, thermal conduction, photocatalytic activity, electrocatalytic activity, antibacterial, antifungal, gas and liquid sensors, anode for microbial fuel cells, cathode for solar cells, field emission devices, capacitative materials for energy storage, etc.

With the GWFs, higher conductivity is obtained, however the synthesis route consists on chemical vapor deposition on a Cu mesh (most widely metal employed as substrate), the subsequent removal of the copper mesh by chemical dissolution and the transfer of the remaining $G$ mesh to a substrate to support it. The GWFs are composed of several G layers with polycrystalline nature. Due to the high conductivity obtained, this method could be employed for applications where high conductivity is needed, being sensors one of the main uses of these types of textile structures. The high sensitivity of these fabrics as strain sensors, as demonstrated by their very high gauge factors, opens the door to new applications such as voice recognition, movement sensors, breath and pulse sensors, etc. Energy storage is another area of investigation where these fabrics are being applied for producing flexible energy storage devices.

Regarding future developments, more effort should be devoted to increasing the adhesion of G/GO/RGO coatings. In the case of GO, given the negative charges of GO due to the presence of oxygen containing functional groups, cationization of the surface of the fabrics should be accomplished. This has been mainly attained by means of chemical compounds (already under investigation, being bovine serum albumin coatings the most employed). The application of other methods such as nitrogen plasma modification to create positive charges has not been studied and could be a possibility.

The application of semiconducting nanoparticles on $\mathrm{G}$ fabrics should be studied in more depth, since mainly $\mathrm{TiO}_{2}$ nanoparticles have been applied [54,56,57,74]. With the functionalization by other semiconductors, G fabrics could be employed as photocatalytic 
materials or could be integrated in solar cells to increase the energy conversion efficiency $[61,87,95]$. Given its organic nature, the modification with organic dyes can be easily achieved through $\pi-\pi$ interactions or hydrophobic interactions [103], and can be used as an approach to increase the bandwith energy absorbance of $G$ materials, which mainly absorb radiation in the UV-region, to visible regions where dyes absorb [104]. This approach would also led to an increase in the energy conversion efficiency in solar cells. Another area of research not covered by bibliography up to date is the employment of modified G materials such as nitrogen-doped G [105-107], metallic doped G [108] that have been applied for the fields of sensors, catalysis, etc. The application of other 2-D materials such as transition metal dichalcogenides should also be subject of future study due to its interesting properties [109-112].

Other field pointed out in bibliography is the production of bionic materials integrating nanomaterials (such as $\mathrm{G}$ or carbon nanotubes) on natural fibers (for example produced by spiders) [113].

\section{Acknowledgements}

J. Molina wishes to thank to the Spanish Ministerio de Ciencia e Innovación (contract CTM2011-23583) for the financial support. J. Molina is grateful to the Conselleria d’Educació, Formació i Ocupació (Generalitat Valenciana) for the Programa VALi+D Postdoctoral Fellowship.

\section{References:}

[1] A.R. Horrocks, B.K. Kandola, P.J. Davies, S. Zhang, S.A. Padbury, Developments in flame retardant textiles - a review, Polym. Degrad. Stabil. 88 (2005) 3-12. 
[2] Y. Shin, D. Yoo, K. Son, Development of thermoregulating textile materials with microencapsulated phase change materials (PCM). II. Preparation and application of PCM microcapsules, J. Appl. Polym. Sci. 96 (2005) 2005-2010.

[3] A. Laforgue, Electrically controlled colour-changing textiles using the resistive heating properties of PEDOT nanofibers, J. Mater. Chem. 20 (2010) 8233-8235.

[4] N.K. Vu, A. Zille, F.R. Oliveira, N. Carneiro, A.P. Souto, Effect of particle size on silver nanoparticle deposition onto dielectric barrier discharge (DBD) plasma functionalized polyamide fabric, Plasma Process. Polym. 10 (2013) 285-296.

[5] J.O. Carneiro, V. Teixeira, J.H.O. Nascimento, J. Neves, P.B. Tavares, Photocatalytic activity and UV-protection of $\mathrm{TiO}_{2}$ nanocoatings on poly(lactic acid) fibres deposited by pulsed magnetron sputtering, J. Nanosci. Nanotechnol. 11 (2011) 1-8.

[6] M. Yu, Z. Wang, H. Liu, S. Xie, J. Wu, H. Jiang, J. Zhang, L. Li, J. Li, Laundering durability of photocatalyzed self-cleaning cotton fabric with $\mathrm{TiO}_{2}$ nanoparticles covalently immobilized, ACS Appl. Mater. Interfaces 5 (2013) 3697-3703.

[7] R. He, T.D. Day, M. Krishnamurthi, J.R. Sparks, P.J.A. Sazio, V. Gopalan, J.V. Badding, Silicon p-i-n junction fibers, Adv. Mater. 25 (2013) 1461-1467.

[8] D. Graham-Rowe, Photonic fabrics take shape, Nat. Photonics 1 (2007) 6-7.

[9] R.F. Service, Electronic textiles charge ahead, Science 301 (2003) 909-911.

[10] J.W. Lee, T. Mayer-Gall, K. Opwis, C.E. Song, J.S. Gutmann, B. List, Organotextile catalysis, Science 341 (2013) 1225-1229.

[11] Ozan Kayacan Ender Yazgan Bulgun, (2009), Heating behaviors of metallic textile structures, International Journal of Clothing Science and Technology 21 (2009) 127-136.

[12] D. Akbarov, B. Baymuratov, P. Westbroek, R. Akbarov, K. Declerck, P. Kiekens, Development of electroconductive polyacrylonitrile fibers through chemical metallization and galvanization, Journal of Applied Electrochemistry 36 (2006) 411-418.

[13] A. Bhattacharyya, M. Joshi, Development of polyurethane based conducting nanocomposite fibers via twin screw extrusion, Fibers and Polymers 12 (2011) 734-740. 
[14] A. Kaynak, S.S. Najar, R.C. Foitzik, Conducting nylon, cotton and wool yarns by continuous vapor polymerization of pyrrole, Synthetic Metals 158 (2008) 1-5.

[15] J. Molina, A.I. del Río, J. Bonastre, F. Cases, Chemical and electrochemical polymerization of pyrrole on polyester textiles in presence of phosphotungstic acid, European Polymer Journal 44 (2008) 2087-2098.

[16] J. Molina, M.F. Esteves, J. Fernández, J. Bonastre, F. Cases, Polyaniline coated conducting fabrics. Chemical and electrochemical characterization, European Polymer Journal 47 (2011) 2003-2015.

[17] K. S. Novoselov, V. I. Fal'ko, L. Colombo, P. R. Gellert, M. G. Schwab, K. Kim. Nature 490 (2012) 192-200.

[18] K.S. Novoselov, A.K. Geim, S.V. Morozov, D. Jiang, Y. Zhang, S.V. Dubonos, I.V. Grigorieva, A.A. Firsov. Science 306 (2004) 666-669.

[19] A.K. Geim. Angew. Chem. Int. Ed. 50 (2011) 6967-6985.

[20] A.C. Ferrari, et al. Nanoscale 7 (2015) 4598-4810.

Reviews [21] Zhen Xu and Chao Gao. Graphene fiber: a new trend in carbon fibers. Materials Today 18 (2015) 480-492.

[22] Fancheng Meng, Weibang Lu, Qingwen Li, Joon-Hyung Byun, Youngseok Oh, Tsu-Wei Chou. Graphene-Based Fibers: A Review. Adv. Mater. 27 (2015) 5113-5131.

[23] Huhu Cheng, Chuangang Hu, Yang Zhao, Liangti Qu. Graphene fiber: a new material platform for unique applications. NPG Asia Materials 6 (2014) e113.

[24] Gengzhi Sun, Xuewan Wang, Peng Chen. Microfiber devices based on carbon materials. Materials Today 18 (2015) 215-226.

[25] Sungjin Park, Rodney S. Ruoff. Chemical methods for the production of graphenes. Nature Nanotechnology 2009.

[26] Daniel R. Dreyer, Sungjin Park, Christopher W. Bielawski, Rodney S. Ruoff. The chemistry of graphene oxide. Chem. Soc. Rev. 39 (2010) 228-240.

[27] D. Li, M.B. Muller, S. Gilje, R.B. Kaner, G.G. Wallace. Processable aqueous dispersions of graphene nanosheets. Nature Nanotechnology 2 (2008) 101-105. 
Coating [28] Mingwei Tian, Xiaoning Tang, Lijun Qu, Shifeng Zhu, Xiaoqing Guo, Guangting Han. Robust ultraviolet blocking cotton fabric modified with chitosan/graphene nanocomposites. Materials Letters 145 (2015) 340-343.

[29] Lijun Qu, Mingwei Tian, Xili Hu, Yujiao Wang, Shifeng Zhu, Xiaoqing Guo, Guangting Han, Xiansheng Zhang, Kaikai Sun, Xiaoning Tang. Functionalization of cotton fabric at low graphene nanoplate content for ultrastrong ultraviolet blocking. Carbon 80 (2014) 565-574.

[30] Mingwei Tian, Xili Hu, Lijun Qu, Shifeng Zhu, Yaning Sun, Guangting Han. Versatile and ductile cotton fabric achieved via layer-by-layer self assembly by consecutive adsorption of graphene doped PEDOT: PSS and chitosan. Carbon 96 (2016) 1166-1174.

[31] Xili Hu, Mingwei Tian, Lijun Qu, Shifeng Zhu, Guangting Han. Multifunctional cotton fabrics with graphene/polyurethane coatings with far-infrared emission, electrical conductivity, and ultraviolet blocking properties. Carbon 95 (2015) 625-633.

[32] Xiaoning Tang, Mingwei Tian, Lijun Qu, Shifeng Zhu, Xiaoqing Guo, Guangting Han, Kaikai Sun, Xili Hu, Yujiao Wang, Xiaoqi Xu. Functionalization of cotton fabric with graphene oxide nanosheet and polyaniline for conductive and UV blocking properties. Synthetic Metals 202 (2015) 82-88.

[33] Kashif Javed, C.M.A. Galib, Fan Yang, Cheng-Meng Chen, Chaoxia Wang. A new approach to fabricate graphene electro-conductive networkson natural fibers by ultraviolet curing method. Synthetic Metals 193 (2014) 41-47.

[34] J.A. Moleon, A. Ontiveros-Ortega, E. Gimenez-Martin, I. Plaza. Effect of N-cetylpyridinium chloride in adsorption of graphene oxide onto polyester. Dyes and Pigments 122 (2015) 310-316. [35] Nadeeka D. Tissera, Ruchira N. Wijesena, J. Rangana Perera, K.M. Nalin de Silva, Gehan A.J. Amaratunge. Hydrophobic cotton textile surfaces using an amphiphilic grapheneoxide (GO) coating. Applied Surface Science 324 (2015) 455-463.

[36] Mohammad Shateri-Khalilabad, Mohammad E. Yazdanshenas. Preparation of superhydrophobic electroconductive graphene-coated cotton cellulose. Cellulose 20 (2013) 963972. 
[37] Yong Ju Yun, Won G. Hong, Wan-Joong Kim, Yongseok Jun, Byung Hoon Kim. A Novel Method for Applying Reduced Graphene Oxide Directly to Electronic Textiles from Yarns to Fabrics. Adv. Mater. 25 (2013) 5701-5705.

[38] Mohammad Shateri-Khalilabad, Mohammad E. Yazdanshenas. Fabricating electroconductive cotton textiles using graphene. Carbohydrate Polymers 96 (2013) 190-195. [39] Bunshi Fugetsu, Eiichi Sano, Hongwen Yu, Kenichiro Mori, Tomo Tanaka. Graphene oxide as dyestuffs for the creation of electrically conductive fabrics. Carbon 48 (2010) 3340-3345.

[40] Zhisong Lu, Cuiping Mao, Huihui Zhang. Highly conductive graphene-coated silk fabricated via a repeated coating-reduction approach. J. Mater. Chem. C 3 (2015), 4265-4268.

[41] J. Molina, A. Zille, J. Fernández, A.P. Souto, J. Bonastre, F. Cases. Conducting fabrics of polyester coated with polypyrrole and doped with graphene oxide. Synthetic Metals 204 (2015) $110-121$

[42] A. I. S. Neves, T. H. Bointon, L. V. Melo, S. Russo, I. de Schrijver, M. F. Craciun, H. Alves. Transparent conductive graphene textile fibers. Scientific Reports 5 (2015) 09866.

[43] J. Molina, J. Fernández, J.C. Inés, A.I. del Río, J. Bonastre, F. Cases. Electrochemical characterization of reduced graphene oxide-coated polyester fabrics. Electrochimica Acta 93 (2013) 44-52.

[44] J. Molina, J. Fernández, A.I. del Río, J. Bonastre, F. Cases. Chemical and electrochemical study of fabrics coated with reduced graphene oxide. Applied Surface Science 279 (2013) 46-54. [45] J. Molina, J. Fernández, M. Fernandes, A.P. Souto, M.F. Esteves, J. Bonastre, F. Cases. Plasma treatment of polyester fabrics to increase the adhesion of reduced graphene oxide. Synthetic Metals 202 (2015) 110-122.

[46] Yarjan Abdul Samad, Yuanqing Li, Saeed M. Alhassan, Kin Liao. Non-destroyable graphene cladding on a range of textile and other fibers and fiber mats. RSC Adv. 4 (2014) 16935-16938. [47] Steven J. Woltornist, Fahad Alhashmi Alamer, Austin McDannald, Menka Jain, Gregory A. Sotzing, Douglas H. Adamson. Preparation of conductive graphene/graphite infused fabrics using an interface trapping method. Carbon 81 (2015) 38-42. 
[48] Wenlong Gu, Yongnan Zhao. Graphene modified cotton textiles. Advanced Materials Research 331 (2011) 93-96.

[49] Dong Han Ha, Suyong Jung, Ho-Jong Kim, Daehee Kim, Wan-Joong Kim, Sam Nyung Yi, Yongseok Jun, Yong Ju Yun. Transition of graphene oxide-coated fiber bundles from insulator to conductor by chemical reduction. Synthetic Metals 204 (2015) 90-94.

[50] Xin Liu, Zongyi Qin, Zhenjun Dou, Na Liu, Long Chen, Meifang Zhu. Fabricating conductive poly(ethyleneterephthalate) nonwoven fabrics using an aqueous dispersion of reduced graphene oxide as a sheet dyestuff. RSC Adv. 4 (2014) 23869-23875.

[51] Sheng-Tsung Hsiao, Chen-Chi M. Ma, Hsi-Wen Tien, Wei-Hao Liao, Yu-Sheng Wang, Shin-Ming Li, Wen-Pin Chuang. Preparation and characterization of silver nanoparticle-reduced graphene oxide decorated electrospun polyurethane fiber composites with an improved electrical property. Composites Science and Technology 118 (2015) 171-177.

[52] Amir Abbas, Yan Zhao, Jianguo Zhou1, Xungai Wang, Tong Lin. Improving Thermal Conductivity of Cotton Fabrics Using Composite Coatings Containing Graphene, Multiwall Carbon Nanotube or Boron Nitride Fine Particles. Fibers and Polymers 14 (2013) 1641-1649.

[53] Guobo Huang, Jianguo Yang, Jianrong Gao, Xu Wang. Thin Films of Intumescent Flame Retardant-Polyacrylamide and Exfoliated Graphene Oxide Fabricated via Layer-by-Layer Assembly for Improving Flame Retardant Properties of Cotton Fabric. Ind. Eng. Chem. Res. 51 (2012) 12355-12366.

[54] Loghman Karimi, Mohammad Esmail Yazdanshenas, Ramin Khajavi, Abosaeed Rashidi, Mohammad Mirjalili. Optimizing the photocatalytic properties and the synergistic effects of graphene and nano titanium dioxide immobilized on cotton fabric. Applied Surface Science 332 (2015) 665-673.

[55] Karthikeyan Krishnamoorthy, Umasuthan Navaneethaiyer, Rajneesh Mohan, Jehee Lee, Sang-Jae Kim. Graphene oxide nanostructures modified multifunctional cotton fabrics. Appl. Nanosci. 2 (2012) 119-126.

[56] Loghman Karimi, Mohammad Esmail Yazdanshenas, Ramin Khajavi, Abosaeed Rashidi, Mohammad Mirjalili. Using graphene $/ \mathrm{TiO}_{2}$ nanocomposite as a new route for preparation of 
electroconductive, self-cleaning, antibacterial and antifungal cotton fabric without toxicity. Cellulose 21 (2014) 3813-3827.

[57] J. Molina, F. Fernandes, J. Fernández, M. Pastor, A. Correia, A.P. Souto, J.O. Carneiro, V. Teixeira, F. Cases. Photocatalytic fabrics based on reduced graphene oxide and $\mathrm{TiO}_{2}$ coatings. Materials Science and Engineering B 199 (2015) 62-76.

[58] Iftikhar Ali Sahito, Kyung Chul Sun, Alvira Ayoub Arbab, Muhammad Bilal Qadir, Sung Hoon Jeong. Integrating high electrical conductivity and photocatalytic activity incotton fabric by cationizing for enriched coating of negatively charged graphene oxide. Carbohydrate Polymers 130 (2015) 299-306.

[59] Murat Kaya Yapici, Tamador Alkhidir, Yarjan Abdul Samad, Kin Liao. Graphene-clad textile electrodes for electrocardiogram monitoring. Sensors and Actuators B 221 (2015) 14691474.

[60] Lu Gan, Songmin Shang, Chun Wah Marcus Yuen Shou-xiang Jiang. Graphene nanoribbon coated flexible and conductive cotton fabric. Composites Science and Technology 117 (2015) 208-214.

[61] Bo Liang, Lu Fang, Yichuan Hu, Guang Yang, Qin Zhu, Xuesong Ye. Fabrication and application of flexible graphene silk composite film electrodes decorated with spiky Pt nanospheres. Nanoscale 6 (2014) 4264-4274.

[62] Yong Ju Yun, Won G. Hong, Nak-Jin Choi, Byung Hoon Kim, Yongseok Jun, Hyung-Kun Lee. Ultrasensitive and Highly Selective Graphene-Based Single Yarn for Use in Wearable Gas Sensor. Scientific Reports 5 (2015) 10904.

[63] Ewa Skrzetuska, Michał Puchalski, Izabella Krucińska. Chemically Driven Printed Textile Sensors Based on Graphene and Carbon Nanotubes. Sensors 14 (2014) 16816-16828.

[64] Jing Liu, Yan Qiao, Chun Xian Guo, Sierin Lim, Hao Song, Chang Ming Li. Graphene/carbon cloth anode for high-performance mediatorless microbial fuel cells. Bioresource Technology 114 (2012) 275-280. 
[65] Iftikhar Ali Sahito, Kyung Chul Sun, Alvira Ayoub Arbab, Muhammad Bilal Qadir, Sung Hoon Jeong. Graphene coated cotton fabric as textile structured counter electrode for DSSC. Electrochimica Acta 173 (2015) 164-171.

[66] Feng Zhao, Lifen Liu, Fenglin Yang, Nanqi Ren. E-Fenton degradation of MB during filtration with Gr/PPy modified membrane cathode. Chemical Engineering Journal 230 (2013) 491-498.

[67] Rajarshi Roy, Arunava Jha, Diptonil Banerjee, Nirmalya Sankar Das, Kalyan Kumar Chattopadhyay. Edge effect enhanced electron field emission in top assembled reduced graphene oxide assisted by amorphous CNT-coated carbon cloth substrate. AIP Advances 3 (2013) 012115. [68] Uday N. Maiti, Soumen Maiti, Nirmalya S. Das, Kalyan K. Chattopadhyay. Hierarchical graphene nanocones over 3D platform of carbon fabrics: A route towards fully foldable graphene based electron source. Nanoscale 3 (2011) 4135-4141.

[69] Ling-Li Xu, Mei-Xia Guo, Si Liu, Shao-Wei Bian. Graphene/cotton composite fabrics as flexible electrode materials for electrochemical capacitors. RSC Adv. 5 (2015) 25244-25249.

[70] Fatemeh Yaghoubidoust, Dedy H.B. Wicaksono, Sheela Chandren, Hadi Nur. Effect of graphene oxide on the structural and electrochemical behavior of polypyrrole deposited on cotton fabric. Journal of Molecular Structure 1075 (2014) 486-493.

[71] Jie Xu, Daxiang Wang, Ye Yuan, Wei Wei, Lanlan Duan, Luoxin Wang, Haifeng Bao, Weilin Xu. Polypyrrole/reduced graphene oxide coated fabric electrodes for supercapacitor application. Organic Electronics 24 (2015) 153-159.

[72] Guihua Yu, Liangbing Hu, Michael Vosgueritchian, Huiliang Wang, Xing Xie, James R. McDonough, Xu Cui, Yi Cui, Zhenan Bao. Solution-Processed Graphene/ $\mathrm{MnO}_{2}$ Nanostructured Textiles for High-Performance Electrochemical Capacitors. Nano Lett. 11 (2011) 2905-2911. [73] Guihua Yu, Liangbing Hu, Nian Liu, Huiliang Wang, Michael Vosgueritchian, Yuan Yang, Yi Cui, Zhenan Bao. Enhancing the Supercapacitor Performance of Graphene/ $\mathrm{MnO}_{2}$ Nanostructured Electrodes by Conductive Wrapping. Nano Lett. 11 (2011) 4438-4442. 
[74] Fancheng Meng, Jingna Zhao, Yuting Ye, Xiaohua Zhang, Shan Li, Jingjing Jia, Zuoguang Zhang, Qingwen Li. Multifunctionalization of carbon nanotube fibers with the aid of graphene wrapping. J. Mater. Chem. 22 (2012) 16277-16282.

[75] Imran Shakir, Zahid Ali, Jihyun Bae, Jongjin Park, Dae Joon Kang. Layer by layer assembly of ultrathin $\mathrm{V}_{2} \mathrm{O}_{5}$ anchored MWCNTs and graphene on textile fabrics for fabrication of high energy density flexible supercapacitor electrodes. Nanoscale 6 (2014) 4125-4130.

[76] Yu-Sheng Wang, Shin-Ming Li, Sheng-Tsung Hsiao, Wei-Hao Liao, Po-Hsiang Chen, ShinYi Yang, Hsi-Wen Tien, Chen-Chi M. Ma, Chi-Chang Hu. Integration of tailored reduced graphene oxide nanosheets and electrospun polyamide-66 nanofabrics for a flexible supercapacitor with high-volume- and high-area-specific capacitance. Carbon 73 (2014) 87-98. [77] Qianlong Zhou, Xingke Ye, Zhongquan Wan, Chunyang Jia. A three-dimensional flexible supercapacitor with enhanced performance based on light weight, conductive graphene-cotton fabric electrode. Journal of Power Sources 296 (2015) 186-196.

[78] Wen-wen Liu, Xing-bin Yan, Jun-wei Lang, Chao Peng, Qun-ji Xue. Flexible and conductive nanocomposite electrode based on graphene sheets and cotton cloth for supercapacitor. J. Mater. Chem. 22 (2012) 17245-17253.

[79] Ananthakumar Ramadoss, Balasubramaniam Saravanakumar, Sang Jae Kim. Thermally reduced graphene oxide-coated fabrics for flexible supercapacitors and self-powered systems. Nano Energy 15 (2015) 587-597.

[80] Chen Zhao, Kewei Shu, Caiyun Wang, Sanjeev Gambhir, Gordon G. Wallace. Reduced graphene oxide and polypyrrole/reduced graphene oxide composite coated stretchable fabric electrodes for supercapacitor application. Electrochimica Acta 172 (2015) 12-19.

[81] Feifei Liu, Suwen Wang, Gaoyi Han, Ruiqin Liu, Yunzhen Chang, Yaoming Xiao. Multiwalled Carbon Nanotubes/Polypyrrole/Graphene/Nonwoven Fabric Composites Used as Electrodes of Electrochemical Capacitor. J. Appl. Polym. Sci. 2014, DOI: 10.1002/APP.41023. [82] Yachang Cao, Miao Zhu, Peixu Li, Rujing Zhang, Xinming Li, Qianming Gong, Kunling Wang, Minlin Zhong, Dehai Wu, Feng Lin, Hongwei Zhu. Boosting supercapacitor performance 
of carbon fibres using electrochemically reduced graphene oxide additives. Phys. Chem. Chem. Phys. 15 (2013) 19550-19556.

[83] Yan Huang, Hong Hu, Yang Huang, Minshen Zhu, Wenjun Meng, Chang Liu, Zengxia Pei, Chonglei Hao, Zuankai Wang, Chunyi Zhi. From Industrially Weavable and Knittable Highly Conductive Yarns to Large Wearable Energy Storage Textiles. ACS Nano 9 (2015) 4766-4775. [84] Libin Liu, You Yu, Casey Yan, Kan Li, Zijian Zheng. Wearable energy-dense and powerdense supercapacitor yarns enabled by scalable graphene-metallic textile composite electrodes. Nature Communications 6 (2015) 7260.

[85] Pingping Yu, Yingzhi Li, Xin Zhao, Lihao Wu, Qinghua Zhang. Graphene-Wrapped Polyaniline Nanowire Arrays on Nitrogen-Doped Carbon Fabric as Novel Flexible Hybrid Electrode Materials for High-Performance Supercapacitor. Langmuir 30 (2014) 5306-5313. GFV [86] Xiao Li, Pengzhan Sun, Lili Fan, Miao Zhu, Kunlin Wang, Minlin Zhong, Jinquan Wei, Dehai Wu, Yao Cheng, Hongwei Zhu. Multifunctional graphene woven fabrics. Scientific Reports 2 (2012) 395.

[87] Xiao Li, Rujing Zhang, Wenjian Yu, Kunlin Wang, Jinquan Wei, Dehai Wu, Anyuan Cao, Zhihong Li, Yao Cheng, Quanshui Zheng, Rodney S. Ruoff, Hongwei Zhu. Stretchable and highly sensitive graphene-on-polymer strain sensors. Scientific Reports 2 (2012) 870.

[88] Wen Wang, Tingting Yang, Hongwei Zhu, Quanshui Zheng. Bio-inspired mechanics of highly sensitive stretchable graphene strain sensors. Applied Physics Letters 106 (2015) 171903. [89] Xiao Lee, Tingting Yang, Xiao Li, Rujing Zhang, Miao Zhu, Hongze Zhang, Dan Xie, Jinquan Wei, Minlin Zhong, Kunlin Wang, Dehai Wu, Zhihong Li, Hongwei Zhu. Flexible graphene woven fabrics for touch sensing. Applied Physics Letters 102 (2013) 163117.

[90] Xiaona Wang, Yunfeng Qiu, Wenwu Cao, PingAn Hu. Highly Stretchable and Conductive Core-Sheath Chemical Vapor Deposition Graphene Fibers and Their Applications in Safe Strain Sensors. Chem. Mater. 27 (2015) 6969-6975.

[91] Tingting Yang, Wen Wang, Hongze Zhang, Xinming Li, Jidong Shi, Yijia He, Quan-shui Zheng, Zhihong Li, Hongwei Zhu. Tactile Sensing System Based on Arrays of Graphene Woven 
Microfabrics: Electromechanical Behavior and Electronic Skin Application. ACS Nano 9 (2015) 10867-10875.

[92] Yan Wang, Li Wang, Tingting Yang, Xiao Li, Xiaobei Zang, Miao Zhu, Kunlin Wang, Dehai Wu, Hongwei Zhu. Wearable and Highly Sensitive Graphene Strain Sensors for Human Motion Monitoring. Adv. Funct. Mater. 24 (2014) 4666-4670.

[93] Tingting Yang, Yan Wang, Xinming Li, Yangyang Zhang, Xiao Li, Kunlin Wang, Dehai Wu, Hu Jin, Zhihong Li, Hongwei Zhu. Torsion sensors of high sensitivity and wide dynamic range based on a graphene woven structure. Nanoscale 6 (2014) 13053-13059.

[94] Yan Wang, Tingting Yang, Junchao Lao, Rujing Zhang, Yangyang Zhang, Miao Zhu, Xiao Li, Xiaobei Zang, Kunlin Wang, Wenjian Yu, Hu Jin, Li Wang, Hongwei Zhu. Ultra-sensitive graphene strain sensor for sound signal acquisition and recognition. Nano Research 8 (2015) 1627-1636.

[95] Zhe Kang, Xinyu Tan, Xiao Li, Ting Xiao, Li Zhang, Junchao Lao, Xinming Li, Shan Cheng, Dan Xie, Hongwei Zhu. Self-deposition of Pt nanoparticles on graphene woven fabrics for enhanced hybrid Schottky junctions and photoelectrochemical solar cells. Phys. Chem. Chem. Phys. 18 (2016) 1992-1997.

[96] Jiecai Han, Xiaona Wang, Yunfeng Qiu, Jiaqi Zhu, PingAn Hu. Infrared-transparent films based on conductive graphene network fabrics for electromagnetic shielding. Carbon 87 (2015) 206-214.

[97] Xiaobei Zang, Qiao Chen, Peixu Li, Yijia He, Xiao Li, Miao Zhu, Xinming Li, Kunlin Wang, Minlin Zhong, Dehai Wu, Hongwei Zhu. Highly Flexible and Adaptable, All-Solid-State Supercapacitors Based on Graphene Woven-Fabric Film Electrodes. Small 10 (2014) 2583-2588. [98] Xiao Li, Xiaobei Zang, Zhen Li, Xinming Li, Peixu Li, Pengzhan Sun, Xiao Lee, Rujing Zhang, Zhenghong Huang, Kunlin Wang, Dehai Wu, Feiyu Kang, Hongwei Zhu. Large-Area Flexible Core-Shell Graphene/Porous Carbon Woven Fabric Films for Fiber Supercapacitor Electrodes. Adv. Funct. Mater. 23 (2013) 4862-4869. 
[99] Xiaobei Zang, Xiao Li, Miao Zhu, Xinming Li, Zhen Zhen, Yijia He, Kunlin Wang, Jinquan Wei, Feiyu Kang, Hongwei Zhu. Graphene/polyaniline woven fabric composite films as flexible supercapacitor electrodes. Nanoscale 7 (2015) 7318-7322.

[100] Xiaobei Zang, Miao Zhu, Xiao Li, Xinming Li, Zhen Zhen, Junchao Lao, Kunlin Wang, Feiyu Kang, Bingqing Wei, Hongwei Zhu. Dynamically stretchable supercapacitors based on graphene woven fabric electrodes. Nano Energy 15 (2015) 83-91.

[101] Xu Liu, Xinying Sun, Zhenyu Wang, Xi Shen, Ying Wu, Jang-Kyo Kim. Planar Porous Graphene Woven Fabric/Epoxy Composites with Exceptional Electrical, Mechanical Properties, and Fracture Toughness. ACS Appl. Mater. Interfaces 7 (2015) 21455-21464.

[102] Liuyang Zhang, Matthew Becton, Xianqiao Wang. Mechanical analysis of graphene-based woven nano-fabric. Materials Science \& Engineering A 620 (2015) 367-374.

[103] J. Molina, J. Fernández, C. García, A.I. del Río, J. Bonastre, F. Cases. Electrochemical characterization of electrochemically reduced graphene coatings on platinum. Electrochemical study of dye adsorption. Electrochimica Acta 166 (2015) 54-63.

[104] Youngbin Lee, Seong Hun Yu, Jiwon Jeon, Hyunmin Kim, Jun Young Lee, Hyungjun Kim, Jong-Hyun Ahn, Euyheon Hwang, Jeong Ho Cho. Hybrid structures of organic dye and graphene for ultrahigh gain photodetectors. Carbon 88 (2015) 165-172.

[105] X.-K. Kong, C.-L. Chen, Q.-W. Chen. Chem. Soc. Rev., 2014, 43, 2841-2857.

[106] W. Zhang, L. Wu, Z. Li, Y. Liu. RSC Adv. 5 (2015) 49521-49533.

[107] J. Duan, S. Chen, M. Jaroniec, S.Z. Qiao. ACS Catal. 5 (2015) 5207-5234.

[108] H. Fei, J. Dong, M.J. Arellano-Jiménez, G. Ye, N.D. Kim, E.L.G. Samuel, Z. Peng, Z. Zhu, F. Qin, J. Bao, M.J. Yacaman, P.M. Ajayan, D. Chen, J.M. Tour. Nat. Commun. 6 (2015) 8668. [109] F. Bonaccorso, A. Lombardo, T. Hasan, Z. Sun, L. Colombo, A.C. Ferrari. Mater. Today 15 (2012) 564-589.

[110] M.C.Z. Liu, H. Zhang. Chem. Soc. Rev. 44 (2015) 2584-2586.

[111] X. Duan, C. Wang, A. Pan, R. Yu, X. Duan. Chem. Soc. Rev. 44 (2015) 8859-8876.

[112] C. Tan, H. Zhang. Chem. Soc. Rev. 44 (2015) 2713-2731. 
[113] Emiliano Lepore, Francesco Bonaccorso, Matteo Bruna, Federico Bosia, Simone Taioli, Giovanni Garberoglio, Andrea. C. Ferrari, Nicola Maria Pugno. Silk reinforced with graphene or carbon nanotubes spun by spiders. 